\title{
Metal-Catalyzed Carbon-Carbon Bond Cleavage of Unstrained Alcohols
}

\section{Journal Article}

Author(s):

Lutz, Marius (iD; Morandi, Bill

Publication date:

2021-01-13

Permanent link:

https://doi.org/10.3929/ethz-b-000463939

Rights / license:

In Copyright - Non-Commercial Use Permitted

Originally published in:

Chemical Reviews 121(1), https://doi.org/10.1021/acs.chemrev.0c00154

Funding acknowledgement:

757608 - Shuttle Catalysis for Reversible Molecular Construction (EC) 
This document is the Accepted Manuscript version of a Published Work that appeared in final form in Chemical Reviews, copyright (C) American Chemical Society after peer review and technical editing by the publisher. To access the final edited and published work see https://doi.org/10.1021/acs.chemrev.0c00154

\title{
Metal-Catalyzed Carbon-Carbon Bond Cleavage of Unstrained Alco- hols
}

\author{
Marius D. R. Lutz and Bill Morandi* \\ ETH Zürich, Vladimir-Prelog-Weg 3, HCI, 8093 Zürich, Switzerland
}

\begin{abstract}
The functionalization of molecules by cleaving inert carbon-carbon single bonds is regarded as a great synthetic challenge due to their inherent stability. In recent years, significant progress has been made in the activation of small rings relying on the release of strain energy. By contrast, the number of catalytic methodologies for the activation of unstrained carbon-carbon single bonds is still limited. This review focuses on the recent developments in transition metal-catalyzed cleavage of $\mathrm{C}-\mathrm{C}$ bonds in unstrained alcohols via $\beta$-carbon elimination. Emphasis is placed on the mechanistic aspects of the discussed transformations and their applications to the deconstruction and reorganization of molecules.
\end{abstract}

\section{CONTENTS}

1. Introduction

2

1.1. Challenges in $\mathrm{C}-\mathrm{C}$ Bond Activation 2

2. $\beta$-Alkynyl Elimination 4

2.1. $\beta$-Alkynyl Elimination with Palladium 4

2.2. $\beta$-Alkynyl Elimination with Rhodium 5

2.3. $\beta$-Alkynyl Elimination with Copper 12

3. $\beta$-Aryl Elimination $\quad 15$

3.1. $\beta$-Aryl Elimination with Palladium 15

3.2. $\beta$-Aryl Elimination with Rhodium 25

3.3. $\beta$-Aryl Elimination with Cobalt 34

3.4. $\quad \beta$-Aryl Elimination with Manganese $\quad 34$

4. $\beta$-Alkyl Elimination 36

4.1. $\beta$-Alkyl Elimination with Palladium 36

4.2. $\beta$-Alkyl Elimination with Rhodium 41

4.3. $\beta$-Alkyl Elimination with Nickel 41

5. $\beta$-Carbon Elimination from Primary Alcohols $\quad 42$

6. Conclusion and Outlook 43

Author Information $\quad 44$

Corresponding Author $\quad 44$ 
This document is the Accepted Manuscript version of a Published Work that appeared in final form in Chemical Reviews, copyright (C) American Chemical Society after peer review and technical editing by the publisher. To access the final edited and published work see https://doi.org/10.1021/acs.chemrev.0c00154 ORCID

44

Funding Sources

44

Notes 44

Biographies

Abbreviations

References

\section{INTRODUCTION}

Carbon-carbon bonds are ubiquitous in organic molecules, including biomolecules, many polymers, and pharmaceuticals. Transition metalcatalyzed cross-coupling strategies have enabled the selective formation of $\mathrm{C}-\mathrm{C}$ bonds in an efficient manner, however the selective cleavage of these inherently inert bonds is still a remaining challenge. ${ }^{1,2}$

The cleavage of $\mathrm{C}-\mathrm{C}$ bonds is commonly encountered in the steam cracking process of crude oil at high temperatures and pressures in the petroleum industry, ${ }^{3}$ and also many classical reactions (for instance, sigmatropic rearrangements, Beckmann rearrangement, Bayer-Villiger oxidation, retro-aldol, and others) allow for $\mathrm{C}-\mathrm{C}$ bond cleavage. However, there is still a lack of mild catalytic methods to activate unbiased $\mathrm{C}-\mathrm{C}$ bonds in a general and efficient manner. With respect to the challenges regarding the valorization of renewable feedstocks such as lignocellulose, ${ }^{4-9}$ as well as the degradation or recycling of industrially relevant polymers, ${ }^{10-12}$ it is of great importance to introduce new methods to selectively cleave $\mathrm{C}-\mathrm{C}$ bonds. The selective activation of $\mathrm{C}-\mathrm{C}$ bonds would further allow for streamlined syntheses without the need to rely on prefunctionalization with reactive functional groups, and therefore such methods are desirable in modern synthetic chemistry. ${ }^{13-15}$

Over the recent decades, $\mathrm{C}-\mathrm{C}$ bond cleavage has become an active field in research and several reviews about the activation of small rings and unstrained systems highlight the recent achievements in this field. ${ }^{1,2,16-25}$ This review focuses on catalytic $\mathrm{C}-\mathrm{C}$ bond cleavage reactions of unstrained alcohols (Figure 1a). Beyond the scope of this review are reactions involving $\mathrm{C}-\mathrm{C}$ oxidative additions (Figure $1 \mathrm{~b}$ ), which have been reviewed elsewhere. ${ }^{2,18,20,21,24,26-29}$ Likewise, retro-allylation reactions (Figure 1c) ${ }^{30}$ and cleavage of alcohols driven by the release of ring strain (Figure 1d) ${ }^{31-34}$ will not be covered herein. Moreover, radical-induced fragmentations and related proton-coupled electron transfer (PCET) processes will also not be discussed, as they have been reviewed recently (Figure 1e). ${ }^{35,36}$ Notably, other strategies in $\mathrm{C}-\mathrm{C}$ bond activation are discussed in other reviews in this thematic issue.

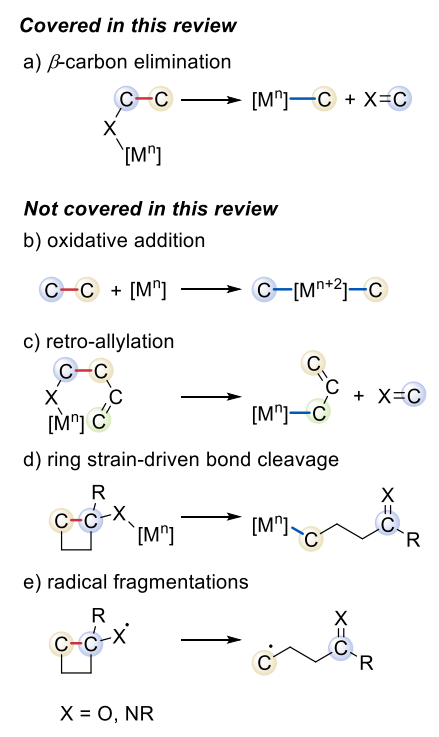

Figure 1. Strategies for inert $\mathrm{C}-\mathrm{C}$ bond cleavages.

\subsection{Challenges in $\mathrm{C}-\mathrm{C}$ Bond Activation}

$\mathrm{C}-\mathrm{C}$ bonds are among the least reactive bonds in synthetic chemistry and remain untouched during most chemical transformations. Their low reactivity can be explained by both thermodynamic and kinetic considerations. 
This document is the Accepted Manuscript version of a Published Work that appeared in final form in Chemical Reviews, copyright (C) American Chemical Society after peer review and technical editing by the publisher. To access the final edited and published work see https://doi.org/10.1021/acs.chemrev.0c00154

Since a structurally unbiased $\mathrm{C}-\mathrm{C}$-bond is significantly lower in energy than most $\mathrm{C}$-heteroatom bonds, its cleavage is disfavored from a thermodynamic standpoint. ${ }^{37}$ To allow the thermodynamically unfavorable cleavage, commonly employed strategies are to either raise the energy of the starting material by ring strain or to stabilize the product by chelation assistance from a non-participating directing group. ${ }^{38-40}$

In addition, compared to various $\mathrm{C}$-heteroatom bonds, the $\mathrm{C}-\mathrm{C}$ single bond is less polarized and neither atom possesses appropriate orbitals that would allow for significant overlap with a transition metal. The relevant orbital interactions between unpolarized $\mathrm{C}-\mathrm{C}$ single and double bonds and $\mathrm{C}-\mathrm{H}$ bonds, and a transition metal are compared in Figure 2. ${ }^{22,23,27}$ In the case of a $\mathrm{C}=\mathrm{C}$ bond (Figure 2a), favorable interactions between the $\pi$-orbitals of the olefin and the metal d-orbitals are possible, allowing for facile coordination and activation of the bond. In contrast, a $\mathrm{C}-\mathrm{H}$ bond is oriented perpendicular to the metal orbitals, albeit the spherical nature of the hydrogen orbitals allows for good overlap with the metal orbitals (Figure $2 \mathrm{~b}$ ). The highly directional $\sigma$-bonding orbital of a $\mathrm{C}-\mathrm{C}$ bond does not allow for significant overlap with the d-orbitals of transition metals unless they are heavily distorted by the latter (Figure $2 \mathrm{c}$ ). In addition, substituents on both ends can sterically prevent the approach of the metal. This renders the activation of $\mathrm{C}-\mathrm{C} \sigma$-bonds difficult from a kinetic perspective as well.

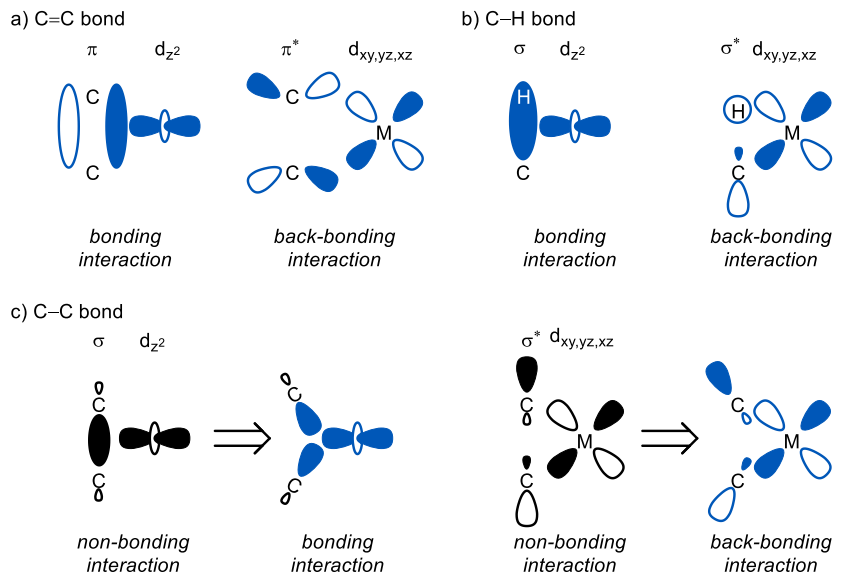

Figure 2. Comparison of the favorable orbital interactions between (a) $\mathrm{C}=\mathrm{C},(\mathrm{b}) \mathrm{C}-\mathrm{H}$ and (c) $\mathrm{C}-\mathrm{C}$ bonds and transition metals. Symmetry-allowed orbital interactions are indicated in blue and white.

Thus, while a $\mathrm{C}-\mathrm{H}$ bond is thermodynamically more stable than a $\mathrm{C}-\mathrm{C}$ bond $(\mathrm{BDE}(\mathrm{C}-\mathrm{H}) \approx 100-110 \mathrm{kcal} / \mathrm{mol}$ vs $\mathrm{BDE}(\mathrm{C}-\mathrm{C}) \approx 90-105$ $\mathrm{kcal} / \mathrm{mol}),{ }^{41}$ it can interact favorably with the d-orbitals of the metal center. This aspect further complicates the selective activation of a $\mathrm{C}-\mathrm{C}$ bond in the presence of proximal $\mathrm{C}-\mathrm{H}$ bonds. Another issue is the selectivity among different $\mathrm{C}-\mathrm{C}$ bonds within a molecule. As in the field of $\mathrm{C}-\mathrm{H}$ activation, the catalyst must differentiate between subtle nuances in steric or electronic properties to favor one $\mathrm{C}-\mathrm{C}$ bond among various others. $^{42}$

The predominant pathway for the activation of $\mathrm{C}-\mathrm{C}$ bonds in unstrained alcohols is $\beta$-carbon elimination. Mechanistically, $\beta$-carbon elimination is similar to $\beta$-hydride elimination, albeit much less studied (Figure 3 ). ${ }^{18}$ Coordination of a transition metal via the oxygen atom enables the interaction with an adjacent group in $\beta$-position, inducing the cleavage of the bond. In contrast to an oxidative addition, this mechanism is redox-neutral as it formally corresponds to the reverse of a migratory insertion into a $\mathrm{C}=\mathrm{O}$ double bond. The result is a metal-bound hydrocarbyl species as well as a ketone or aldehyde derivative. As mentioned before, this reaction is often endothermic, however, the release of a second byproduct is entropically favorable and can provide a driving force for the otherwise energetically uphill process.

Because of the reasons discussed above, $\beta$-hydride elimination generally outcompetes $\beta$-carbon elimination, thus the selective activation of a $\mathrm{C}-\mathrm{C}$ bond within a substrate bearing $\beta$-hydrogen atoms (i.e., $1^{\circ}$ and $2^{\circ}$ alcohols) is still a challenge (Figure 3 ).

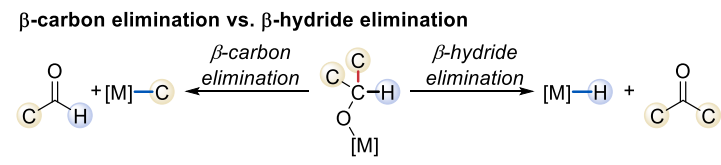

Figure 3. Competition between activation of adjacent $\mathrm{C}-\mathrm{C}$ and $\mathrm{C}-\mathrm{H}$ bonds in $\beta$-position.

These challenges notwithstanding, tremendous advances in the field have been made in recent years, as the following sections show. Herein we discuss the recent developments in metal-catalyzed $\mathrm{C}-\mathrm{C}$ bond activation reactions, classified by the type of bond being cleaved and the transition metal employed. 
This document is the Accepted Manuscript version of a Published Work that appeared in final form in Chemical Reviews, copyright (C) American Chemical Society after peer review and technical editing by the publisher. To access the final edited and published work see https://doi.org/10.1021/acs.chemrev.0c00154

\section{2. $\beta$-ALKYNYL ELIMINATION}

$\mathrm{C}(\mathrm{sp})-\mathrm{C}\left(\mathrm{sp}^{3}\right)$ bonds are among the easiest $\mathrm{C}-\mathrm{C}$ bonds to activate by virtue of their steric accessibility and the relatively low basicity of the resulting acetylide-fragment.

It should be noted that propargylic alcohols can undergo facile $\mathrm{C}-\mathrm{C}$ bond cleavage (retro-Favorskii reaction) under basic conditions and elevated temperatures without the need of a catalyst. ${ }^{43-45}$ For this reason, it is crucial to design control experiments to demonstrate the involvement of the catalyst. While not all the publications discussed herein have conducted such metal-free control experiments, we have erred on the side of caution and included any ambiguous example.

\section{1. $\beta$-Alkynyl Elimination with Palladium}

The first example of palladium-catalyzed $\beta$-alkynyl elimination of propargylic alcohols was described by Chow and co-workers in $2001 .{ }^{46}$ In the Sonogashira cross-coupling of terminal alkynes with aryl halides, a common challenge is the suppression of oxidative homocoupling products. By using tertiary propargylic alcohols $\mathbf{1}$ as alkyne surrogates, they achieved higher yields and reduced the amount of homocoupling compared to the corresponding terminal alkynes (Scheme 1).

\section{Scheme $1^{a}$}
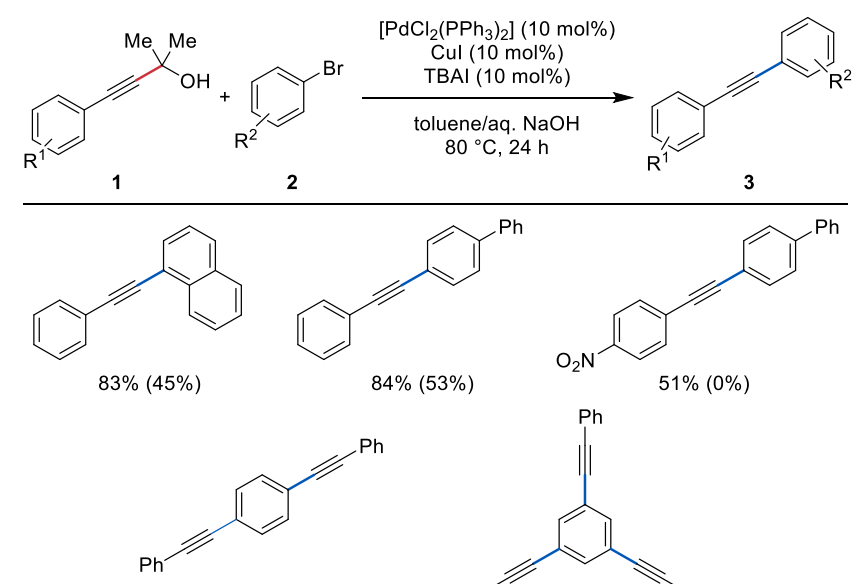

$78 \%(6 \%)$

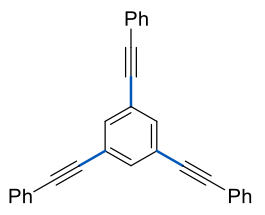

${ }^{a}$ Yields for reactions with terminal alkynes given in parenthesis

Uemura et al. disclosed an alkyne-alkene Heck-type coupling under an oxygen atmosphere that proceeded via chemoselective $\beta$-carbon elimination (Scheme 2). ${ }^{47}$ The propargylic $\mathrm{C}-\mathrm{C}$ bond of $\mathbf{4}$ is selectively cleaved under the reaction conditions and the formed intermediate can react with the terminal alkene 5 to afford the enyne product $\mathbf{6}$ in moderate yields. In the case of styrene, a mixture of regioisomers was obtained, while with olefins bearing aliphatic rests isomerization of the double bond via $\beta$-hydride elimination occurred.

\section{Scheme 2}

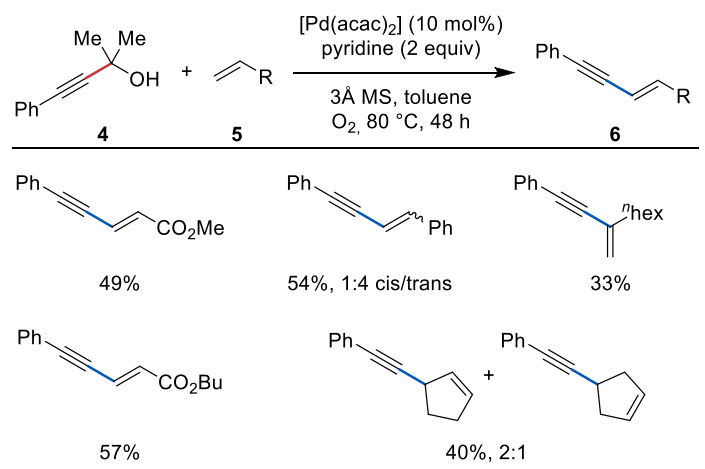


This document is the Accepted Manuscript version of a Published Work that appeared in final form in Chemical Reviews, copyright (C) American Chemical Society after peer review and technical editing by the publisher. To access the final edited and published work see https://doi.org/10.1021/acs.chemrev.0c00154

\section{2. $\beta$-Alkynyl Elimination with Rhodium}

In 2005, Miura and co-workers reported the homocoupling of tert-propargyl alcohols 7 to form 2-hydroxymethyl-(E)-enynes 8 with high stereoand regioselectivity (Scheme 3). ${ }^{48}$ Bidentate phosphine ligands were optimal for this transformation with dppb being the best. Several aromatic propargylic alcohols underwent the reaction under the release of benzophenone $(\mathrm{R}=\mathrm{Ph})$ or acetone $(\mathrm{R}=\mathrm{Me})$ in good yields and regiocontrol, however, when the substrate contained an aliphatic substituent on the alkyne, the reaction did not proceed. The authors proposed a mechanism that is initiated by coordination of substrate 7 to the rhodium catalyst with concomitant release of water to give $\mathbf{9}$. This intermediate then undergoes $\beta$-carbon elimination to release ketone $\mathbf{1 0}$ and alkynyl-bound rhodium species $\mathbf{1} 1$ that regioselectively inserts in a syn fashion across a second equivalent of the propargyl alcohol. The resulting vinyl complex $\mathbf{1 2}$ is then proposed to undergo geometrical isomerization to $\mathbf{1 4}$ to account for the observed selectivity. The isomerization might proceed via a zwitterionic resonance structure 13a that allows for free rotation and favors rotamer $\mathbf{1 3 b}$ exhibiting an additional interaction between the hydroxy group and the metal center. ${ }^{49}$ Proton transfer from the starting material furnishes the product and closes the catalytic cycle. Interestingly, the reaction was inhibited when stoichiometric amounts of 4-ethynyltoluene were added to the reaction, suggesting that no free alkyne is formed during the reaction.

Scheme 3
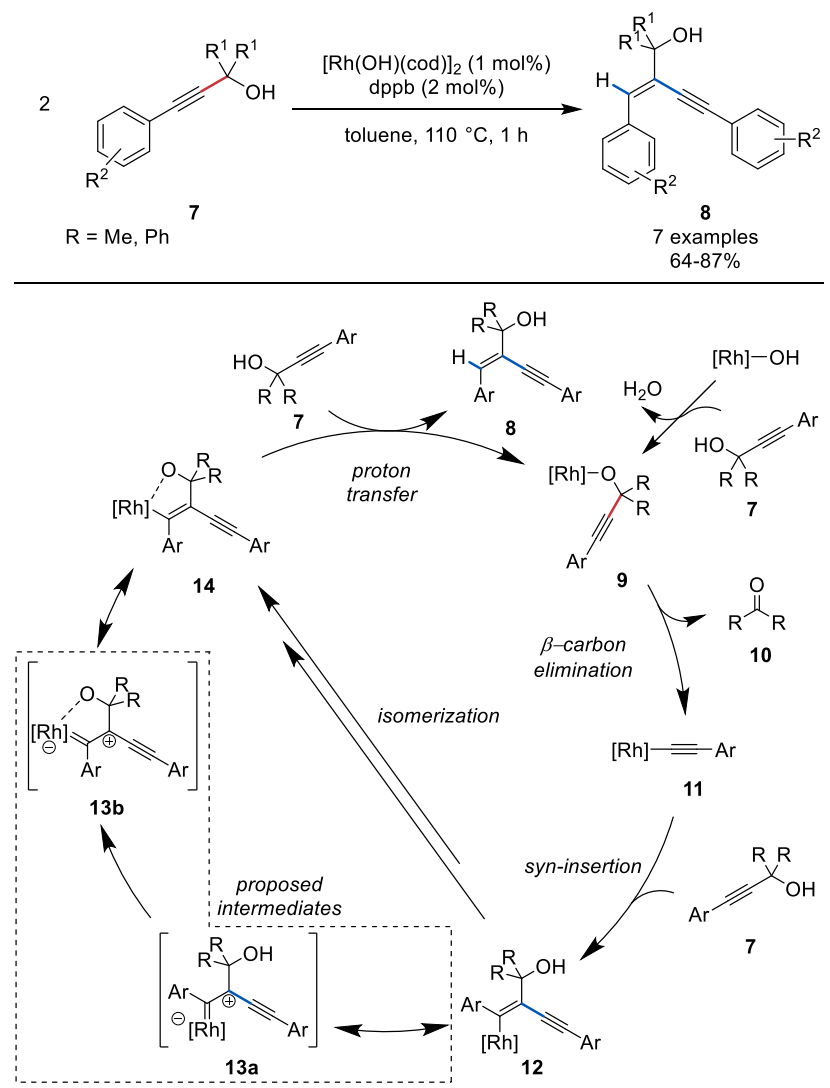

Recently, Dou reported the related dimerization of aliphatic propargyl alcohols 15 that were previously unreactive. ${ }^{50}$ In this case, 2 -alkynylated 1,3-butadienes 16 were obtained instead of but-3-ynol products 8 (Scheme 4). A variety of mono- and disubstituted $\gamma$-alkyl propargyl alcohols were tolerated, including acyclic and cyclic alkyl substituents in the $\alpha$-position. 
This document is the Accepted Manuscript version of a Published Work that appeared in final form in Chemical Reviews, copyright (C) American Chemical Society after peer review and technical editing by the publisher. To access the final edited and published work see https://doi.org/10.1021/acs.chemrev.0c00154

\section{Scheme 4}

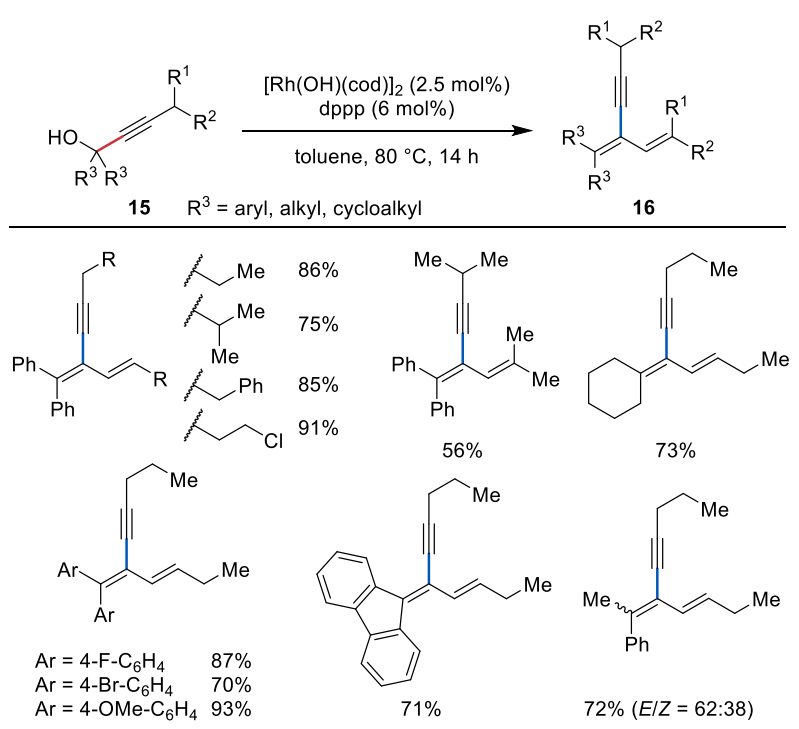

The reaction mechanism is proposed to begin with coordination of $\mathbf{1 5}$ to the metal center, followed by $\beta$-alkynyl elimination from alkoxide complex 17 to afford alkynyl rhodium species 19 (Scheme 5). Carborhodation with a second equivalent of the substrate affords the enyne intermediate $\mathbf{2 0}$ in analogy to intermediate $\mathbf{1 2}$ discussed above. In contrast to the mechanism discussed in Scheme 3, the availability of $\beta$-hydrides favors $\beta$-hydride elimination to form an allene that is coordinated to a rhodium hydride species (21). Reinsertion into the allene yields $\pi$-allyl species 22 that can further isomerize to 23 . The authors propose a $\beta$-oxygen elimination pathway from 23 releasing product 16 to account for the loss of the $[\mathrm{Rh}]-\mathrm{OH}$ fragment, which has been proposed before in such systems but has limited mechanistic support. An alternative mechanism could involve the formation of isomer $\mathbf{2 4}$ that is stabilized by chelation to the alcohol and allows for $\delta$-oxygen elimination via a cyclic transition state. ${ }^{51}$ 
This document is the Accepted Manuscript version of a Published Work that appeared in final form in Chemical Reviews, copyright (C) American Chemical Society after peer review and technical editing by the publisher. To access the final edited and published work see https://doi.org/10.1021/acs.chemrev.0c00154

Scheme 5

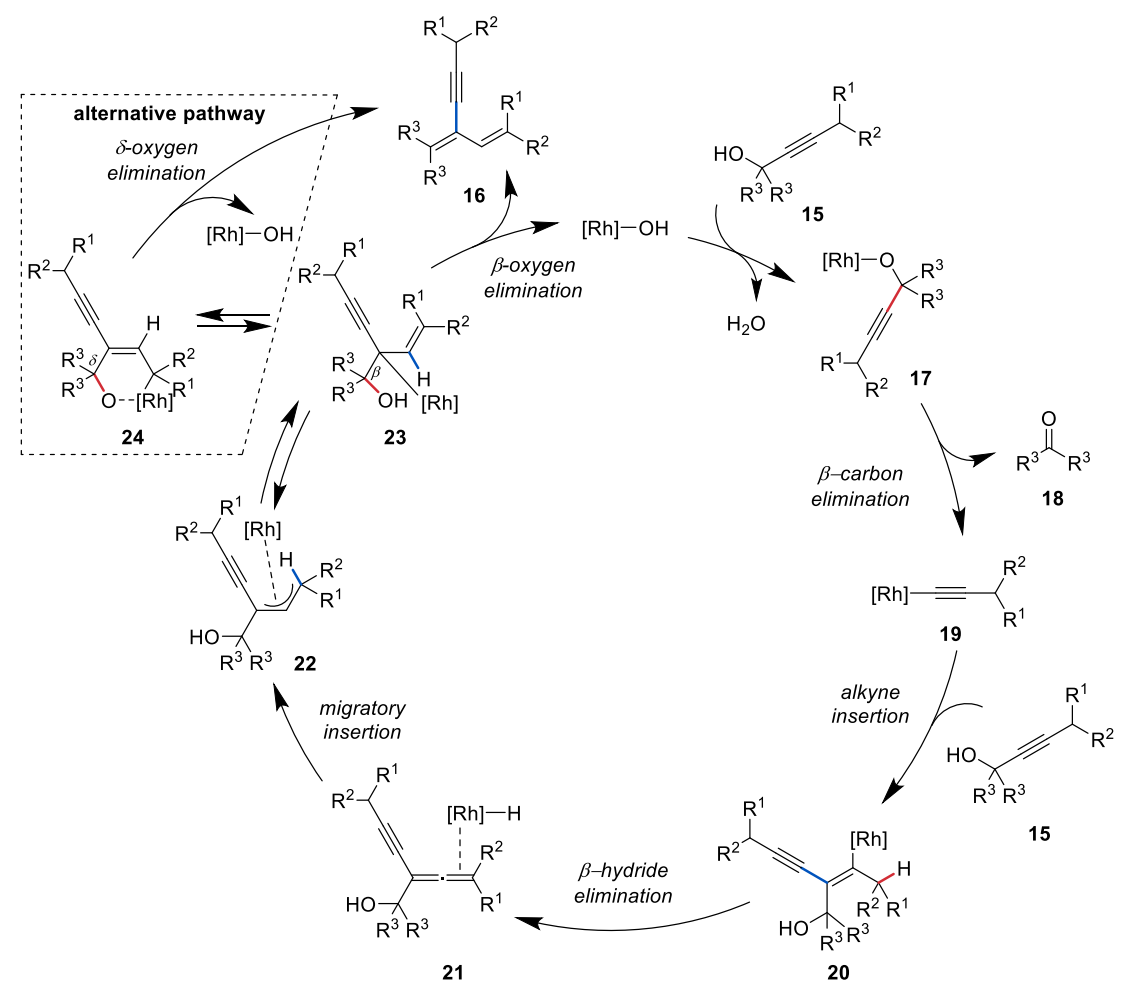

Hayashi et al. achieved the asymmetric intramolecular rearrangement of alkynyl alkenyl alcohols $\mathbf{2 5}$ by means of $\beta$-alkynyl elimination (Scheme 6).$^{52}$ In contrast to $\mathrm{sp}^{2}$-configured groups, the conjugative alkynylation of $\alpha, \beta$-unsaturated ketones with terminal alkynes is limited to a few examples as the alkyne substrate readily dimerizes under the reaction conditions. ${ }^{53,54}$ To circumvent this issue, the authors employed substrates that already contain the alkyne moiety in the form of propargylic alcohol 25 . The reaction proceeds via deprotonation and coordination of the alcohol to the catalyst (27), followed by $\beta$-alkynyl elimination. The resulting organorhodium species $\mathbf{2 8}$ is still bound to the alkene and thereby undergoes conjugate addition to form rhodium enolate 29 that is turned over to release product 26 . Several $\beta$-ethynylketones could be accessed in high ee's using chiral ligands from racemic starting materials. Notably, the cleavage of the alkynyl group was also selective in substrates containing adjacent alkenyl- and heteroaryl groups.

Scheme 6

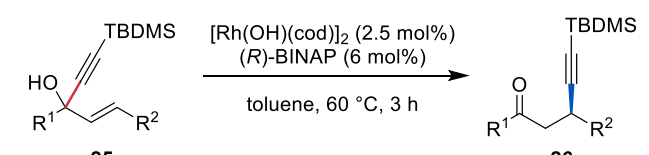

2526

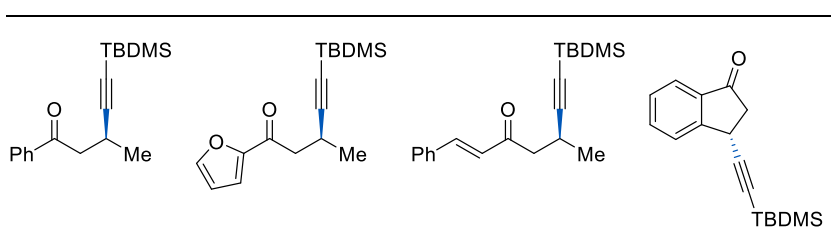

$88 \%, 94 \%$ ee $\quad 89 \%, 91 \%$ ee $\quad 78 \%, 96 \%$ ee $\quad 86 \%, 71 \%$ ee

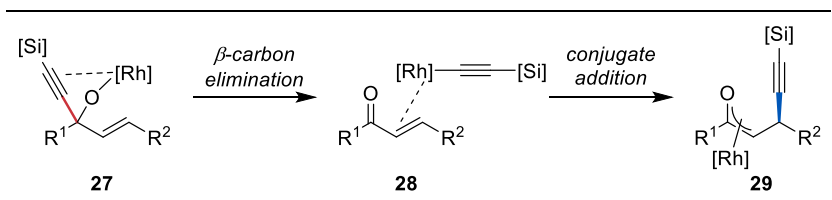


This document is the Accepted Manuscript version of a Published Work that appeared in final form in Chemical Reviews, copyright (C) American Chemical Society after peer review and technical editing by the publisher. To access the final edited and published work see https://doi.org/10.1021/acs.chemrev.0c00154

Shintani and Hayashi developed a rearrangement of bis(alkynyl) alcohols 30 to indanones $\mathbf{3 1}$ using the same relay strategy (Scheme 7). ${ }^{55}$ Several silylated (bis)alkynyl alcohols underwent the reaction in good yields, including both benzylic (30) and allylic alcohols (32). When the reaction was carried out in an intermolecular fashion with free alkyne 34 and ynone 35 , the product was not obtained, due to proton exchange of the enyne intermediate with free alkyne before the migration step (vide infra). The reaction presumably proceeds via $\beta$-alkynyl elimination from the alkoxide complex 36, followed by regioselective insertion into the resulting ynone 37. Subsequently, 1,4-rhodium migration and migratory insertion into the alkene take place to furnish intermediate $\mathbf{4 0}$ and, after protonolysis, the product (31).

\section{Scheme 7}
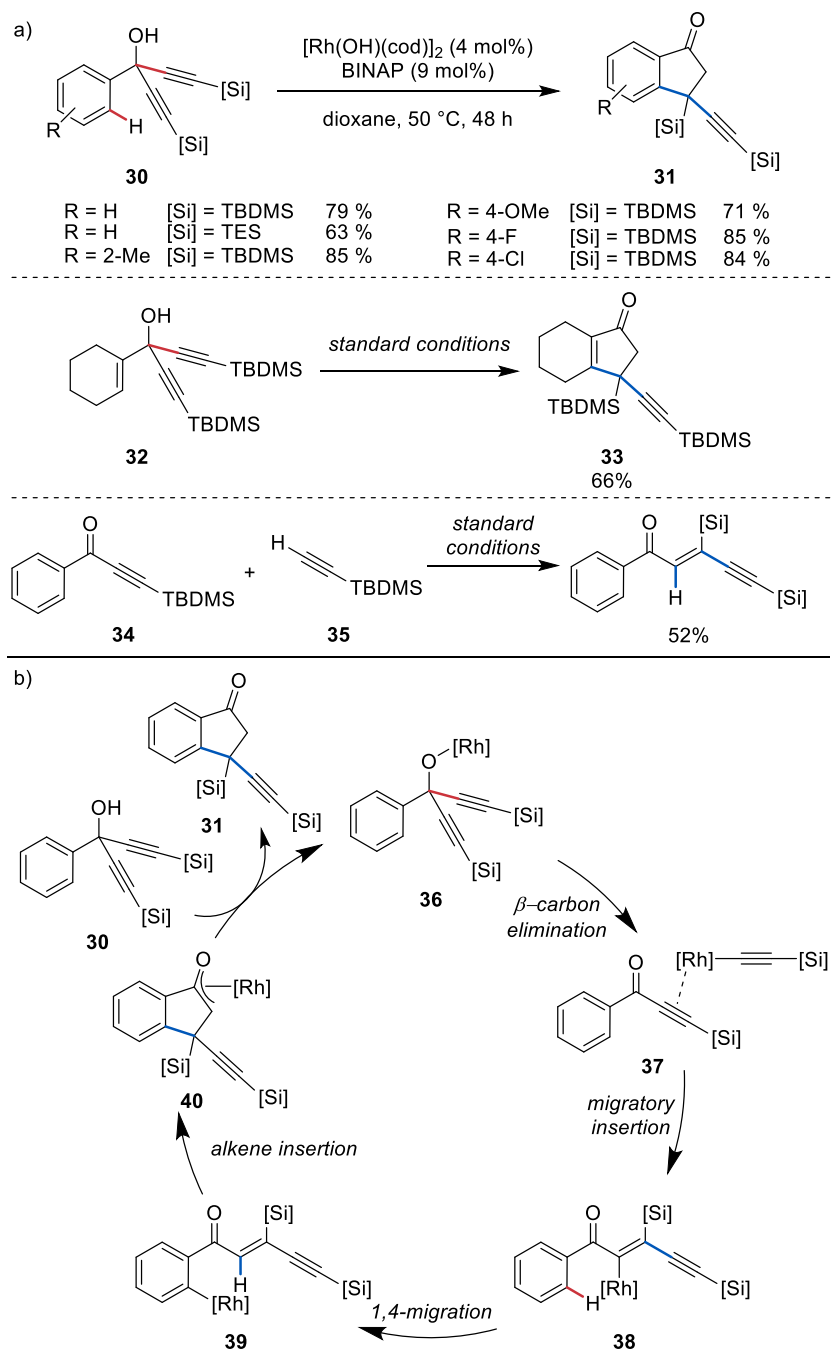

Hayashi further reported that rhodium could also catalyze the oxidative coupling of alkyne surrogates with olefins in extension to Uemura's work with palladium. ${ }^{47}$ Specifically, substituted propargyl alcohols $\mathbf{4 1}$ were reacted with acrylates $\mathbf{4 2}$ to afford conjugated enyne esters $\mathbf{4 3}$ (Scheme 8) ${ }^{56}$ Here, instead of oxygen, an excess of acrylate was used to turn over the $[\mathrm{Rh}]-\mathrm{H}$ species formed. The proposed catalytic cycle is initiated by $\beta$-alkynyl elimination from alkoxide-bound intermediate $\mathbf{4 4}$ and subsequent conjugate addition onto the acrylate ester to afford rhodium enolate 46. In contrast to intermediate 29 in Scheme 6, $\beta$-hydride elimination takes place to release the enyne product $\mathbf{4 3}$ after the addition step. The resulting rhodium hydride (47) then reacts with an additional equivalent of acrylate to regenerate the catalyst and release 49 as a byproduct. 
This document is the Accepted Manuscript version of a Published Work that appeared in final form in Chemical Reviews, copyright (C) American Chemical Society after peer review and technical editing by the publisher. To access the final edited and published work see https://doi.org/10.1021/acs.chemrev.0c00154

\section{Scheme 8}
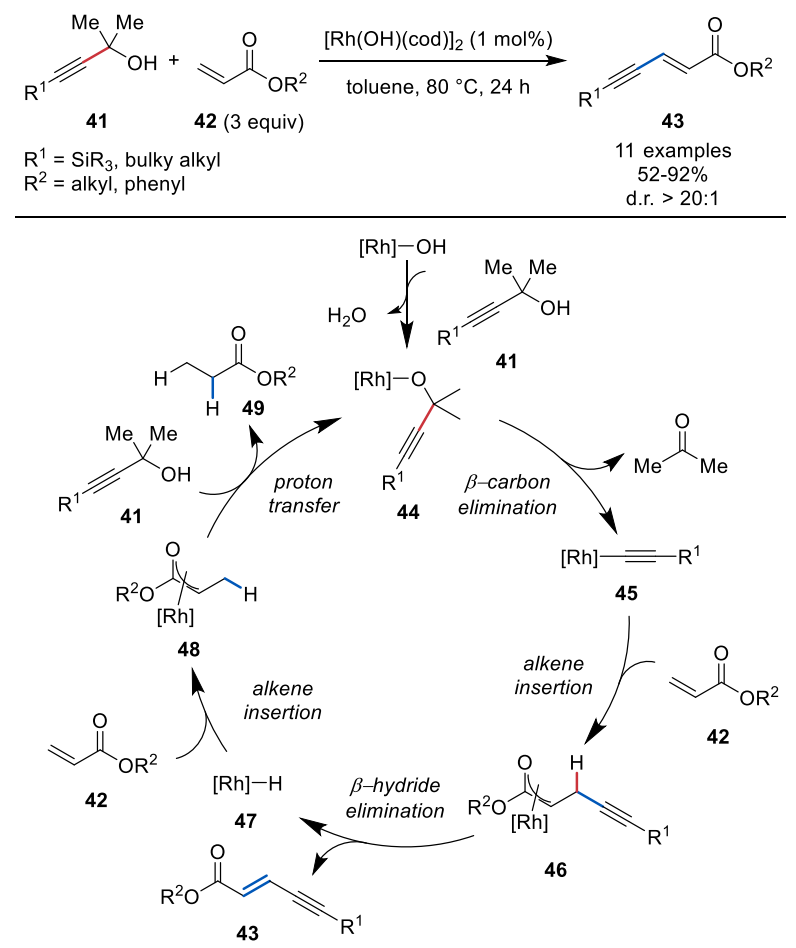

The same group later disclosed the asymmetric alkynylation of cyclic $\alpha, \beta$-unsaturated carbonyl compounds $\mathbf{5 0}$ via $\mathrm{C}-\mathrm{C}$ bond cleavage using silylated tert-propargyl alcohols 51 (Scheme 9). ${ }^{57}$ In addition to cyclic unsaturated ketones, lactams and lactones were also tolerated. It was found that the bulky TIPS group on the acetylene and the bulky diene ligand Fc-bod were crucial to obtain good yields and stereoselectivity. Other chiral diene ligands such as Ph-bod were less effective due to premature catalyst deactivation. The authors conducted mechanistic studies to understand the cause of the catalyst deactivation and the difference between Fc-bod and other diene ligands. Alkynyl rhodium species $\mathbf{5 4}$ is in equilibrium with its dimeric form 56, the latter being the resting state in the catalytic cycle. Independent synthesis of the proposed resting state (56) and $\mathbf{5 7}$ allowed the tentative assignment of structure $\mathbf{5 7}$ as the deactivation product, which is formed more slowly in the case of Fcbod. 
This document is the Accepted Manuscript version of a Published Work that appeared in final form in Chemical Reviews, copyright (C) American Chemical Society after peer review and technical editing by the publisher. To access the final edited and published work see https://doi.org/10.1021/acs.chemrev.0c00154

Scheme 9
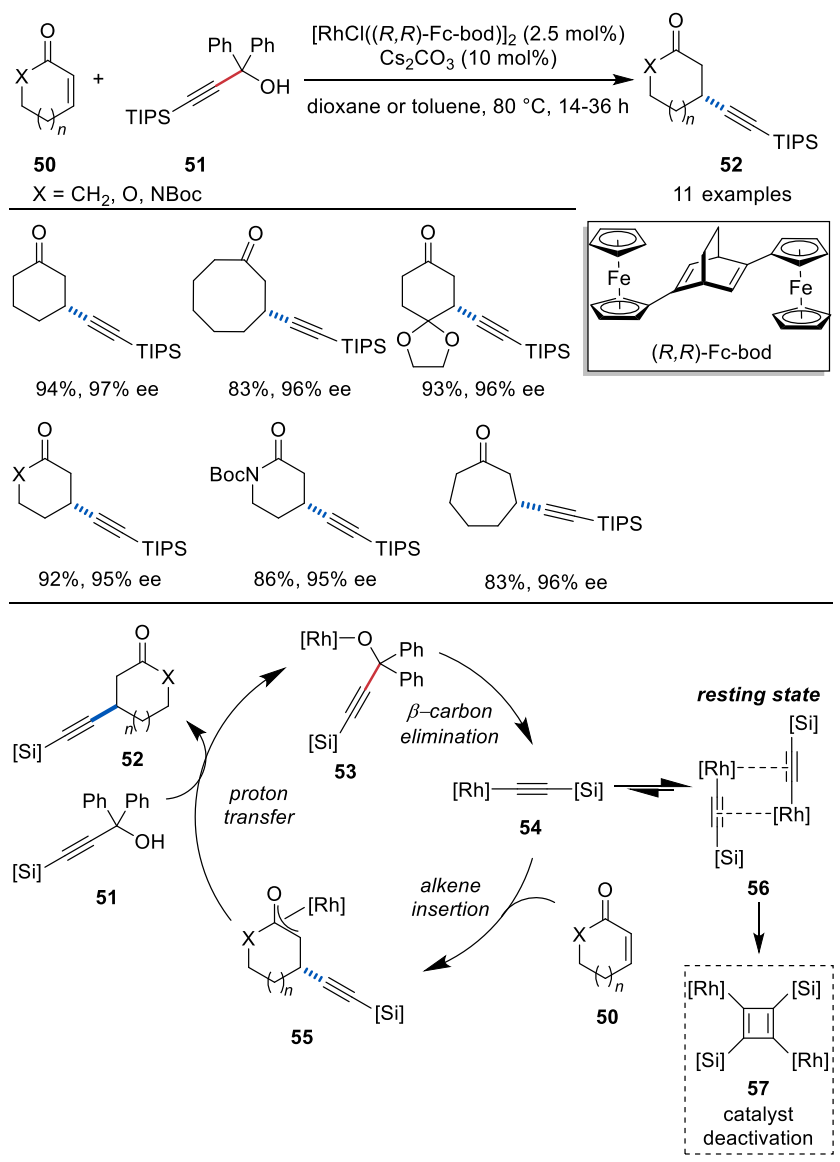

Recently, Dou expanded the scope of the asymmetric intermolecular alkynylation to $\beta, \gamma$-unsaturated $\alpha$-ketoesters $\mathbf{5 8}$ (Scheme 10$).{ }^{58}$ The chiral diene ligand $\mathrm{Fc}$-bod that was used in the previous reaction of cyclic $\alpha, \beta$-unsaturated carbonyl compounds was not effective in this case. In contrast, the bulky phosphine ligand DM-BINAP delivered the desired alkynylated products in good yields and ee's. The authors showed that terminal alkynes only gave traces of product, attributing this to the competing alkyne dimerization pathway. A variety of aryl- and heteroaryl groups in the $\gamma$-position of $\mathbf{5 8}$ were tolerated, but alkyl- and styryl-substituted substrates did not undergo the transformation.

\section{Scheme 10}

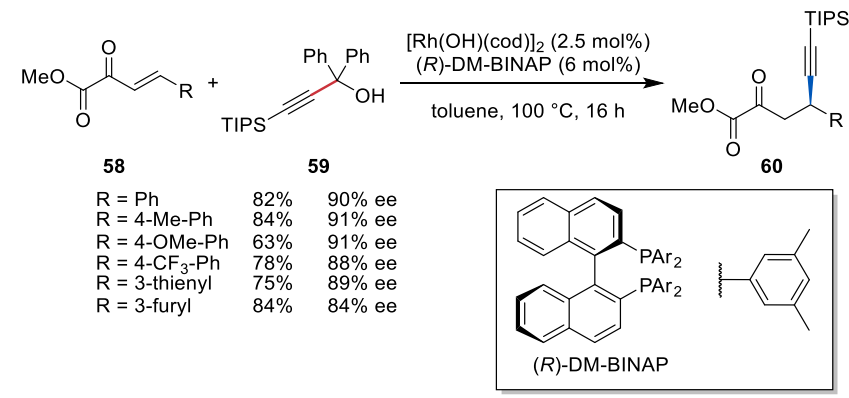

Lautens recently disclosed an alkynylation/aldol cyclization sequence of keto-enones 61 affording cyclic $\alpha$-propargyl- $\beta$-hydroxyketones 63 with high enantio- and diastereoselectivity (Scheme 11). ${ }^{59} \mathrm{~A}$ broad range of six-membered adducts were furnished, bearing aliphatic and aromatic groups on both sides of the keto-enone. Several bulky alkynes, including aliphatic ones, were tolerated, but terminal alkynes lead to homodimerization instead. Notably, a tetrahydropyran ring with three adjacent chiral centers could be constructed with high enantioselectivity, albeit with low yield. The authors propose a mechanism in which rhodium-acetylide $\mathbf{6 5}$ is formed after $\beta$-carbon elimination that subsequently inserts 
This document is the Accepted Manuscript version of a Published Work that appeared in final form in Chemical Reviews, copyright (C) American Chemical Society after peer review and technical editing by the publisher. To access the final edited and published work see https://doi.org/10.1021/acs.chemrev.0c00154

in a 1,4-fashion into the $\alpha, \beta$-unsaturated ketone to afford species 66 . The resulting oxa- $\pi$-allyl intermediate cyclizes via a six-membered transition state leading to the syn-configured product 63.

Scheme 11
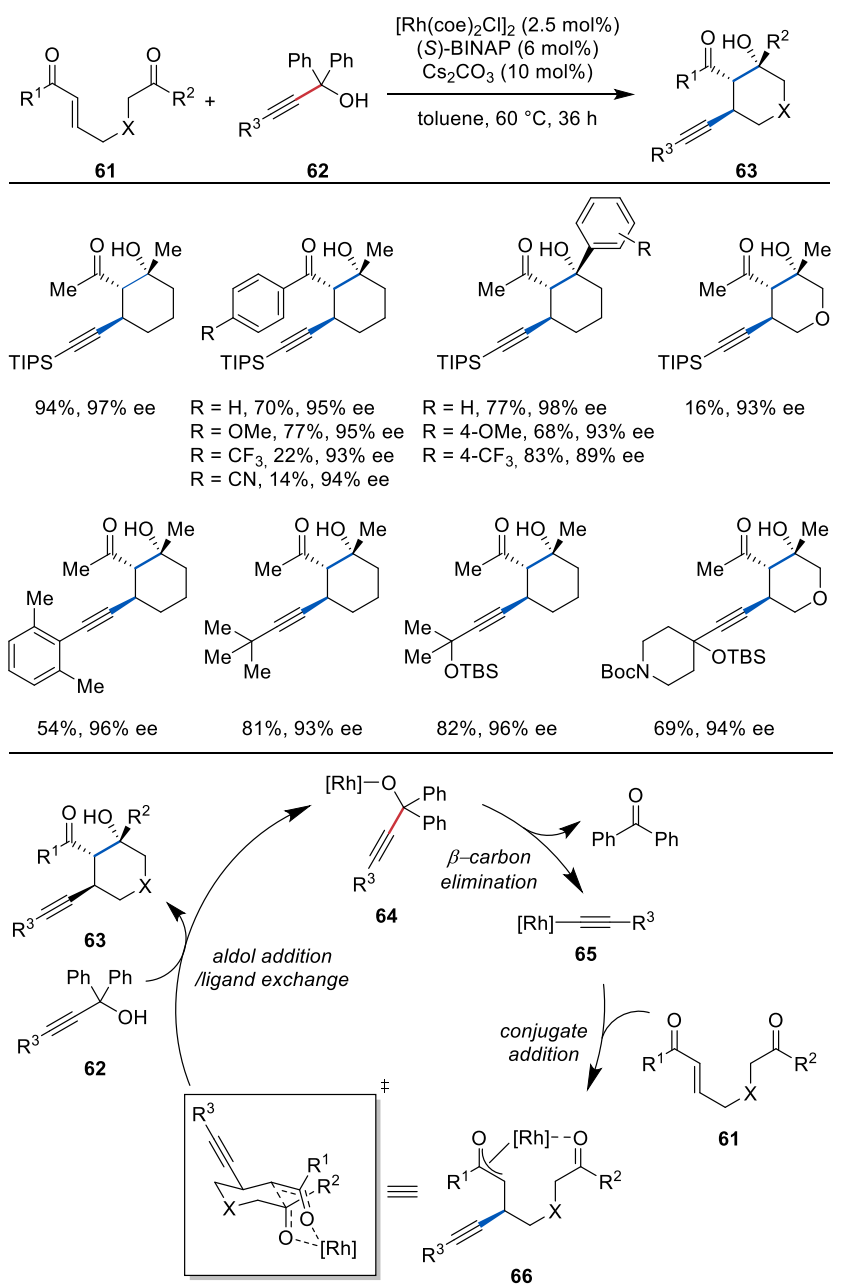

Tobisu and Chatani recently developed a rhodium-catalyzed cross-coupling reaction of aryl carbamates $\mathbf{6 7}$ with propargyl alcohols $\mathbf{6 8}$ that proceeds with concomitant cleavage of a $\mathrm{C}-\mathrm{O}$ and a $\mathrm{C}-\mathrm{C}$ bond (Scheme 12$).{ }^{60}$ In this work, an electron-rich and sterically demanding NHCligand proved to be ideal. Interestingly, the reaction outcome strongly depended on the nature of substituents on the propargyl alcohol substrate; only TIPS-protected alkynes afforded high yields, while TMS- and phenyl-acetylenes were detrimental to the reaction. The isopropyl groups in $\alpha$-position to the alcohol were also critical for an efficient reaction, as the free acetylene and other aryl-and alkyl-substituted propargyl alcohols led to lower yields. With the optimized conditions in hand, several aryl carbamates could be alkynylated in moderate to good yields, albeit only a single propargyl alcohol was used in this study. The authors suggest that $\beta$-alkynyl elimination from the alkoxide-complex $\mathbf{7 0}$ precedes the oxidative addition of the aryl carbamate to give species 72. Reductive elimination from this intermediate leads to the product. While plausible, there is little direct evidence for this mechanism. 
This document is the Accepted Manuscript version of a Published Work that appeared in final form in Chemical Reviews, copyright (C) American Chemical Society after peer review and technical editing by the publisher. To access the final edited and published work see https://doi.org/10.1021/acs.chemrev.0c00154

Scheme 12

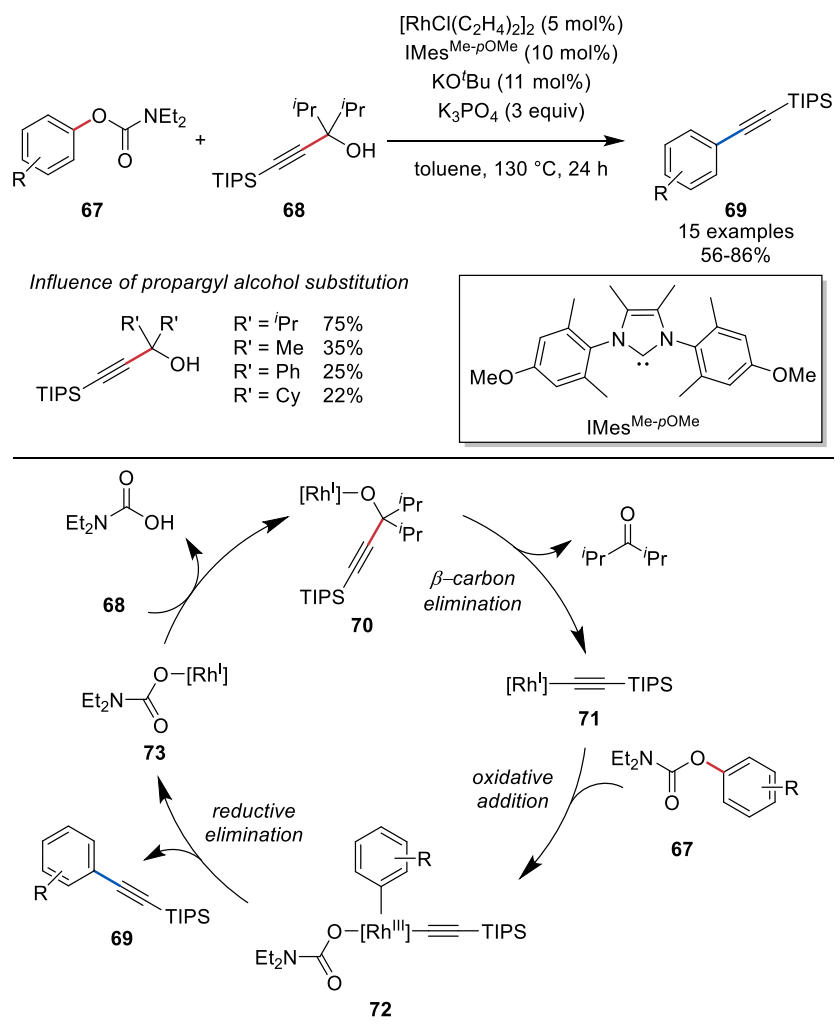

\section{3. $\beta$-Alkynyl Elimination with Copper}

Wen and co-workers disclosed a cascade annulation of 1-(pyridin-2-yl)-1H-indoles (74) and propargylic alcohols 75 to form substituted pyrido[2,1-a]-indoles (76) utilizing both rhodium and copper. ${ }^{61}$ In the process, several $\mathrm{C}-\mathrm{C}(\mathrm{sp}), \mathrm{C}-\mathrm{H}$ and $\mathrm{C}-\mathrm{N}$ bonds are cleaved and formed (Scheme 13). Both electron-rich and electron-poor arenes were tolerated on either reaction partners but steric bulk was detrimental to the reaction. The authors found that superstoichiometric copper was essential for the success of the reaction, as it served the two-fold purpose of activating the propargylic alcohol by forming a copper acetylide and reoxidizing the rhodium catalyst. Both metals were found to be essential and cooperative, as without rhodium Glaser homocoupling product was exclusively formed, while leaving out copper led to no reaction. To shed more light on the mechanism of this transformation, the authors isolated the bis-ligated rhodium complex 77 that was exclusively formed in the presence of stoichiometric amounts of copper(II). When $\mathbf{7 7}$ and the copper acetylide were reacted, no product was observed unless additional copper was added.

From these experiments the authors propose a mechanism that is initiated by oxidation of the rhodium(I) catalyst followed by cyclometalation with the substrate to give complex 77. In parallel, copper coordinates to the propargylic alcohol and induces $\beta$-carbon elimination to afford a copper acetylide (78). Transmetalation to rhodium (79) followed by reductive elimination affords intermediate $\mathbf{8 1}$ that undergoes several transformations to afford the annulated product (76). In parallel, rhodium complex 82 is oxidized by copper and undergoes cyclometalation with 74, closing the catalytic cycle. 
This document is the Accepted Manuscript version of a Published Work that appeared in final form in Chemical Reviews, copyright (C) American Chemical Society after peer review and technical editing by the publisher. To access the final edited and published work see https://doi.org/10.1021/acs.chemrev.0c00154

Scheme 13
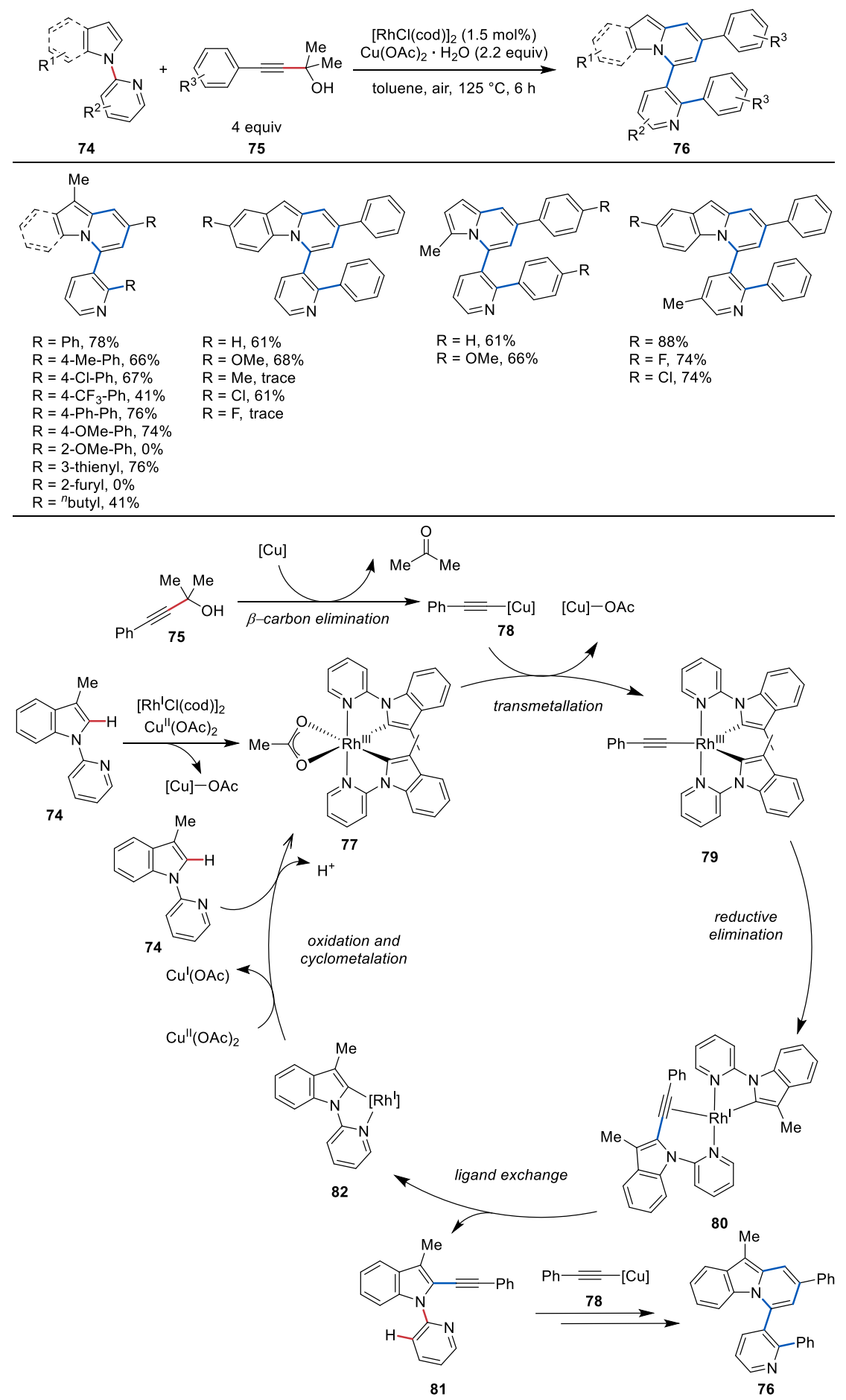

In a subsequent study, the authors disclosed that introduction of a methyl group at the C6 position next to the pyridine nitrogen allowed access to the $\mathrm{C} 2$-alkynylated product $\mathbf{8 5}$ under the same reaction conditions, preventing the cascade annulation observed previously (Scheme 14$){ }^{62}$ 
This document is the Accepted Manuscript version of a Published Work that appeared in final form in Chemical Reviews, copyright (C) American Chemical Society after peer review and technical editing by the publisher. To access the final edited and published work see https://doi.org/10.1021/acs.chemrev.0c00154

A series of 1-(6-methylpyridin-2-yl)-1H-indoles (83) were alkynylated in good yields following this protocol. Notably, carbazoles also underwent the reaction with good yields.

\section{Scheme 14}
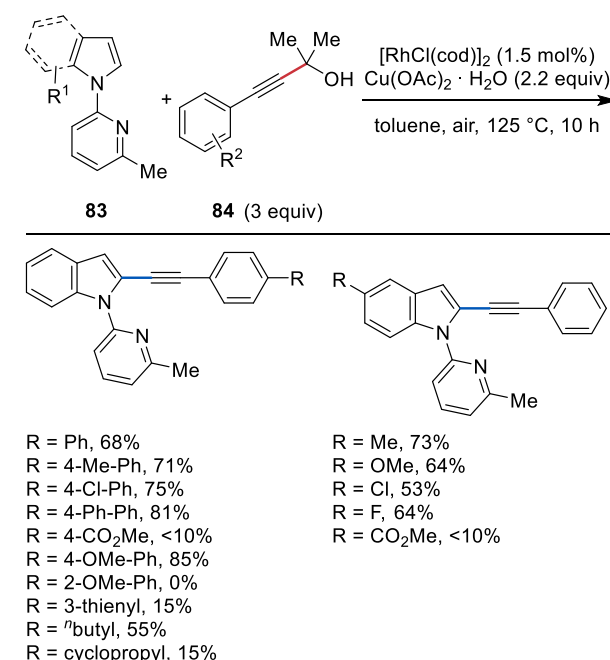

$\mathrm{R}=\mathrm{Me}, 73 \%$

$\mathrm{R}=\mathrm{OMe}, 64 \%$

$\mathrm{R}=\mathrm{Cl}, 53 \%$

$\mathrm{R}=\mathrm{F}, 64 \%$
$\mathrm{R}=\mathrm{CO}_{2} \mathrm{Me},<10 \%$

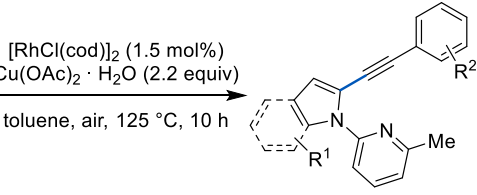

85

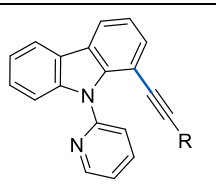

$\mathrm{R}=\mathrm{Ph}, 61 \%$

$\mathrm{R}=4-\mathrm{Cl}-\mathrm{Ph}, 82 \%$

$\mathrm{R}=4-\mathrm{Ph}-\mathrm{Ph}, 73 \%$

$\mathrm{R}=\mathrm{CO}_{2} \mathrm{Me}, 39 \%$

$\mathrm{R}=4-\mathrm{OMe}-\mathrm{Ph}, 66 \%$

$\mathrm{R}=2-\mathrm{OMe}-\mathrm{Ph}, 0 \%$
$\mathrm{R}=2-\mathrm{CO}_{2} \mathrm{Me}-\mathrm{Ph}, 55 \%$

$\mathrm{R}=3$-thienyl, $48 \%$

$R=$ cyclopropyl, $15 \%$

$\mathrm{R}={ }^{n}$ butyl, $62 \%$

Inspired by this reaction, Zhou and co-workers developed an annulative coupling of $N$-aryl-2-aminopyridine $\mathbf{8 6}$ and propargyl alcohols $\mathbf{8 7}$ to give indoles $\mathbf{8 8}$ using cooperative rhodium and copper catalysis (Scheme 15). ${ }^{63}$ Mechanistic experiments confirmed that both metals were required for the transformation, with copper being responsible for the $\mathrm{C}-\mathrm{C}$ bond cleavage. Kinetic isotope effect (KIE) experiments were conducted with 86 and $d_{5}-86$ in parallel $\left(\mathrm{k}_{\mathrm{H}} / \mathrm{k}_{\mathrm{D}}=1.0\right)$ and in intermolecular competition $\left(\mathrm{k}_{\mathrm{H}} / \mathrm{k}_{\mathrm{D}}=1.1\right)$. From these results, it was concluded that $\mathrm{C}-\mathrm{H}$ activation is not part of the rate-determining step. In the presence of $\mathrm{D}_{2} \mathrm{O}, \mathrm{H} / \mathrm{D}$ exchange was observed, which could imply that $\mathrm{C}-\mathrm{H}$ activation is reversible. The reaction proceeds according to a similar mechanism as the one discussed above, starting with concerted metalationdeprotonation (CMD)-type $\mathrm{C}-\mathrm{H}$ activation of the substrate with the $\mathrm{Rh}(\mathrm{III})$ complex to give intermediate 90. After formation of copperacetylide 91 under release of acetone, transmetalation with the rhodium-complex leads to complex $\mathbf{9 2}$ that subsequently undergoes reductive elimination. The intermediate $\mathbf{9 3}$ then cyclizes to afford the indole core (88). 
This document is the Accepted Manuscript version of a Published Work that appeared in final form in Chemical Reviews, copyright (C) American Chemical Society after peer review and technical editing by the publisher. To access the final edited and published work see https://doi.org/10.1021/acs.chemrev.0c00154

Scheme 15
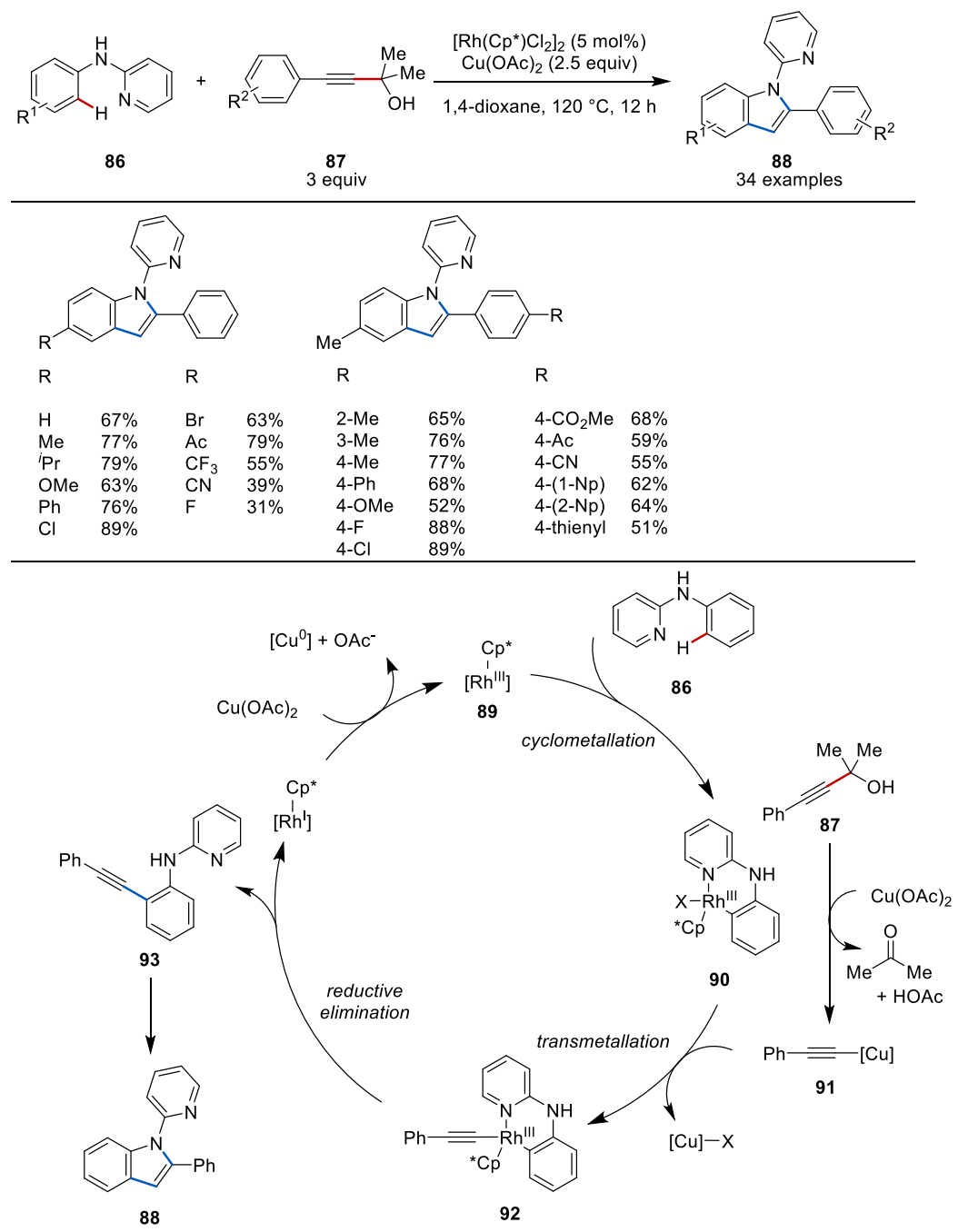

\section{3. $\beta$-ARYL ELIMINATION}

For reasons detailed in the introduction, $\beta$-carbon elimination and $\beta$-hydride elimination proceed via a similar reaction path. For the latter, an agostic interaction between the migrating hydride and the metal center is implied to precede the cleavage. ${ }^{64,65}$ Therefore, the same should be conceivable for the elimination of a hydrocarbyl group. Indeed, in the case of $\beta$-aryl elimination, agostic interactions between the $\pi$-system of the to-be-cleaved group and an unsaturated metal centers have been observed in X-ray crystal structures..$^{20,66}$

\section{1. $\beta$-Aryl Elimination with Palladium}

In a seminal publication in 2001, the group of Miura reported the first cross-coupling reaction proceeding via $\mathrm{C}\left(\mathrm{sp}^{2}\right)-\mathrm{C}\left(\mathrm{sp}^{3}\right)$ bond cleavage of unstrained alcohols. ${ }^{67}$ Under the action of a palladium catalyst, tertiary benzylic alcohols 94 undergo $\mathrm{C}-\mathrm{C}$ bond cleavage to release a ketone and act as coupling partners to afford biaryls with aryl bromides 95 (Scheme 16).

The reaction outcome is highly dependent on the steric environment of the alcohol substrate, with sequential $\mathrm{C}-\mathrm{H}$ and $\mathrm{C}-\mathrm{C}$ activations taking place unless an ortho-methyl substituent was introduced to favor $\beta$-carbon elimination over competing $\mathrm{C}-\mathrm{H}$ arylation processes. 
This document is the Accepted Manuscript version of a Published Work that appeared in final form in Chemical Reviews, copyright (C) American Chemical Society after peer review and technical editing by the publisher. To access the final edited and published work see https://doi.org/10.1021/acs.chemrev.0c00154

Scheme 16

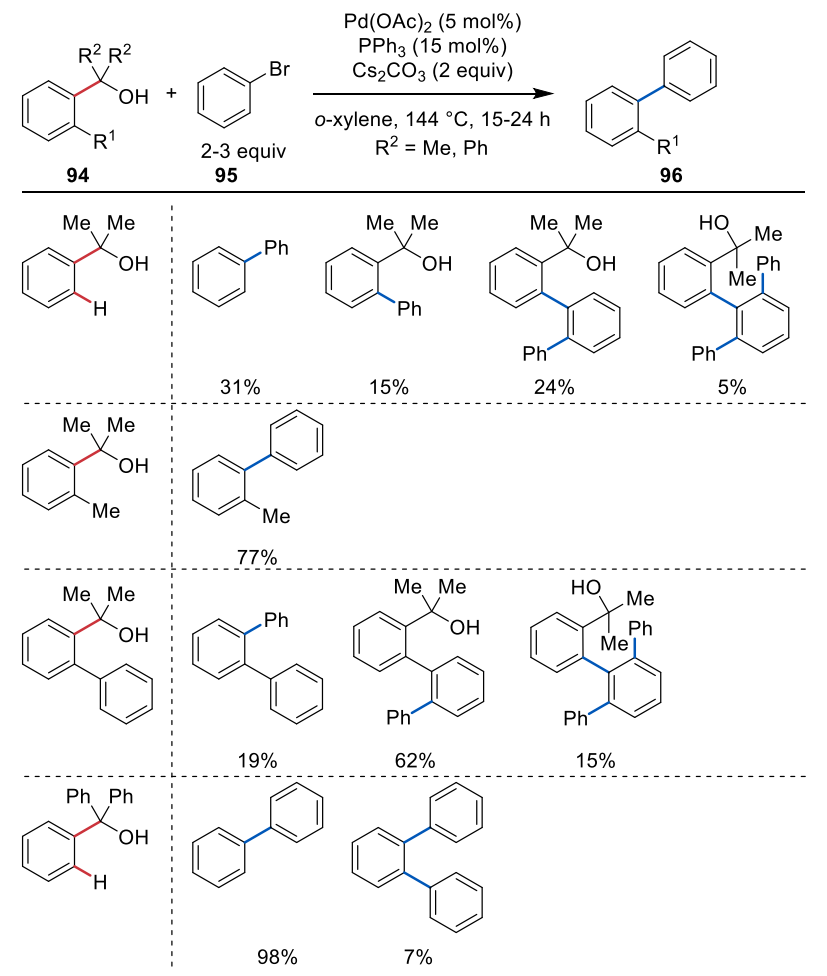

Changing the ligand to the bulky phosphine $\mathrm{PCy}_{3}$ allowed to cross-couple triarylmethanols $\mathbf{9 7}$ also with aryl chlorides $\mathbf{9 8}$ to give biaryls $\mathbf{9 9}$ in good yields (Scheme 17). ${ }^{68}$ Importantly, both electron-rich and -poor substituents were tolerated on the aryl chloride and steric bulk in ortho-

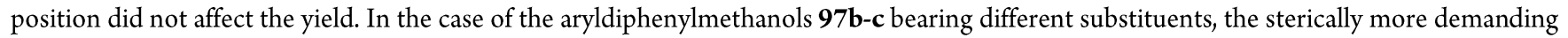
group was selectively cleaved.

\section{Scheme 17}

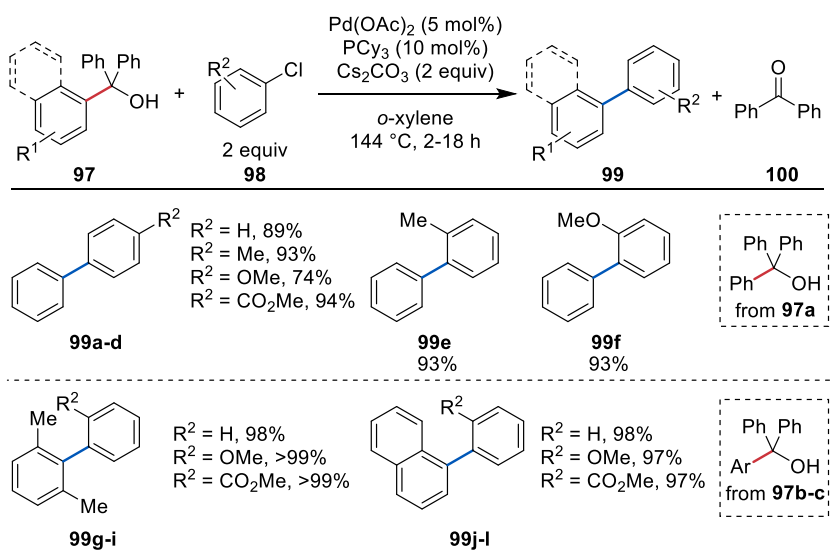

To study the factors governing the selectivity of the $\beta$-carbon-elimination, intramolecular competition experiments with monosubstituted triarylmethanols 101 (two phenyl groups and one substituted aryl group) were carried out (Table 1). In the case of an electron-neutral $p$-tolyl group, a statistical mixture was observed (entry 2). However, when either electron-rich or electron-poor substituents in the para-position were introduced, a small trend towards cleavage of the substituted aryl group was observed (entries 3-4). In addition, when steric bulk was introduced in the ortho-position, the most sterically demanding group was cleaved selectively, regardless of the electronic nature of the substituent (entries 5-7). 
This document is the Accepted Manuscript version of a Published Work that appeared in final form in Chemical Reviews, copyright (C) American Chemical Society after peer review and technical editing by the publisher. To access the final edited and published work see https://doi.org/10.1021/acs.chemrev.0c00154

Table 1

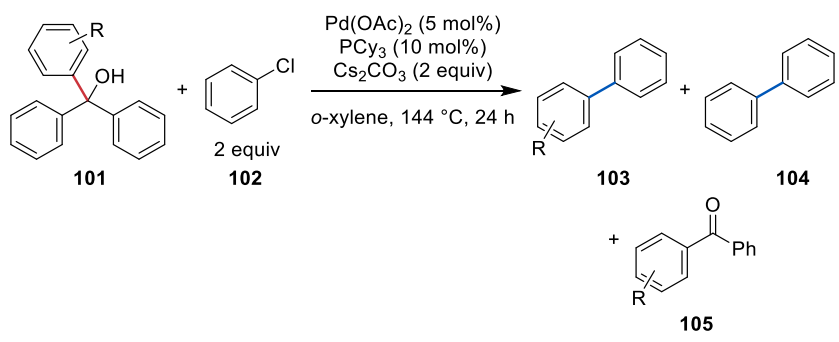

\begin{tabular}{llll}
\hline entry & $\mathbf{R}$ & Yield 103+104(\%) & Ratio 103:104 \\
\hline $1^{a}$ & $\mathrm{H}$ & 89 & - \\
2 & $4-\mathrm{Me}$ & 92 & $1: 2$ \\
3 & $4-\mathrm{OMe}$ & 88 & $1: 1$ \\
4 & $4-\mathrm{CF}_{3}$ & 85 & $1.3: 1$ \\
5 & $2-\mathrm{Me}$ & 94 & $10: 1$ \\
6 & $2-\mathrm{OMe}$ & $>99$ & $>99: 1$ \\
7 & $2-\mathrm{CF}_{3}$ & 99 & $50: 1$ \\
\hline
\end{tabular}

${ }^{a} 1$ eq. $\mathrm{PhCl}$ and $\mathrm{Cs}_{2} \mathrm{CO}_{3}$

Several other triarylalcohol scaffolds were then investigated (Scheme 18). The 9-phenylxanthen-9-ol scaffold (106) can serve as a selective donor of the exocyclic aryl group. In contrast, in the case of 109, the internal C-C bond was cleaved due to relief of ring strain. With 2-heteroaryl-containing triarylalcohols $\mathbf{1 1 1}$, the heteroatom-containing ring was selectively cleaved.

\section{Scheme 18}

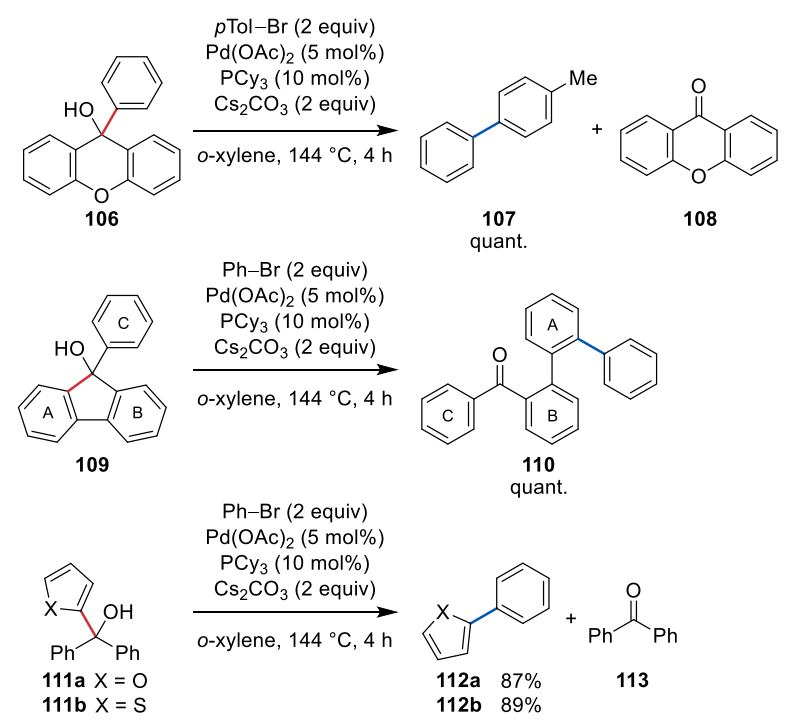

Beyond triarylmethanols, 2-aryl-2-propanols 114 could also be employed, however, an ortho-substituent had to be introduced to prevent competing $\mathrm{C}-\mathrm{H}$ arylation reactions (vide supra). Notably, when using ( $R$ )-BINAP as the ligand, an enantioenriched binaphthyl could be obtained, highlighting the potential of using this reaction for enantioselective synthesis (Scheme 19). Importantly, no cleavage of the methyl groups was observed, which is in line with the higher bond strength of the $\mathrm{C}\left(\mathrm{sp}^{3}\right)-\mathrm{C}\left(\mathrm{sp}^{3}\right)$ bond. 
This document is the Accepted Manuscript version of a Published Work that appeared in final form in Chemical Reviews, copyright (C) American Chemical Society after peer review and technical editing by the publisher. To access the final edited and published work see https://doi.org/10.1021/acs.chemrev.0c00154

Scheme 19
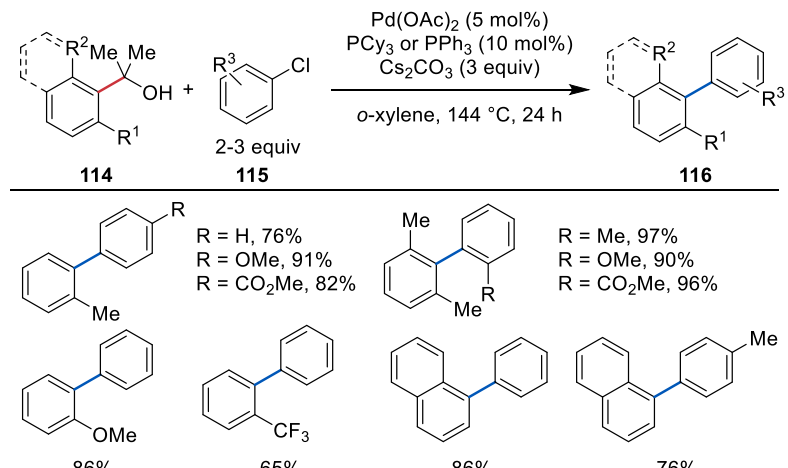

$86 \%$

$65 \%$
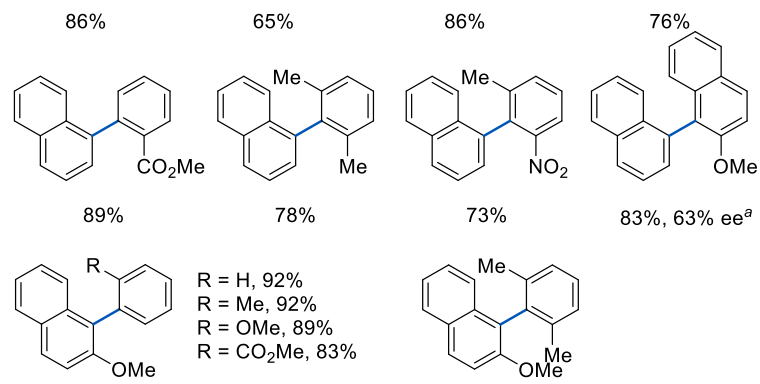

$\mathrm{R}=\mathrm{Me}, 92 \%$

R $=$ OMe, $89 \%$

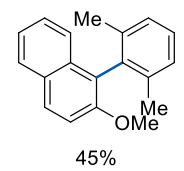

${ }^{a}$ Using $10 \mathrm{~mol} \%(R)$-BINAP as ligand.

Taking advantage of the propensity of 2-([1,1'-biphenyl]-2-yl)propan-2-ol (117) to undergo multiple C-C bond and directed C-H bond cleavages, triphenylenes 119 could be efficiently synthesized by reaction of 117 with 1,2-dibromoarenes (118) (Scheme 20).

Scheme 20

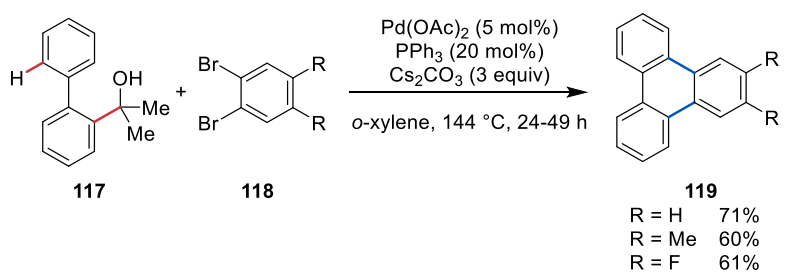

In separate work, Johnson and co-workers interrogated the reaction mechanism of the palladium-catalyzed $\beta$-aryl elimination of triaryl alcohols and cross-coupling to aryl halides reported by Miura. ${ }^{69}$ Intramolecular competition experiments with a series of aryldiphenylmethanols $\mathbf{1 2 0}$ were carried out to gain an understanding of the factors governing $\beta$-aryl elimination selectivity (Table 2). The ortho-substituted arenes were preferably cleaved, following the trend of the steric bulk imposed by the group (entries 1-3; $\mathrm{Cl}>\mathrm{OMe}>\mathrm{Me}$ ). The selectivity was rationalized studying the X-ray structure of an analogous rhodium alkoxide complex where the to-be-cleaved aryl group is shown to interact with the metal center (see section 3.2).$^{70}$ The steric clash between the ortho-substituted arene and the bulky phosphine ligands usually employed can be minimized in this conformation leading to preferential cleavage of this group. In contrast, electronically neutral substitution had little effect on the ratio (entries 4-6). Further, the electronic properties of the aryl group played only a minor role, with both electron-rich (entries 7,10$)$ and electron-poor substituents favoring the elimination (entries 8-9,11-12). 
This document is the Accepted Manuscript version of a Published Work that appeared in final form in Chemical Reviews, copyright (C) American Chemical Society after peer review and technical editing by the publisher. To access the final edited and published work see https://doi.org/10.1021/acs.chemrev.0c00154

Table 2

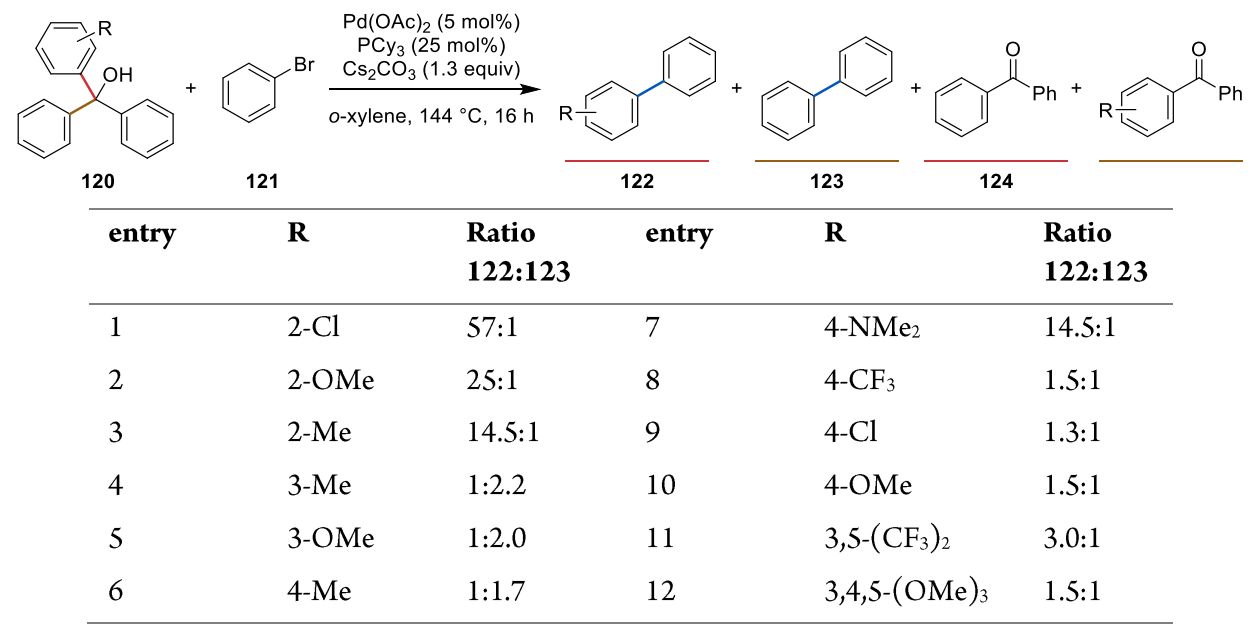

With two competing aryl halides, the more electron-poor aryl halide reacted faster, which is in accordance with the observed selectivity for the oxidative addition step. A rapid pre-equilibrium exists before the turnover-limiting step, which was found to be the $\beta$-aryl elimination. To probe, whether $\beta$-aryl elimination and reductive elimination are irreversible, an exogenous ketone (125) was added to the reaction mixture of the triaryl alcohol and aryl halide (Scheme 21). No scrambling products were observed, suggesting that $\mathrm{C}-\mathrm{C}$ bond activation is irreversible or that reductive elimination is too fast to allow for ligand exchange. Reductive elimination was shown to be irreversible by similar means by subjecting the biaryl product to the reaction conditions.

\section{Scheme 21}

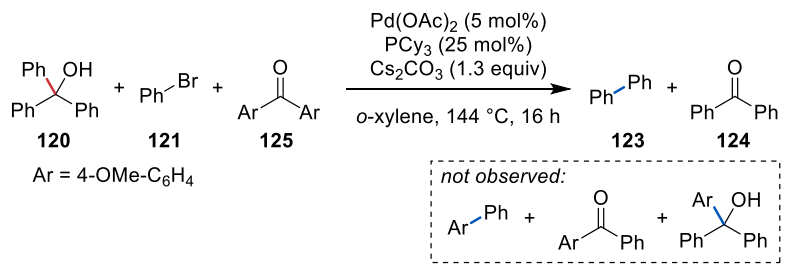

From these findings, the authors propose the catalytic cycle depicted in Scheme 22. The in situ formed palladium $(0)$ species $\mathbf{1 2 6}$ undergoes oxidative addition of the aryl halide $\mathbf{1 2 1}$ and transmetalates with $\mathbf{1 2 0}$ to form alkoxide complex $\mathbf{1 2 8}$. Rate-determining $\beta$-phenyl elimination releases benzophenone and the biaryl product is formed by irreversible reductive elimination from complex 129. 
This document is the Accepted Manuscript version of a Published Work that appeared in final form in Chemical Reviews, copyright (C) American Chemical Society after peer review and technical editing by the publisher. To access the final edited and published work see https://doi.org/10.1021/acs.chemrev.0c00154

Scheme 22

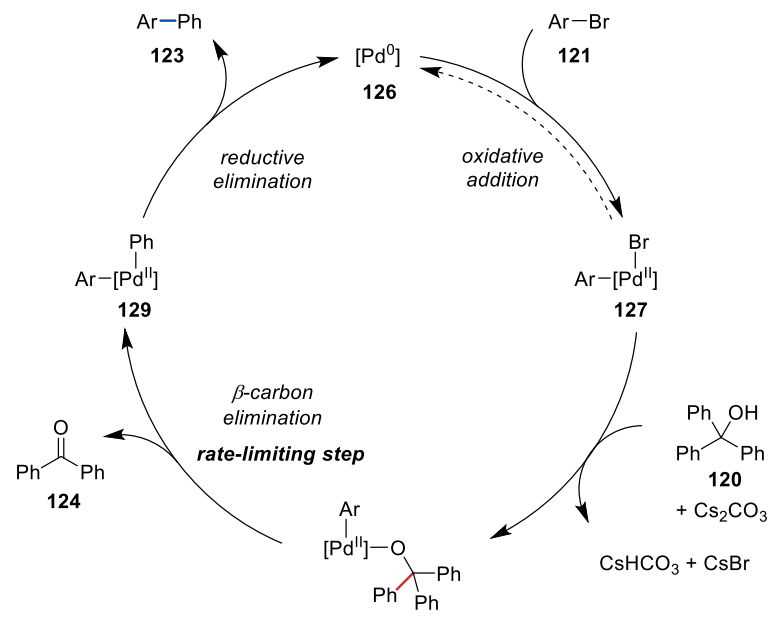

The reaction described above was subjected to multivariate linear regression analysis by Sigman and co-workers to parametrize the factors that contribute to the observed selectivity. ${ }^{71}$ While Hammett analysis is a powerful tool to elucidate reaction mechanisms using the electronic influence exerted by the substituted aryl rings, it cannot be used for ortho-substituents, as the steric influence cannot be uncoupled from the electronic factor. ${ }^{72}$ The authors developed a regression model that predicts the observed selectivity using two parameters, the infrared stretching frequency of the $\mathrm{C}-\mathrm{O}-\mathrm{H}$ bond $\left(v_{\mathrm{C}-O-H}\right)$ and the parameter $B_{1,0}$ that describes the steric influence of the ortho-substituent: $\Delta \Delta \mathrm{G}^{\ddagger}=\mathrm{k}+\alpha v_{\mathrm{C}-O-H}$ $+\beta B_{1,0}$. These values could be obtained experimentally or computationally from Sterimol ${ }^{73}$ and matched the experimentally measured $\Delta \Delta \mathrm{G}^{\ddagger}$ values (Ar/Ph ratios).

Miura later reported the palladium-catalyzed dehydroarylation of triarylmethanols $\mathbf{1 3 0}$ and hydroarylation of alkynes 131 by exploiting $\beta$-carbon cleavage. ${ }^{74}$ Interestingly, the bulky ligand $\mathrm{P}(1-\mathrm{Np})_{3}$ suppressed biaryl coupling with aryl bromides and promoted base-mediated dehydroarylation of 130 instead. After optimization of the reaction conditions, catalytic amounts of aryl bromide and base were sufficient to dehydroarylate a range of triaryl methanols. Moreover, when an alkyne was introduced, hydroarylation across the triple bond took place. Using the same conditions, diphenylacetylene (Table 3, entries 1-4) and activated $\alpha, \beta$-unsaturated ketones could be hydroarylated in good yield (entries 5-6). In contrast, aliphatic alkynes were not tolerated in the reaction. Use of xanthene-9-ol-derived donors allowed to transfer several arenes with high selectivity and reduced catalyst loading (entries 4-6). 
This document is the Accepted Manuscript version of a Published Work that appeared in final form in Chemical Reviews, copyright (C) American Chemical Society after peer review and technical editing by the publisher. To access the final edited and published work see https://doi.org/10.1021/acs.chemrev.0c00154

Table 3

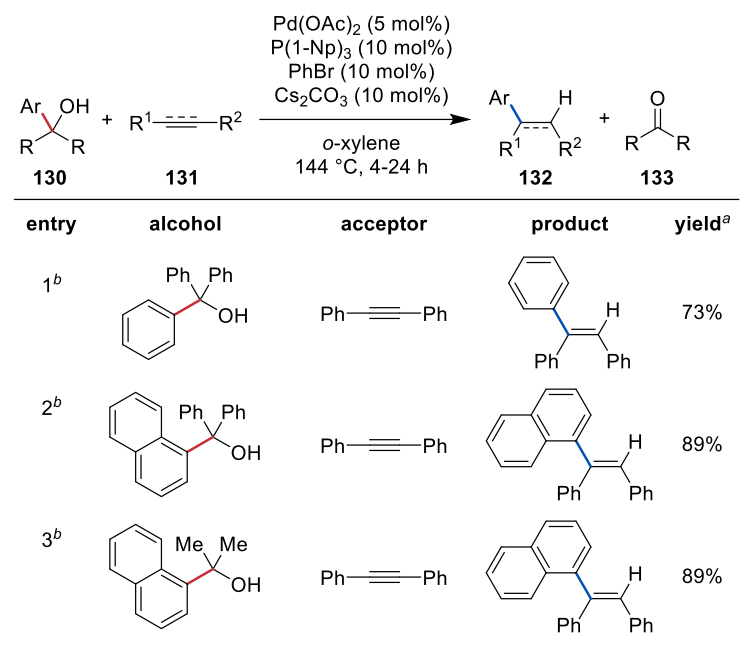

$4 \mathrm{MeO}$

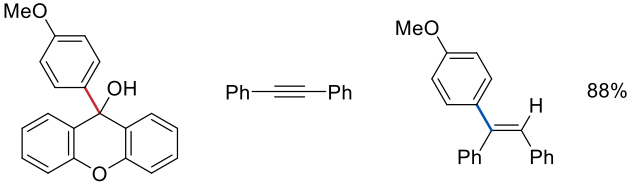

5
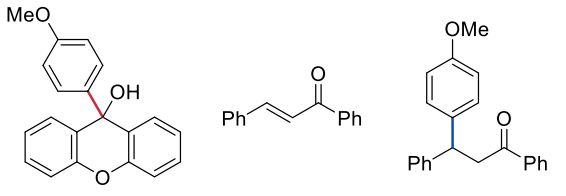

$96 \%$

6
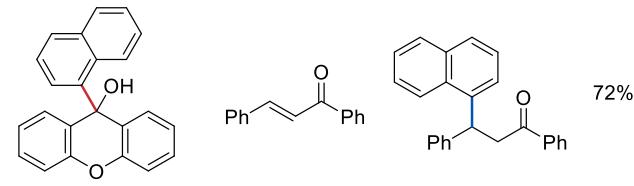

${ }^{a}$ GC yield. ${ }^{b}$ With $10 \mathrm{~mol} \%$ of $\mathrm{Pd}(\mathrm{OAc})_{2}$ and $20 \mathrm{~mol} \%$ of ligand and base.

The same group reported an efficient synthesis of arylated thiophenes and benzothiophenes via tandem $\mathrm{C}-\mathrm{C}$ and $\mathrm{C}-\mathrm{H}$ bond activation of diphenyl 2- and 3-thiophene-methanols 134 and 136 (Scheme 23). ${ }^{75,76}$ By varying the amount of aryl bromide coupling partner, the authors developed two synthetic protocols to obtain either unsymmetrically substituted thiophenes $\mathbf{1 3 5}$ in a two-step procedure (Scheme 23a) or symmetrically bis-arylated (benzo)thiophenes 137 in one pot (Scheme 23b). 
This document is the Accepted Manuscript version of a Published Work that appeared in final form in Chemical Reviews, copyright (C) American Chemical Society after peer review and technical editing by the publisher. To access the final edited and published work see https://doi.org/10.1021/acs.chemrev.0c00154

Scheme 23

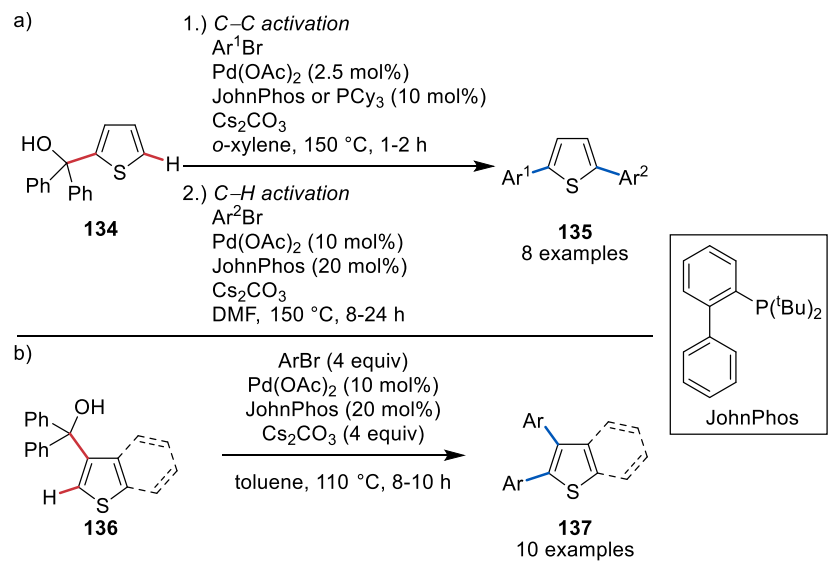

Concomitantly to Miura's work, Kotschy and coworker reported the ipso-arylation of benzo[b]thien-2-ylmethanols 138 with aryl bromides (Scheme 24)..$^{7}$ Adapting the previously developed conditions for ipso-arylation of $\mathbf{1 3 4}$ furnished the 2-(hetero)arylbenzo[b]thiophene products 140 in high yields.

\section{Scheme 24}

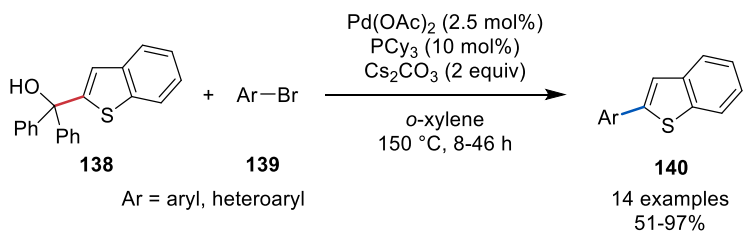

Nishihara reported the annulation of (o-bromophenyl)propan-2-ols 141 with $o$-iodobiphenyls 142 and ( $Z$ )- $\beta$-halostyrenes 143 that allowed access to substituted triphenylenes 144 and phenanthrenes 145 (Scheme 25) ${ }^{78,79}$ Using this method, the authors were able to construct a wide range of unsymmetrical polyarenes in moderate to excellent yields. The reaction tolerated a variety of functional groups but was sensitive to steric bulk ortho to the activated C-H bond of 142.

Scheme 25

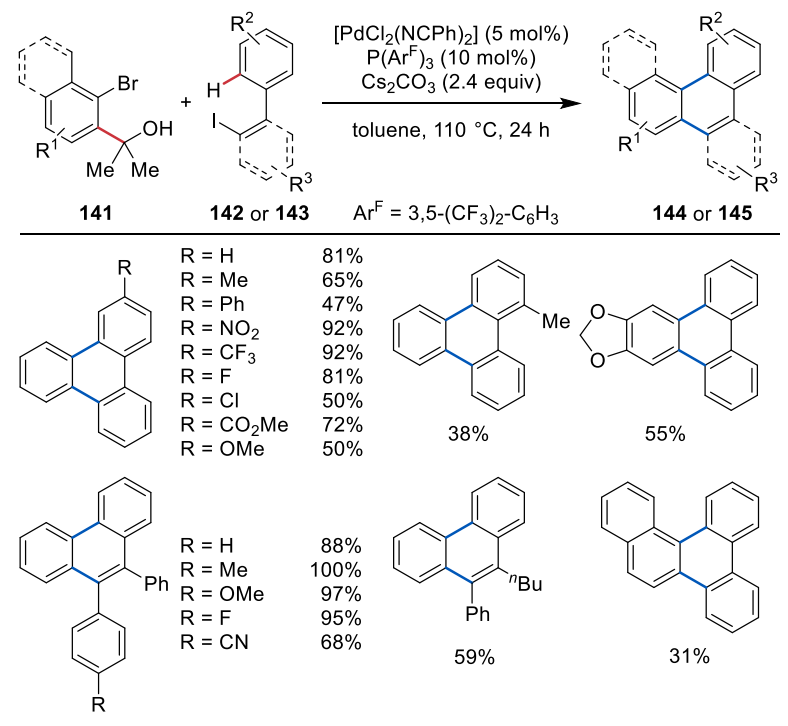


This document is the Accepted Manuscript version of a Published Work that appeared in final form in Chemical Reviews, copyright (C) American Chemical Society after peer review and technical editing by the publisher. To access the final edited and published work see https://doi.org/10.1021/acs.chemrev.0c00154

The same group later showed that phenanthrenes 149 can be constructed in a modular fashion from (o-bromophenyl)propan-2-ols 146, aryl bromides 147 and alkynes 148 in a three-component reaction (Scheme 26). ${ }^{80}$ This reaction proceeded favorably because oxidative addition of the aryl bromide was followed by fast alkyne insertion leading to the same intermediate as employed above.

Scheme 26

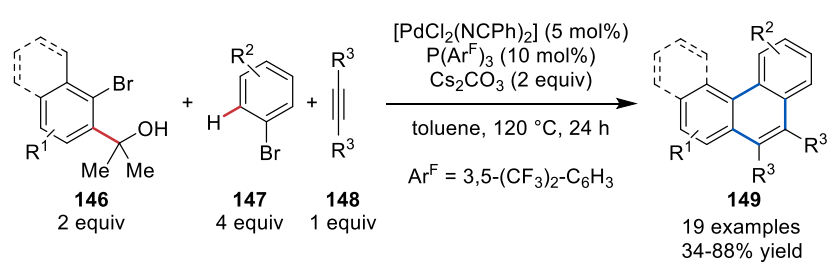

Satyanarayana reported the annulative homocoupling of ortho-bromobenzyl alcohols $\mathbf{1 5 0}$ under palladium-catalysis to afford chromenes 151. ${ }^{81,82}$ Several electron-neutral and -rich chromenes could be prepared using this method (Scheme 27).

Scheme 27

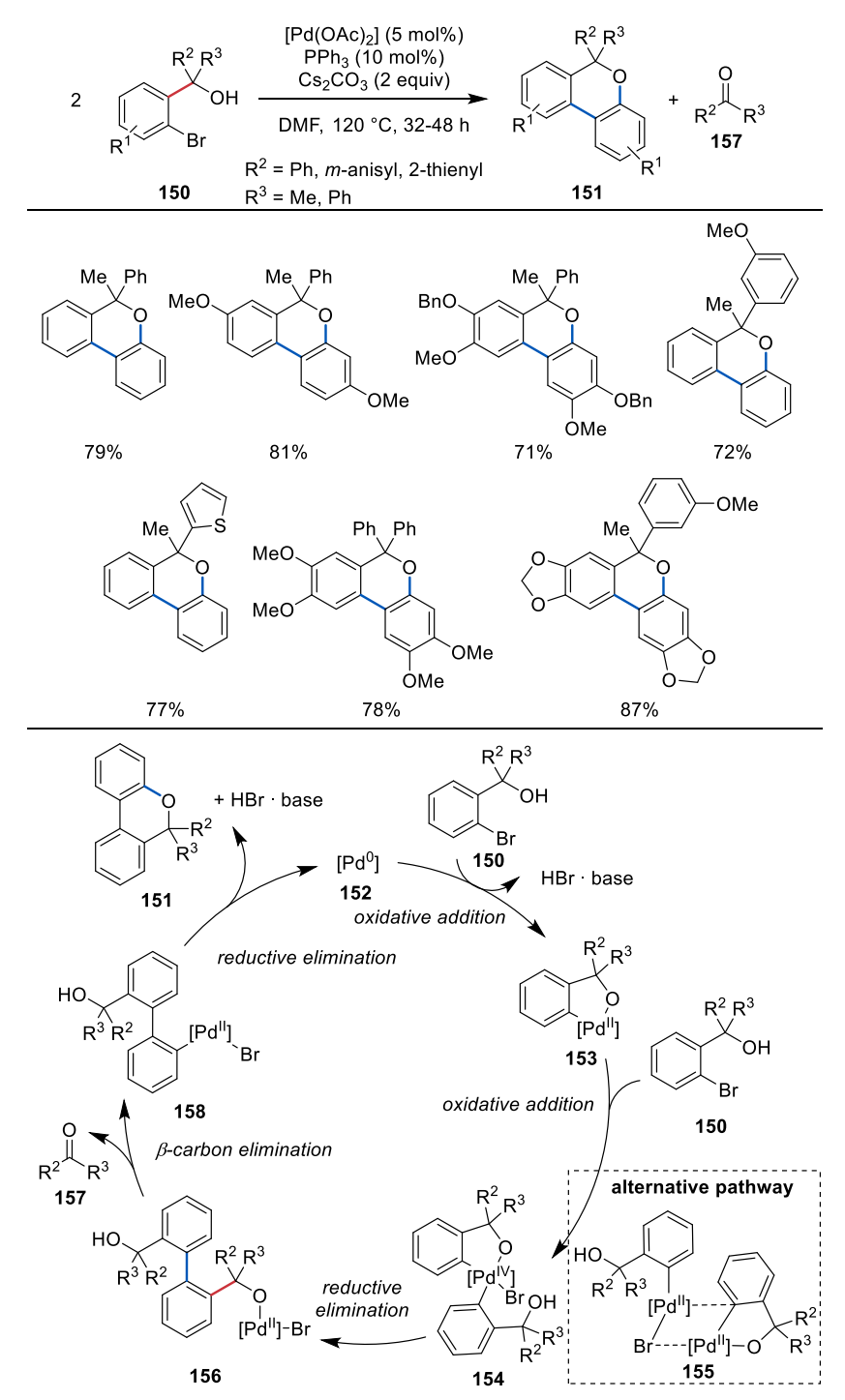

The authors propose a mechanism that proceeds via a twofold oxidative addition of the substrate via Pd(IV) intermediate 154, followed by reductive biaryl coupling. Alternatively, transmetalation with a second Pd(II) complex could occur (155) to effect the biaryl coupling. ${ }^{83,84}$ The 
This document is the Accepted Manuscript version of a Published Work that appeared in final form in Chemical Reviews, copyright (C) American Chemical Society after peer review and technical editing by the publisher. To access the final edited and published work see https://doi.org/10.1021/acs.chemrev.0c00154

resulting intermediate $\mathbf{1 5 6}$ is then set up for $\beta$-carbon elimination to release ketone $\mathbf{1 5 7}$ and afford 158. Finally, Buchwald-Hartwig coupling furnishes the product and turns over the palladium catalyst.

Recently, $\mathrm{Gu}$ and co-workers disclosed an enantioselective biaryl atropoisomer synthesis that proceeds by selective $\beta$-aryl elimination of 9-arylfluoren-9-ol derivatives 159 (Scheme 28). ${ }^{85}$ The introduction of ortho-substituents adjacent to the biaryl linkage imposed additional torsional strain in the substrate that allowed for milder reaction conditions enabling high enantioselectivity. The reaction between the tertiary alcohol and aryl bromide 160 proceeded in excellent yield with $\mathrm{Pd}(\mathrm{acac})_{2}$ and $\mathrm{BINAP}$, although without stereoinduction. Changing the ligand to chiral phosphoramidite scaffolds increased the ee substantially, but the yield decreased at the same time. The optimum was found using a combination of a strong base and a more active palladium(II) precatalyst. Under the optimized conditions, a variety of chiral biaryls could be formed, tolerating both electron-rich and -poor substituents, heterocycles, halides, and a phosphine oxide. The imposed torsional strain in the molecule was crucial, as replacement of the methyl groups with hydrogen or fluorine atoms at the backbone shuts down the reactivity.

The authors propose that in situ formed $\mathrm{Pd}(0)$ species 162 undergoes oxidative addition of the aryl bromide to form intermediate $\mathbf{1 6 3}$ (Scheme $28 \mathrm{~b})$. Transmetalation with the deprotonated substrate $\mathbf{1 6 4}$ formed under the reaction conditions gives rise to species $\mathbf{1 6 5}$. It was unclear whether the $\beta$-carbon elimination step towards $\mathbf{1 6 6}$ was atroposelective or whether the cleavage was reversible to give a matched and a mismatched intermediate that would undergo reductive elimination at different rates. Finally, irreversible reductive elimination releases product 161.

Scheme 28

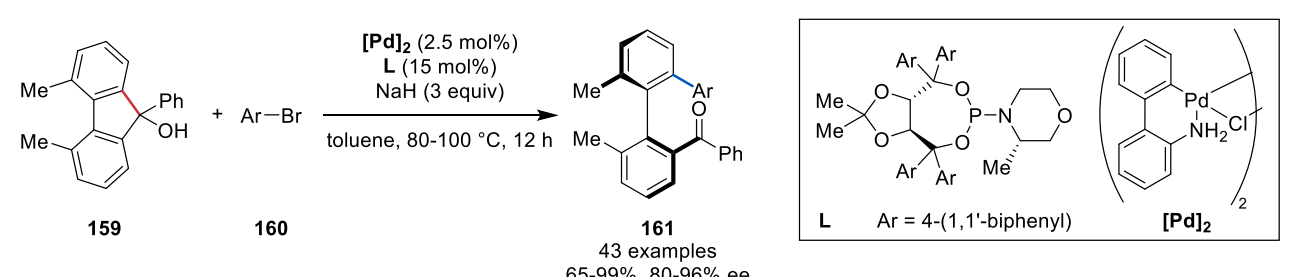
$65-99 \%, 80-96 \%$ ee

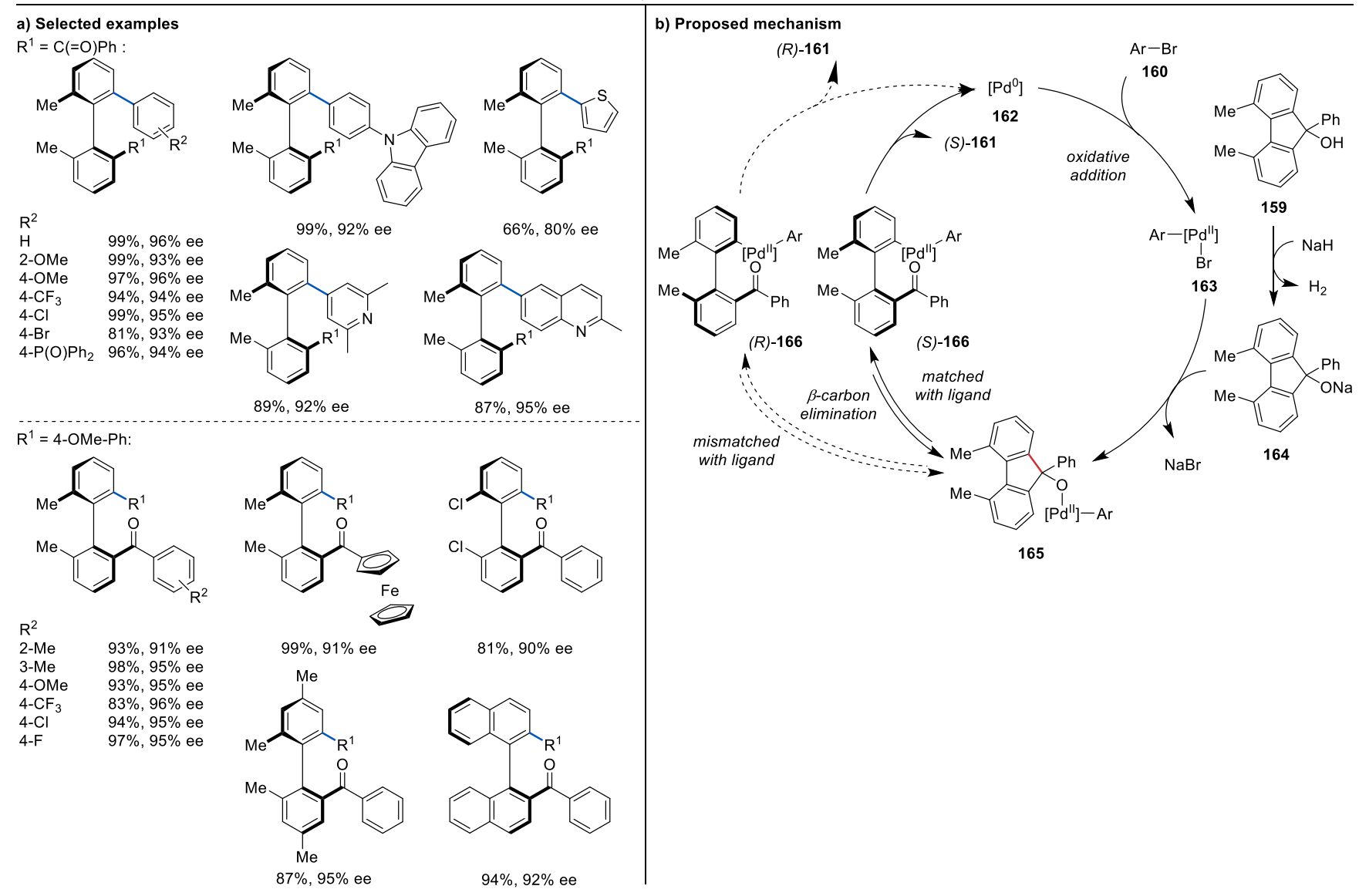


This document is the Accepted Manuscript version of a Published Work that appeared in final form in Chemical Reviews, copyright (C) American Chemical Society after peer review and technical editing by the publisher. To access the final edited and published work see https://doi.org/10.1021/acs.chemrev.0c00154

\section{2. $\beta$-Aryl Elimination with Rhodium}

The Hartwig group investigated the tendency of rhodium(I) alkoxide complexes towards $\beta$-aryl elimination in a series of stoichiometric studies $^{70,86}$. While not catalytic in nature, the study was an insightful contribution to the field. A series of alkoxide complexes (167-176) were prepared and isolated in the presence of an excess of $\mathrm{PEt}_{3}$ to aid their isolation (Scheme 29). The X-ray structure of $\mathbf{1 6 7}$ gave insight into the mechanism of $\beta$-phenyl elimination, where an agostic $\eta^{2}$-interaction of the $\pi$-system of one of the phenyl groups and the rhodium center was observed together with a lengthening of the $\mathrm{C}\left(\mathrm{sp}^{3}\right)-\mathrm{C}\left(\mathrm{sp}^{2}\right)$ bond. This interaction is likely to be key to the bond cleavage and further explains why alkyl groups are non-transferrable groups.

Scheme 29

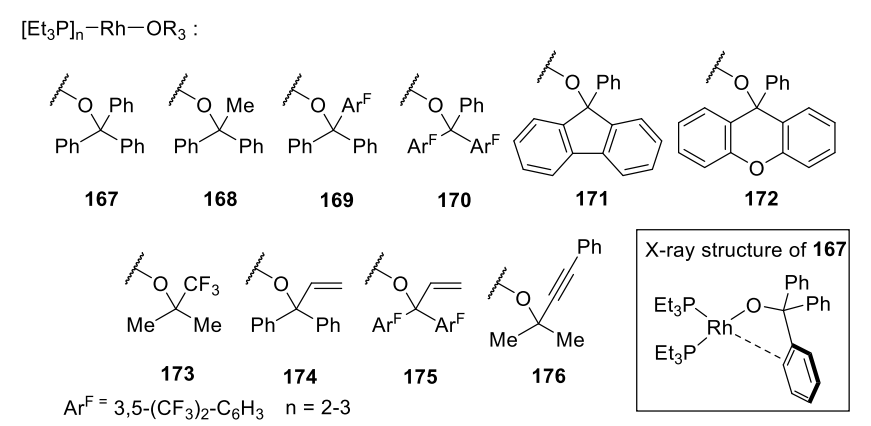

Heating complexes 167-172 in the presence of $\mathrm{PEt}_{3}$ led to $\beta$-aryl elimination to afford the aryl-rhodium complexes and the corresponding ketones. As observed in the case of palladium, the more electron-deficient group was cleaved exclusively in complexes 169 and $\mathbf{1 7 0 .}$. In contrast, $\mathrm{CF}_{3}$-containing complex 173 and the vinyl complexes 174-175 did not undergo $\mathrm{C}-\mathrm{C}$ cleavage, demonstrating the lower propensity of the $\mathrm{C}-$ $\mathrm{C}$ (vinyl) bond to cleave. Propargyl complex $\mathbf{1 7 6}$ could not be isolated, as it decomposed to the alkynyl complex at low temperatures. Phenyl elimination from complex 167 was irreversible in the presence of added phosphine and occurred at $50{ }^{\circ} \mathrm{C}$ within 1 hour, as followed by $\mathrm{NMR}$ spectroscopy. Summarizing, the propensity for $\mathrm{C}-\mathrm{C}$ cleavage from rhodium complexes follows the trend of hybridization $\left(\mathrm{C}(\mathrm{sp})>\mathrm{C}\left(\mathrm{sp} \mathrm{p}^{2}\right) \gg\right.$ $\left.\mathrm{C}\left(\mathrm{sp}^{3}\right)\right)$ and is facilitated by precoordination of the group to be cleaved.

The activation barrier for $\beta$-carbon elimination from rhodium alkoxides was calculated by DFT by Lin and co-workers and compared with the corresponding barriers for $\beta$-hydride eliminations. ${ }^{87}$ According to their calculations, the elimination of a phenyl group requires a much larger barrier $\left(\Delta \mathrm{G}^{\ddagger}=23.4 \mathrm{kcal} \mathrm{mol}^{-1}\right)$ compared to hydride $\left(\Delta \mathrm{G}^{+}=4.5 \mathrm{kcal} \mathrm{mol}^{-1}\right)$.

The group of Hayashi reported the first example of rhodium-catalyzed $\beta$-aryl elimination in the 1,4-arylation of $\alpha, \beta$-unsaturated ketones $\mathbf{1 7 7}$ with tertiary alcohols $\mathbf{1 7 8}$ in $2007 .^{88}$ The scaffold of the donor alcohol was crucial to activate the C-C(aryl) bond. While acyclic alcohols, as well as several cyclic donors used previously with palladium, remained unreactive, a 10-benzyl-9-aryl-dihydroacridin-9-ol scaffold (177) served as a selective donor to give the desired products in excellent yield (Scheme 30). While no ligand was required for this transformation, a chiral diene ligand allowed to access the arylated ketone product in high enantiomeric excess.

\section{Scheme 30}

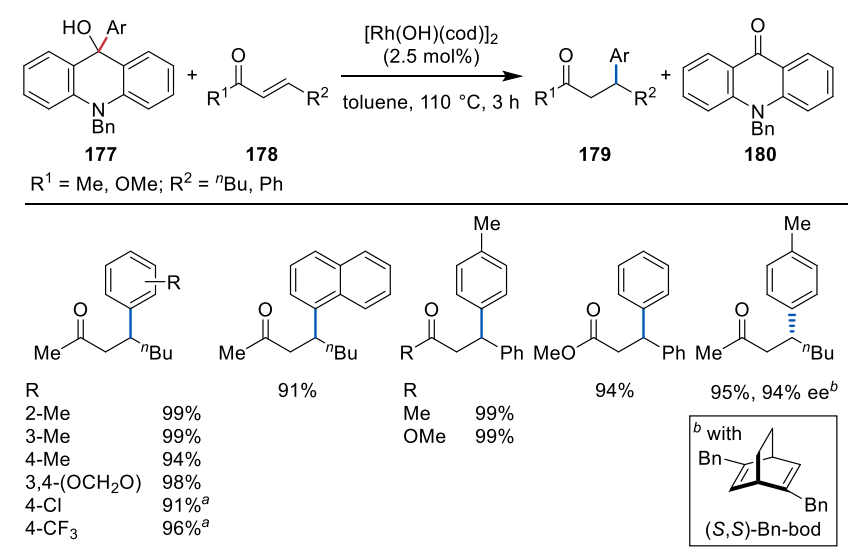


This document is the Accepted Manuscript version of a Published Work that appeared in final form in Chemical Reviews, copyright (C) American Chemical Society after peer review and technical editing by the publisher. To access the final edited and published work see https://doi.org/10.1021/acs.chemrev.0c00154

${ }^{a} 10 \mathrm{~h}$ reaction time ${ }^{b}$ Reaction conditions: $\left[\mathrm{RhCl}\left(\mathrm{C}_{2} \mathrm{H}_{4}\right)_{2}\right]_{2}(2.5 \mathrm{~mol} \%),(S, S)-\mathrm{Bn}-\mathrm{bod}(10 \mathrm{~mol} \%)$ and $\mathrm{Cs}_{2} \mathrm{CO}_{3}(10 \mathrm{~mol} \%), 24 \mathrm{~h}$.

Miura and Satoh reported a tandem-C-C and C-H cleaving coupling of triarylalcohols $\mathbf{1 8 1}$ with internal alkynes $\mathbf{1 8 2}$ to furnish naphthalenes 185 (Scheme 31). ${ }^{89}$ Phenyl-substituted cyclopentadiene ligands 183-184 were essential for the success of the coupling, as C ${ }^{*}$ (pentamethylcyclopentadienyl) gave low yield. Notably, both $\mathrm{Rh}(\mathrm{I})$ and $\mathrm{Rh}(\mathrm{III})$ precursors enabled the reaction in the presence of a stoichiometric amount of an oxidant. The authors propose that $\mathrm{Rh}$ (III) alkoxide complex $\mathbf{1 8 7}$ undergoes CMD at the ortho-position to give rhodacycle $\mathbf{1 8 8}$. The alkyne 182 then inserts into the rhodium-carbon bond and a diaryl ketone is liberated from $\mathbf{1 8 9}$ via $\beta$-carbon elimination to afford species 190. A second equivalent of alkyne inserts and reductive elimination from 191 or 192 affords the product and a Rh(I) species, which is reoxidized by copper(II).

Scheme 31

${ }^{a} \mathrm{GC}$ yield ${ }^{b} \mathrm{Using}\left[\mathrm{Cp}^{*} \mathrm{RhCl}_{2}\right]_{2} / \mathbf{1 8 4}$
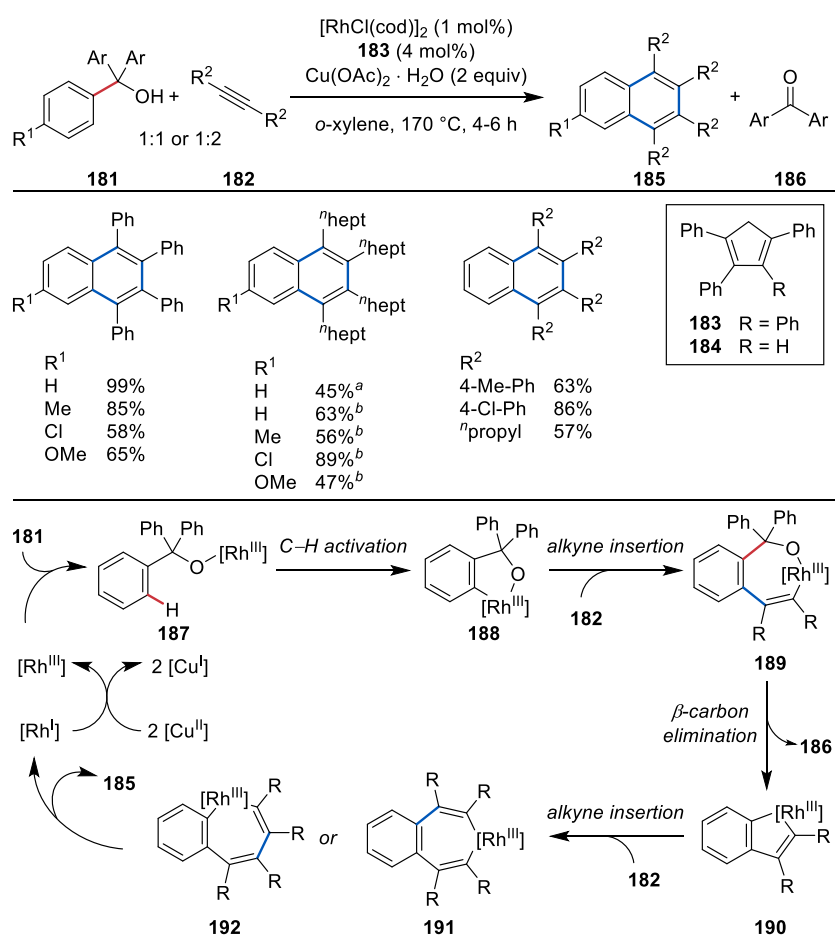

Morimoto recently disclosed a carbonylative annulation of $\alpha, \alpha$-dimethyl-(2-bromoaryl)methanols 193 with internal alkynes 194 to construct indenones 197 (Scheme 32). ${ }^{90}$ Key to the development of this reaction was the choice of the carbonyl source. Previous studies by Larock using a similar system with $\mathrm{CO}$ gas as carbonyl source led to the formation of lactones 195, as migratory insertion of the CO ligand into the carbonrhodium bond followed by trapping with the alcohol outcompeted insertion of the alkyne and $\beta$-carbon elimination processes. ${ }^{91}$ In contrast, slow release of $\mathrm{CO}$ by decarbonylation of furfural (196) under the reaction conditions gave access to the desired indenone products in moderate yields. Control experiments showed that $\beta$-aryl elimination took place exclusively in the presence of alkyne 194. When the reaction was conducted without the alkyne, lactone 195 was formed instead. Further, when using CO gas instead of furfural, the reaction was inhibited. From these observations, a mechanism for the transformation was proposed (Scheme 32). Alkoxide complex 198 is formed under the reaction conditions which undergoes oxidative addition of the $\mathrm{C}-\mathrm{Br}$ bond to give intermediate $\mathbf{1 9 9}$. At this point, migratory insertion of 194 results in species 200. Then, $\beta$-aryl elimination takes place from this intermediate to afford rhodacycle $\mathbf{2 0 1}$ under the release of acetone. The authors suggested that the CO moiety is delivered by transmetalation with another rhodium species that arises from decarbonylation of 196 . Migratory insertion of the carbonyl group followed by reductive elimination releases the product. 
This document is the Accepted Manuscript version of a Published Work that appeared in final form in Chemical Reviews, copyright (C) American Chemical Society after peer review and technical editing by the publisher. To access the final edited and published work see https://doi.org/10.1021/acs.chemrev.0c00154

Scheme 32

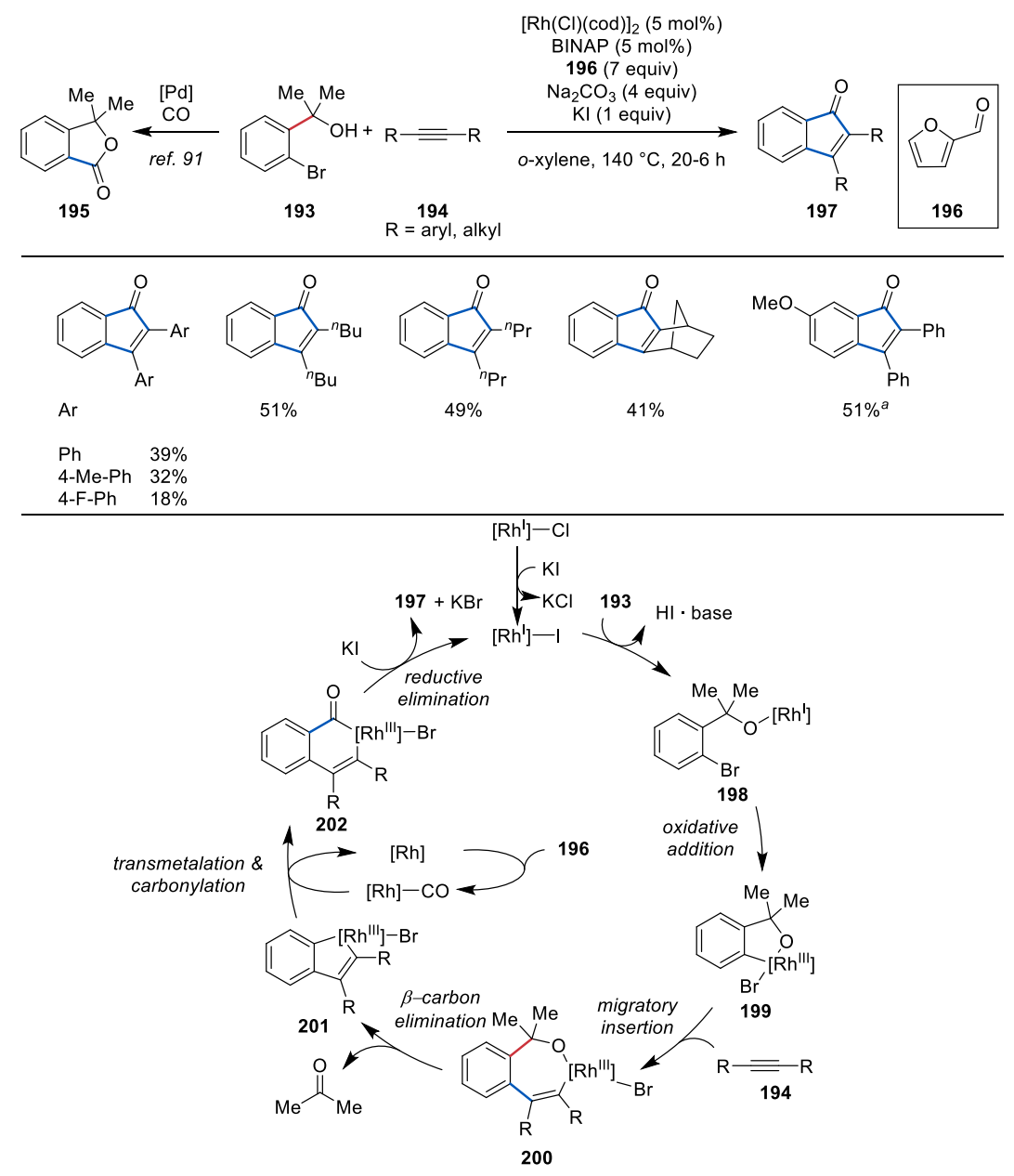

In contrast to tertiary alcohols, adjacent hydrogens in secondary and primary alcohols render metal alkoxide complexes prone to undergo $\beta$ hydride elimination, hindering selective $\mathrm{C}-\mathrm{C}$ bond cleavage. However, the judicious choice of directing groups has allowed to suppress unwanted $\beta$-hydride elimination as the next examples show.

Shi reported a selective $\mathrm{Rh}$ (III) catalyzed alkenylation of secondary benzylic alcohols 203 using a directing group strategy, avoiding oxidation to the ketone by $\beta$-hydride elimination (Scheme 33)..$^{92}$ The scope of the reaction was broad, both with regard to the aryl alcohols and the olefins. Besides styrenes, aliphatic terminal olefins were tolerated. Further, secondary and tertiary alcohols containing a second alcohol group in metaposition underwent the coupling selectively, highlighting the importance of the directing effect. In contrast to secondary and tertiary alcohols, primary ones were not compatible. Notably, substrates with an ortho-C-H bond were alkenylated a second time via a CMD pathway upon addition of a second equivalent of alkene and oxidant. 
This document is the Accepted Manuscript version of a Published Work that appeared in final form in Chemical Reviews, copyright (C) American Chemical Society after peer review and technical editing by the publisher. To access the final edited and published work see https://doi.org/10.1021/acs.chemrev.0c00154

Scheme 33
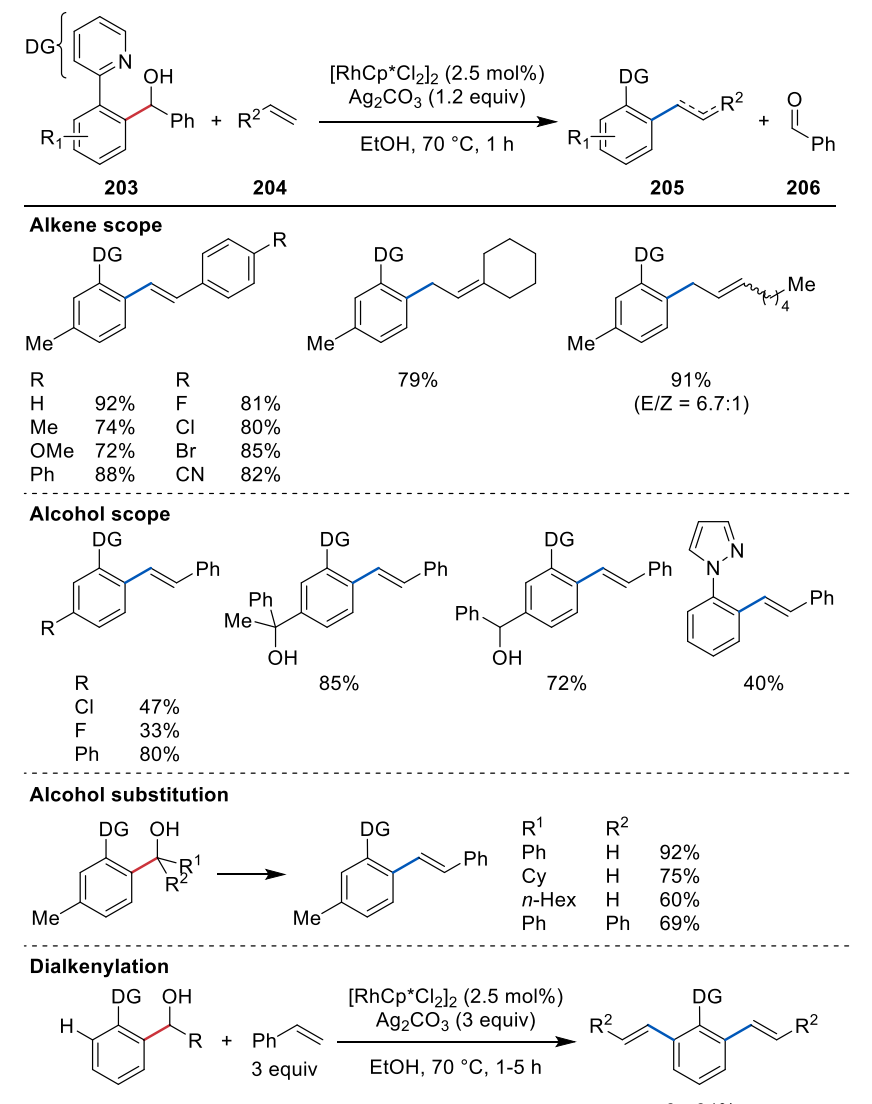

The proposed mechanism begins with the coordination of the substrate to afford chelated complex 207 that undergoes $\beta$-carbon elimination to form the thermodynamically favorable five-membered cyclometalated intermediate $\mathbf{2 0 8}$ (Scheme 34). Migratory insertion of the alkene and $\beta$-hydride elimination from $\mathbf{2 1 0}$ afforded the product and $\mathrm{Rh}(\mathrm{I})$ species $\mathbf{2 1 2}$ that was reoxidized by silver(I).

Scheme 34

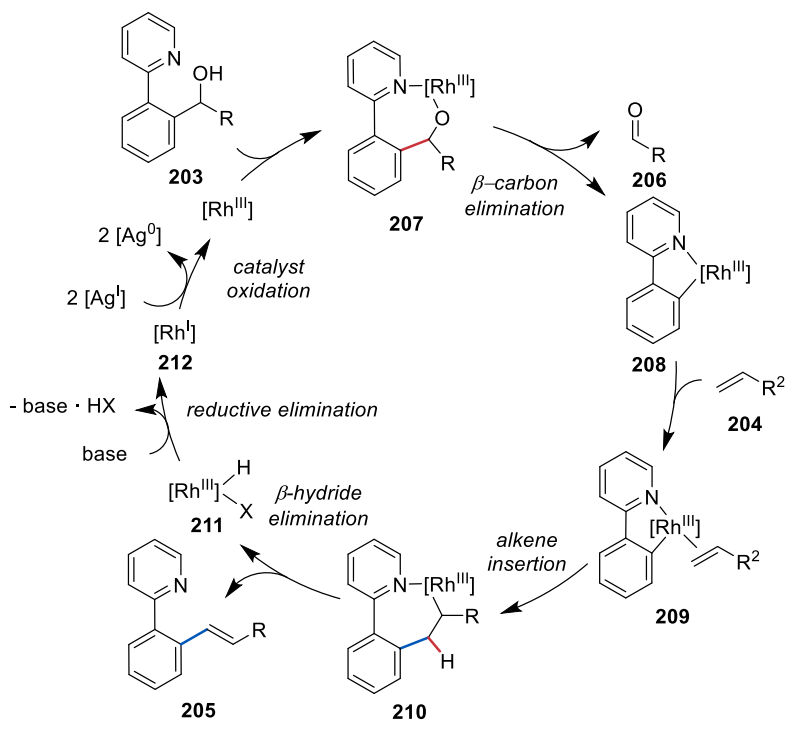


This document is the Accepted Manuscript version of a Published Work that appeared in final form in Chemical Reviews, copyright (C) American Chemical Society after peer review and technical editing by the publisher. To access the final edited and published work see https://doi.org/10.1021/acs.chemrev.0c00154

The same group extended the reaction to aryl silanes $\mathbf{2 1 4}$ as coupling partners (Scheme 35a). ${ }^{93}$ The previous reaction conditions were not suitable for this transformation and had to be adapted. Switching to a cationic rhodium species and employing AgF as additive were found to be ideal, as the latter acted both as oxidant and activating agent for the silane. With the optimized conditions in hand, several (hetero)aryl silanes could be efficiently coupled to secondary and tertiary alcohols. Notably, even a primary alcohol gave the desired product in $26 \%$ yield. A deuterium labeling experiment with $d_{4}-\mathbf{2 1 3}$ revealed significant isotope scrambling of the ortho-position, meaning that reversible protodemetalation/C-H activation occurred under the reaction conditions (Scheme 35b). Moreover, a small amount of diarylated product 216 was found that arose from $\mathrm{C}-\mathrm{H}$ activation of the second ortho-position. A competition experiment between 217 and 218 showed that while $\mathrm{C}-\mathrm{C}$ activation is the predominant pathway operating, both $\mathrm{C}-\mathrm{C}$ and $\mathrm{C}-\mathrm{H}$ activation take place under the reaction conditions ( $\mathrm{Scheme} 35 \mathrm{c}$ ).

\section{Scheme 35}

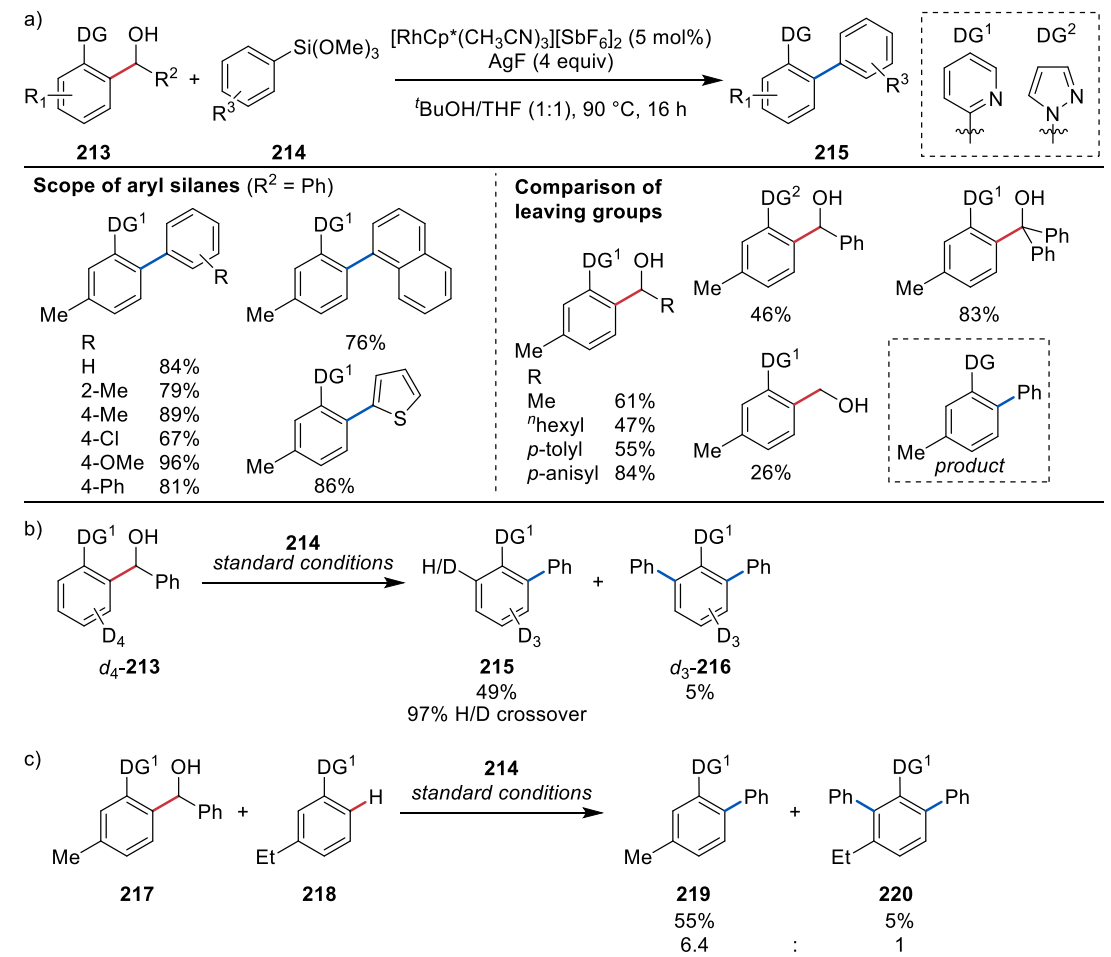

Shi et al. also demonstrated that imines are competent coupling partners in the directed $\mathrm{C}-\mathrm{C}$ bond cleavage of secondary benzylic and allylic alcohols, thereby providing a direct transformation from an alcohol into an amine. ${ }^{94} \mathrm{~A}$ wide range of secondary and tertiary benzylic alcohols 221, as well as allylic alcohols 226, reacted with tosyl-protected benzaldimines $\mathbf{2 2 2}$ to form the corresponding amines (Scheme 36). Notably, benzaldehydes $\mathbf{2 2 3}$ could also be used as coupling partners, allowing for functional group metathesis of the alcohol moiety. The reaction was driven by the difference of electrophilicity and therefore only electron-deficient aldehydes were tolerated in this case. The authors propose a mechanism that proceeds similarly to the previously discussed catalytic cycle, in which $\mathrm{Rh}$ (III) species $\mathbf{2 2 8}$ forms a five-membered intermediate 229 after $\mathrm{C}-\mathrm{C}$ bond cleavage. From a series of kinetic and mechanistic experiments, it was shown that complex 229 undergoes reversible protodemetalation. In other terms, both $\mathrm{C}-\mathrm{C}$ and $\mathrm{C}-\mathrm{H}$ activation are viable due to the directing group. Coordination of the imine (231) is followed by rate-limiting insertion into the carbon-metal bond (232) to release the product. 
This document is the Accepted Manuscript version of a Published Work that appeared in final form in Chemical Reviews, copyright (C) American Chemical Society after peer review and technical editing by the publisher. To access the final edited and published work see https://doi.org/10.1021/acs.chemrev.0c00154

Scheme 36

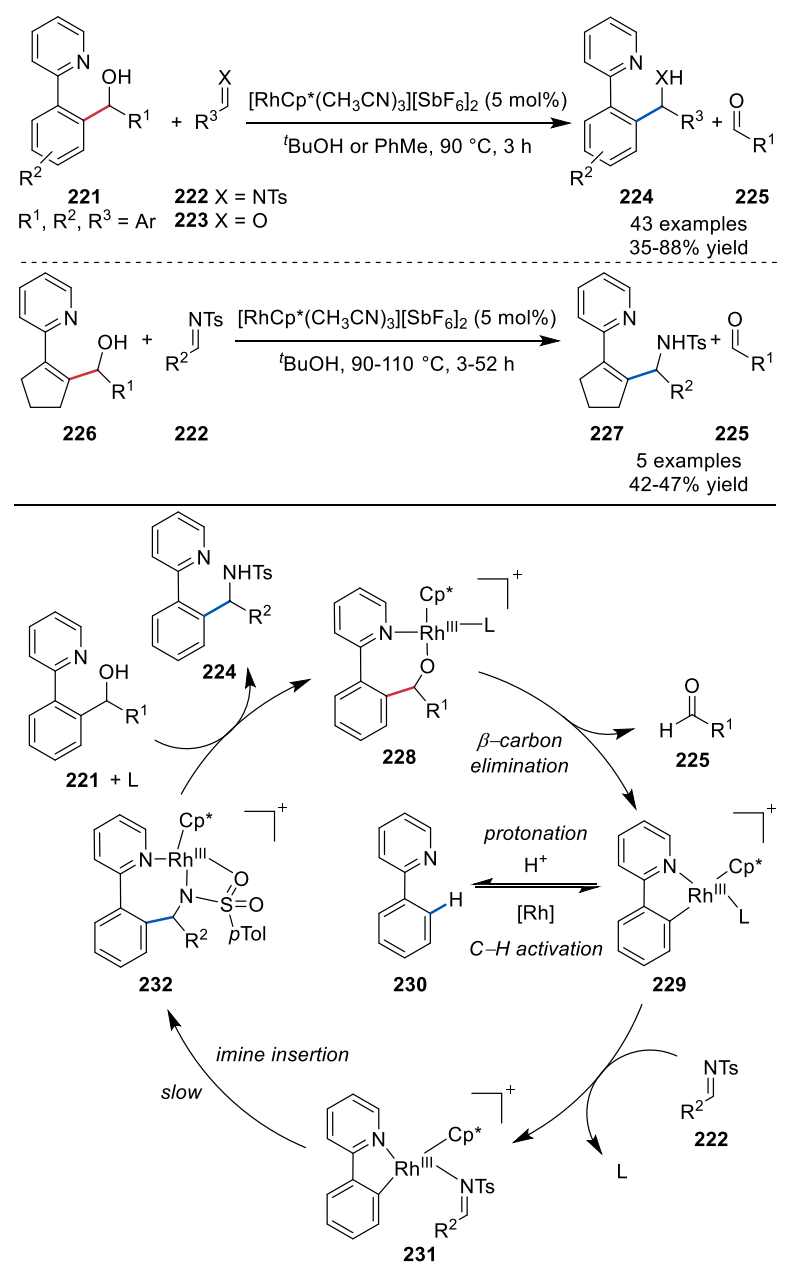

Based on previous studies, the reductive cleavage of benzylic alcohols 233 was achieved using hydrogen as the reductant (Scheme 37$).{ }^{95}$ In this reaction, the rhodacycle intermediate $\mathbf{2 3 9}$ formed after cleavage of the aldehyde group was intercepted with hydrogen and reductive elimination afforded the protonated substrate and a rhodium hydride (240). The latter species could then reduce the released aldehyde $\mathbf{2 3 8}$ to the corresponding alcohol 235. Alternatively, the rhodacycle 239 could be protonated to give $\mathbf{2 3 6}$ and re-engage in a new $\mathrm{C}-\mathrm{C}$ bond cleavage, while a second catalytic cycle operates independently with the rhodium hydride. Both pyridyl and pyrazolyl directing groups were applicable and a wide range of benzylic alcohols could be cleaved in good yields, including ester- and halide-containing arenes. 
This document is the Accepted Manuscript version of a Published Work that appeared in final form in Chemical Reviews, copyright (C) American Chemical Society after peer review and technical editing by the publisher. To access the final edited and published work see https://doi.org/10.1021/acs.chemrev.0c00154

\section{Scheme $37^{a}$}
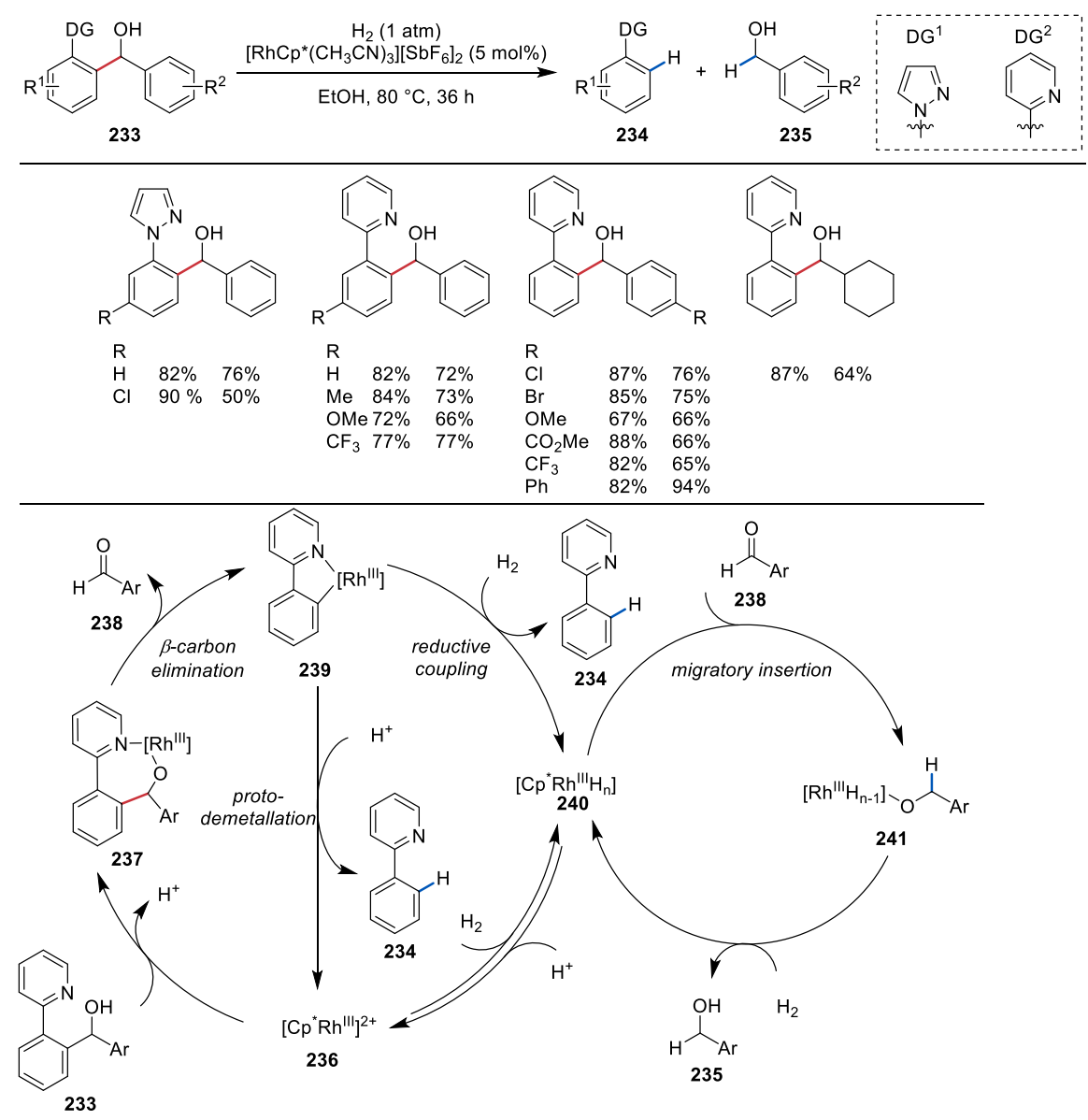

${ }^{a}$ The yields refer to products 234 and $\mathbf{2 3 5}$, respectively.

Ackermann and co-workers disclosed a directed $\mathrm{sp}^{2}$-alkenylation enabled by an electrochemical rhodium system. ${ }^{96}$ Prior to this report, this reaction required a stoichiometric silver oxidant to turn over (vide supra), which could be eliminated here by using electricity as an oxidant. ${ }^{92}$ 2-Imidazolyl- and 2-pyridinyl-substituted aryl alcohols $\mathbf{2 4 2}$ could be coupled with alkenes $\mathbf{2 4 3}$ in good to excellent yields using this methodology (Scheme 38). Several leaving groups were tolerated, including alkyl and aryl-substituted $2^{\circ}$ and $3^{\circ}$ alcohols as well as a $2^{\circ}$ amine. Notably, substrates without an alcohol moiety did not undergo the transformation, excluding the possibility of free radical-processes. The alkene scope exhibited a wide functional group tolerance, including aryl halides, acrylate esters and phosphonate esters. Notably, directed $\mathrm{C}-\mathrm{H}$ activation is less efficient under the reaction conditions ( $16 \%$ versus $82 \%)$. 
This document is the Accepted Manuscript version of a Published Work that appeared in final form in Chemical Reviews, copyright (C) American Chemical Society after peer review and technical editing by the publisher. To access the final edited and published work see https://doi.org/10.1021/acs.chemrev.0c00154

Scheme 38
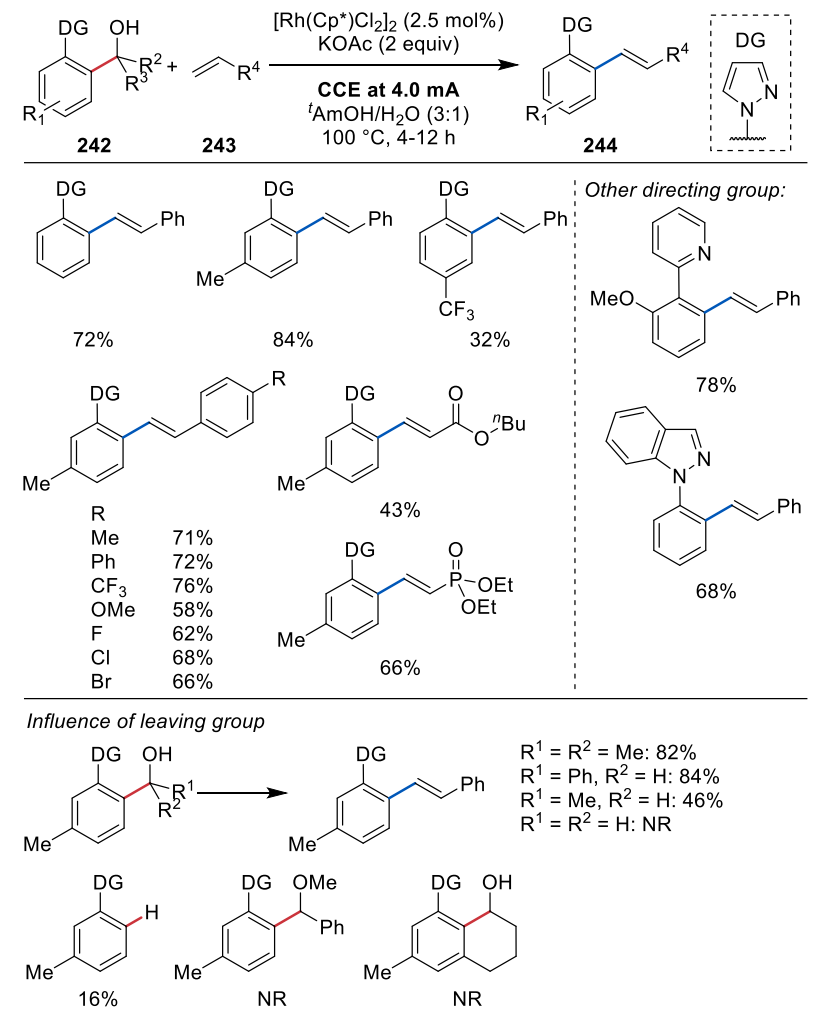

The authors interrogated the mechanism of the transformation with a range of conventional and electrochemical methods. No deuterium incorporation into $\mathbf{2 4 2}$ or $\mathbf{2 4 4}$ was observed when using $\mathrm{D}_{2} \mathrm{O}$ as co-solvent, indicating that $\mathrm{C}-\mathrm{C}$ bond activation is followed by fast insertion of the alkene. The presence of $\mathrm{H}_{2}$, which formed by reductive coupling of the two protons at the cathode, was confirmed by headspace GC-analysis. Further, the putative cyclometalated intermediate $\mathbf{2 4 6}$ was independently synthesized and found to be catalytically competent. Lastly, cyclic voltammetry experiments concluded that oxidation of $\mathrm{Rh}(\mathrm{I})$ to $\mathrm{Rh}(\mathrm{III})$ is facile, while both substrates are electrochemically inert under the reaction conditions. Based on these observations, the authors proposed a catalytic cycle that is reminiscent of related $\mathrm{Rh}$ (III)-mediated mechanisms. After coordination of the $\mathrm{Rh}$ (III) complex to the substrate (245), directed $\beta$-aryl elimination occurs to liberate a ketone. The cyclometalated complex 246 is then intercepted by the alkene $\mathbf{2 4 3}$ which undergoes $\beta$-hydride-elimination and reductive elimination of HOAc to form the product and $\mathrm{Rh}(\mathrm{I})$ complex 249 . The catalyst is then reoxidized to $\mathrm{Rh}(\mathrm{III})$ at the anode. At the cathode two protons are reduced to $\mathrm{H}_{2}$. 
This document is the Accepted Manuscript version of a Published Work that appeared in final form in Chemical Reviews, copyright (C) American Chemical Society after peer review and technical editing by the publisher. To access the final edited and published work see https://doi.org/10.1021/acs.chemrev.0c00154

\section{Scheme 39}

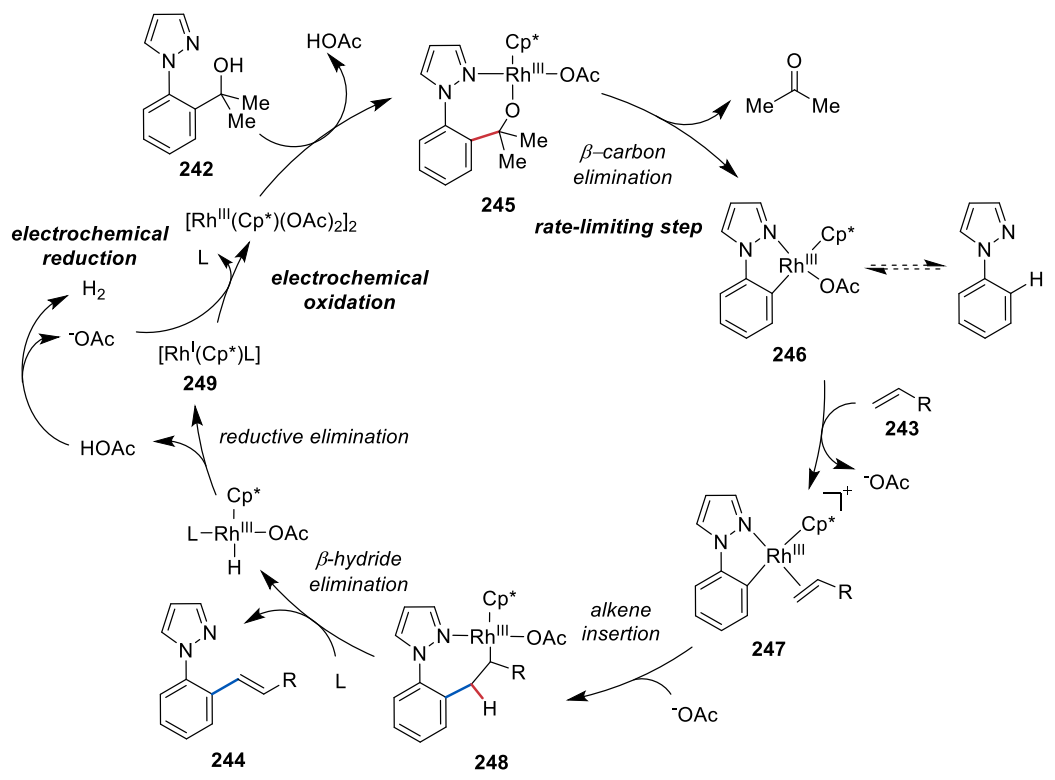

The group of Yu recently disclosed a directed heteroarylation of indole-derived secondary alcohols $\mathbf{2 5 0}$ to yield heterobiaryls $\mathbf{2 5 2}$. $^{97}$ Various heterocycles, including benzoxazoles, oxazoles and benzothiazoles were efficiently coupled with electron-rich and-poor indole alcohols bearing a pyrimidinyl directing group (Scheme 40). The authors further isolated the presumed rhodacyclic intermediate $\mathbf{2 5 3}$ that is formed after $\beta$ carbon elimination and demonstrated its catalytic competence.

Scheme 40
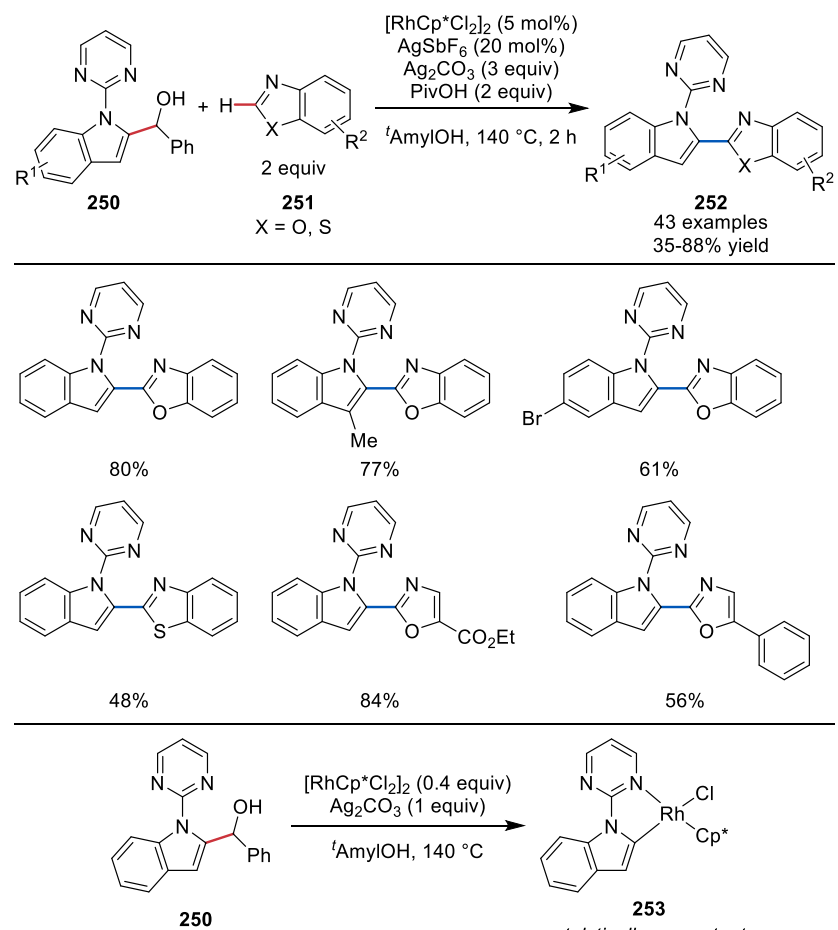
This document is the Accepted Manuscript version of a Published Work that appeared in final form in Chemical Reviews, copyright (C) American Chemical Society after peer review and technical editing by the publisher. To access the final edited and published work see https://doi.org/10.1021/acs.chemrev.0c00154

\section{3. $\beta$-Aryl Elimination with Cobalt}

While there were several recent examples of catalytic $\mathrm{C}-\mathrm{C}$ bond cleavage of alcohols, the large majority relied on precious transition metals, such as palladium and rhodium. For reasons of sustainability, it is desirable to develop catalytic systems based on earth-abundant $3 \mathrm{~d}-\mathrm{elements.}{ }^{98}$ In 2015, Morandi and co-workers disclosed a cobalt-catalyzed functionalization of benzylic alcohols 254 via $\beta$-carbon elimination, demonstrating that more sustainable base metals can also catalyze the cleavage of $\mathrm{C}-\mathrm{C}$ bonds (Scheme 41$).{ }^{99}$ Similar to the rhodium-catalyzed reactions, a cationic cobalt(III) species was key to enable the reactivity. The reaction could tolerate both electron-rich and -deficient substrates in addition to steric bulk in the ortho-position. In addition to secondary alcohols, several tertiary alcohols were tolerated. The presumed metallacycle intermediate formed in situ could be trapped with multiple electrophiles, allowing for further functionalization. Interestingly, the same cyanation reaction proceeds with low yield when rhodium was employed as the catalyst, hinting at the higher nucleophilicity of the coordinated alkylintermediate in the case of cobalt. Preliminary mechanistic experiments revealed that the $\beta$-carbon elimination step is irreversible.

\section{Scheme 41}

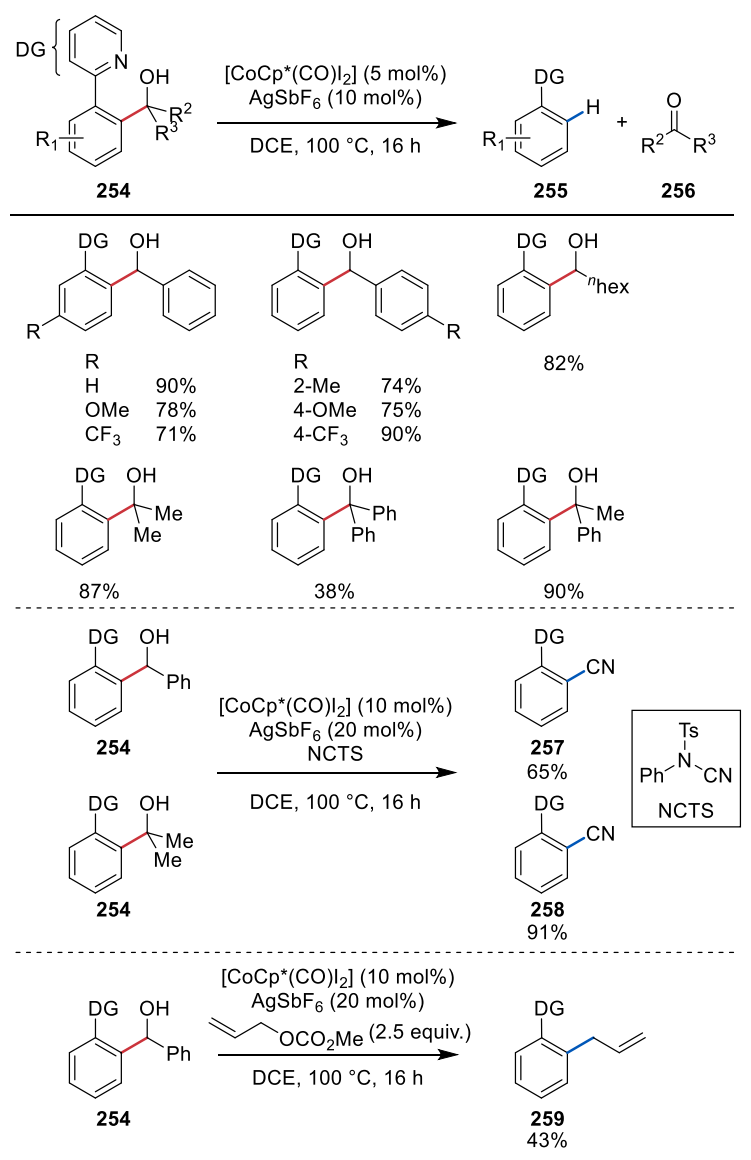

\section{4. $\beta$-Aryl Elimination with Manganese}

Ackermann and co-workers demonstrated that directed C-C bond cleavage can be effected with a non-precious manganese catalyst, notably, under aqueous conditions. ${ }^{100}$ Tertiary alcohols 260 bearing pyridyl and pyrazolyl directing groups were smoothly reacted with allylic lactones 261 to afford allylated products 262 (Scheme 42a). Meanwhile, reaction with terminal and internal alkynes 263 exclusively gave the (E)-configured insertion products 264 (Scheme $42 b$ ). The authors further demonstrated the feasibility of the conjugate addition into $\alpha, \beta$-unsaturated ketones 265 (Scheme 42c). 
This document is the Accepted Manuscript version of a Published Work that appeared in final form in Chemical Reviews, copyright (C) American Chemical Society after peer review and technical editing by the publisher. To access the final edited and published work see https://doi.org/10.1021/acs.chemrev.0c00154

Scheme 42
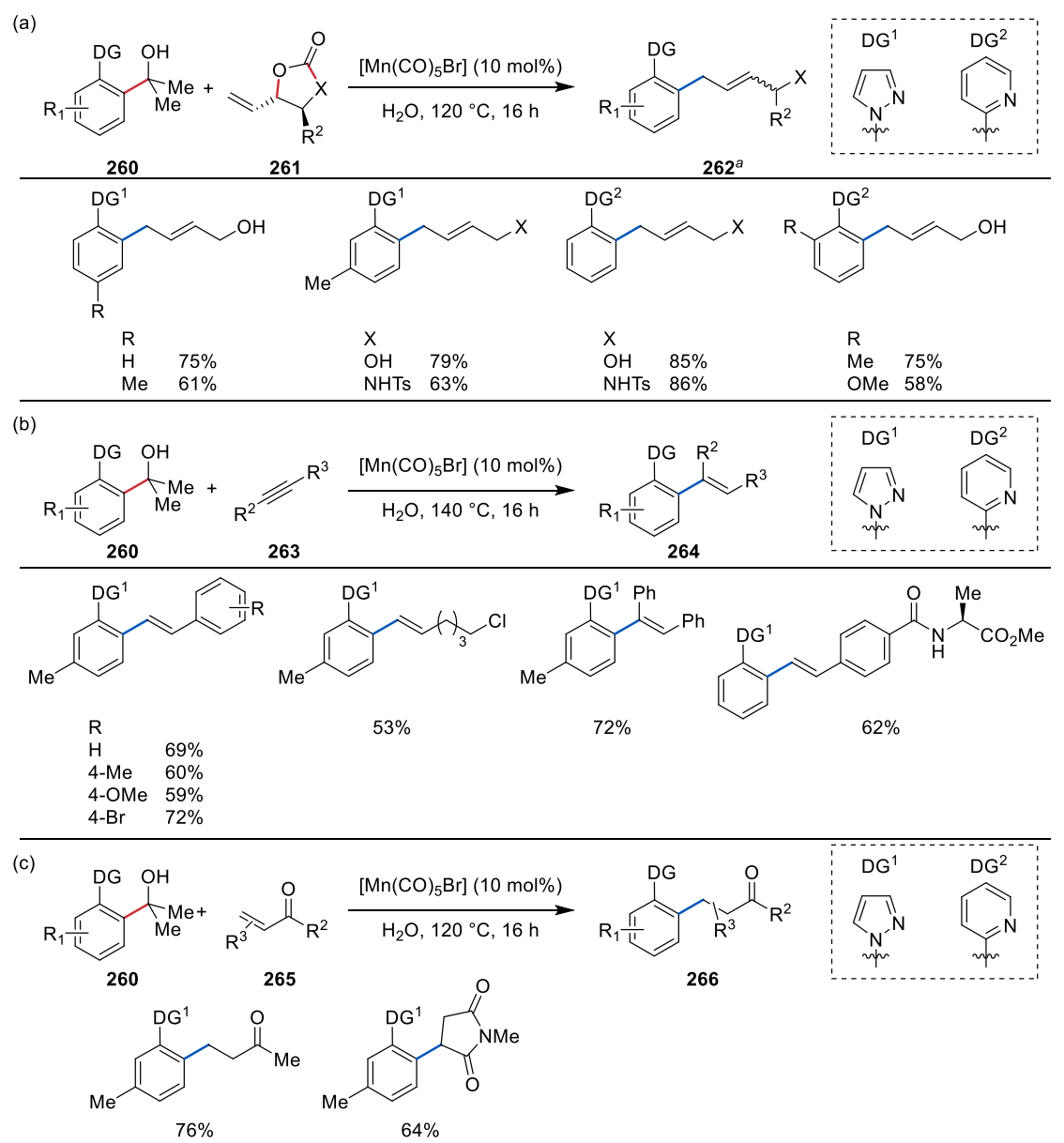

${ }^{a}$ Both olefin isomers were obtained with an $(E / Z)$ ratio of 3:1 to 5:1. The major diastereomer is depicted.

To rule out the possibility of $\mathrm{C}-\mathrm{H}$ activation, the reaction was carried out in $\mathrm{D}_{2} \mathrm{O}$ which did not result in $\mathrm{H} / \mathrm{D}$ scrambling in the ortho-position. Based on additional mechanistic experiments, the mechanism shown in Scheme 43 was proposed which proceeds similarly to the catalytic cycles involving $\mathrm{Rh}$ (III) (vide supra). The mechanistic proposal was further supported by kinetic and computational studies which indicate that $\beta$-carbon elimination from intermediate $\mathbf{2 6 7}$ is rate-limiting and the resulting metallacycle $\mathbf{2 6 8}$ can undergo insertion into alkynes and alkenes. In the case of 261, C-O cleavage affords alkene complex 271 that releases $\mathrm{CO}_{2}$ to afford the product after protonation. 
This document is the Accepted Manuscript version of a Published Work that appeared in final form in Chemical Reviews, copyright (C) American Chemical Society after peer review and technical editing by the publisher. To access the final edited and published work see https://doi.org/10.1021/acs.chemrev.0c00154

Scheme 43

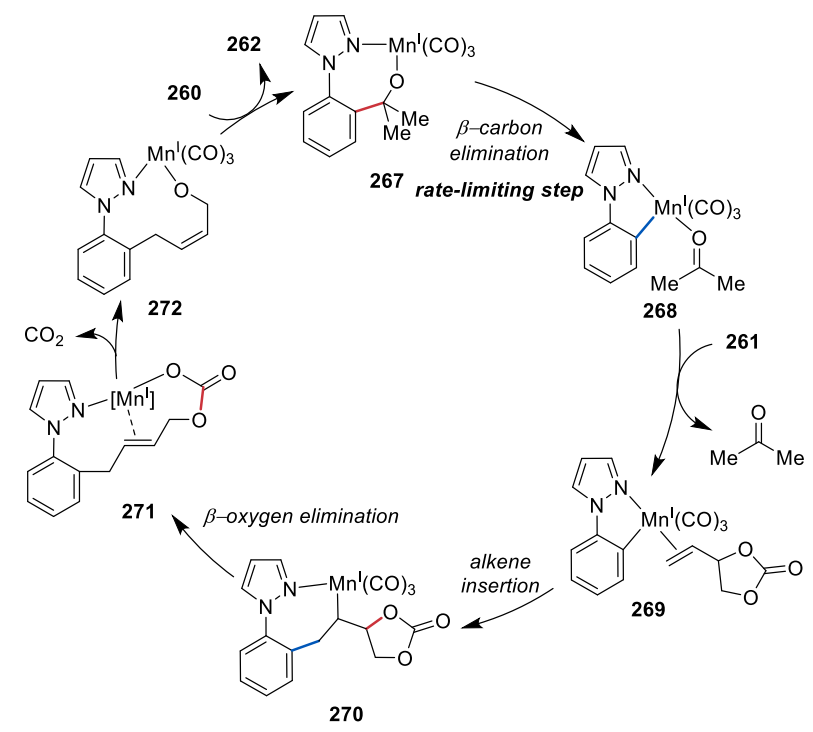

\section{4. $\beta$-ALKYL ELIMINATION}

The cleavage of unstrained $\mathrm{C}\left(\mathrm{sp}^{3}\right)-\mathrm{C}\left(\mathrm{sp}^{3}\right)$-bonds poses a great challenge due to the inherent high bond enthalpy. Several early transition metals with a $\mathrm{d}^{0}$ configuration that are active in olefin polymerization are able to catalyze $\beta$-alkyl eliminations. ${ }^{16}$ In contrast, few examples with late transition metals exist, among them many are restricted to stoichiometric reactions or strained systems. ${ }^{20,24,101,102}$

Nevertheless, there have been significant advances by utilizing chelation-assistance and directing groups to enable the cleavage of an alkyl group. It should be noted, that some reactions described herein do not proceed via a classical $\beta$-carbon elimination mechanism, but are listed here for comprehensiveness.

\section{1. $\beta$-Alkyl Elimination with Palladium}

The Miura group disclosed an intriguing transformation that converts $\alpha$-hydroxyisobutyrophenone (273) and aryl bromides $\mathbf{2 7 4}$ into $1,1,2,2$ tetraphenylethanes $\mathbf{2 7 5}$ that involves successive C-C and C-H bond cleavages (Scheme 44). ${ }^{103}$ While the mechanism is not completely understood yet, the authors believe that a Pd(II)-aryl species induces a 1,2-methyl shift in 277 to form $\alpha$-hydroxy enolate 278 that is further $\alpha$-arylated twice to give 279. ${ }^{104-106}$ Subsequently, a retro- $\alpha$-ketol-rearrangement takes place which results in $\alpha$-hydroxyketone $\mathbf{2 8 0}$ that undergoes $\beta$-carbon elimination to release diketone $\mathbf{2 8 2}$. The cleaved palladium biarylmethane moiety $\mathbf{2 8 1}$ assumedly dimerizes via reductive coupling to give the product $\mathbf{2 7 5}$. The diketone $\mathbf{2 8 2}$ can further react with an excess of aryl bromide to form the observed isochromanone byproduct $\mathbf{2 7 6}$ by an unknown mechanism. 
This document is the Accepted Manuscript version of a Published Work that appeared in final form in Chemical Reviews, copyright (C) American Chemical Society after peer review and technical editing by the publisher. To access the final edited and published work see https://doi.org/10.1021/acs.chemrev.0c00154

Scheme 44
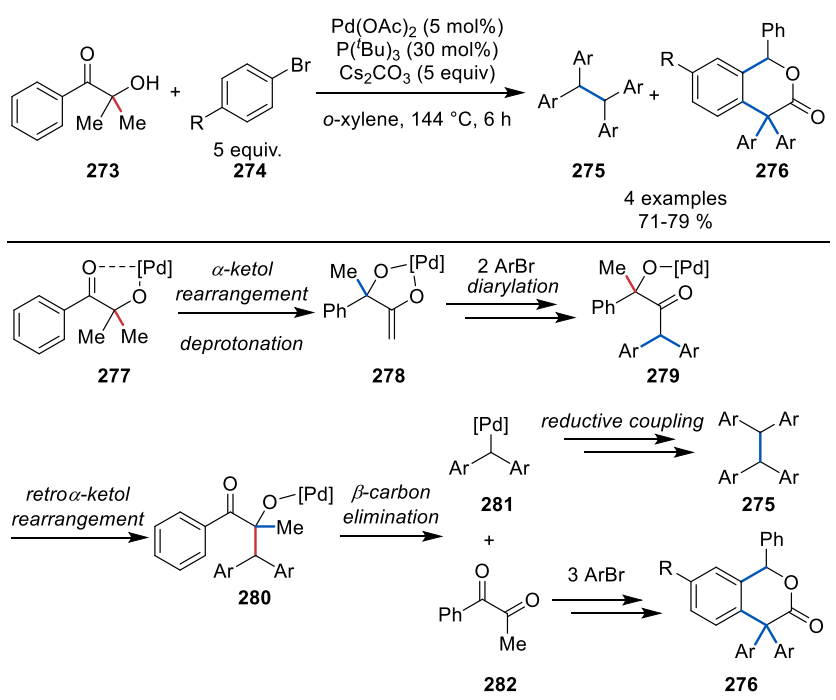

An example of chelation-assisted $\mathrm{C}\left(\mathrm{sp}^{3}\right)-\mathrm{C}\left(\mathrm{sp}^{3}\right)$ cleavage was reported by Oshima and Yorimitsu in 2007. ${ }^{107} 2$-(2-Pyridyl)-ethanol derivatives $\mathbf{2 8 3}$ were successfully coupled to aryl halides bearing a variety of functional groups under the effect of palladium catalysis (Scheme 45 ). Translocating or removing the pyridine directing group was detrimental to the reaction. The reaction tolerated both electron-rich and -poor arenes, however, alkyl and benzyl halides did not lead to the desired product. A proposed catalytic cycle begins with the oxidative addition of $\mathbf{2 8 4}$, and the resulting palladium(II) species $\mathbf{2 8 6}$ subsequently coordinates the (2-pyridyl)-alcohol 283 in a bidentate fashion to set the stage for $\beta$-carbon elimination. The resulting intermediate $\mathbf{2 8 8}$ is in equilibrium with species $\mathbf{2 8 9}$. Reductive elimination from the stabilized intermediatefurnishes the product and closes the cycle. 
This document is the Accepted Manuscript version of a Published Work that appeared in final form in Chemical Reviews, copyright (C) American Chemical Society after peer review and technical editing by the publisher. To access the final edited and published work see https://doi.org/10.1021/acs.chemrev.0c00154

Scheme 45

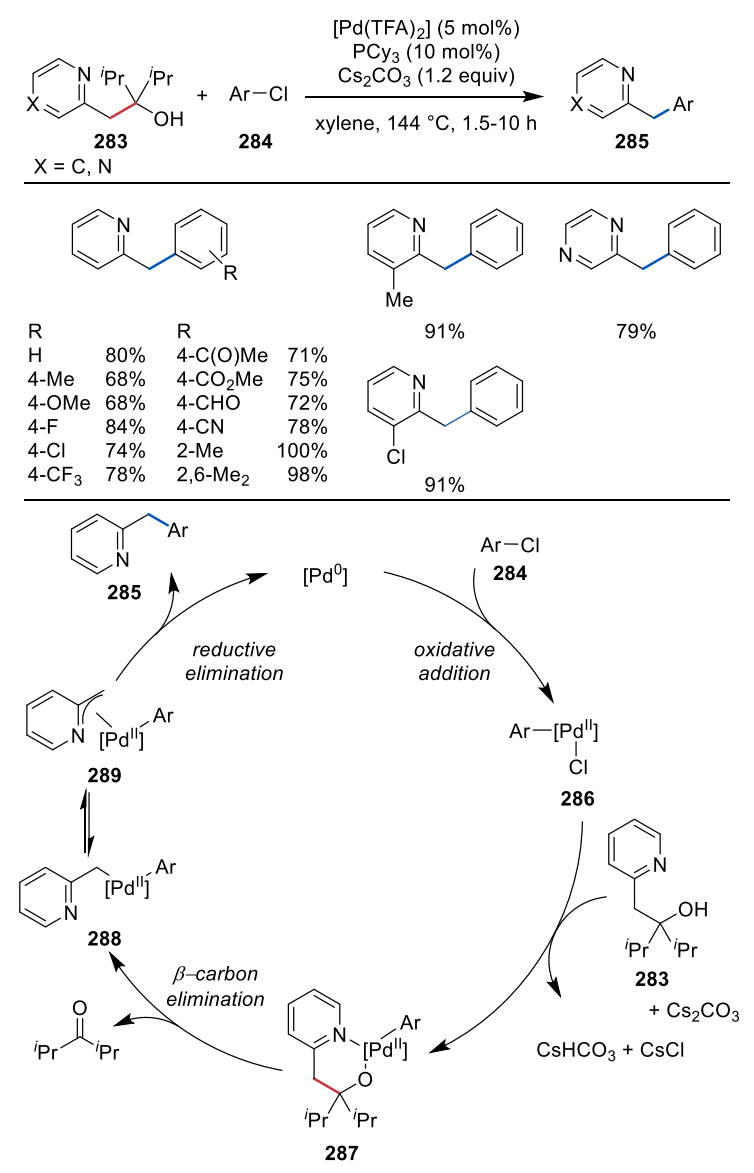

The scope of the reaction was further expanded to pyridine- $N$-oxides 290, which required the use of a bidentate ligand (Scheme $46 a) .{ }^{108} \mathrm{Nota}-$ bly, less bulky dimethyl- and alkyl-aryl alcohols underwent the transformation, while diaryl alcohols did not yield the product, although the corresponding ketone was observed. Interestingly, cleavage of the benzylic bond was preferred over the competing retro-allylation process (Scheme 46b). ${ }^{30}$

Scheme 46

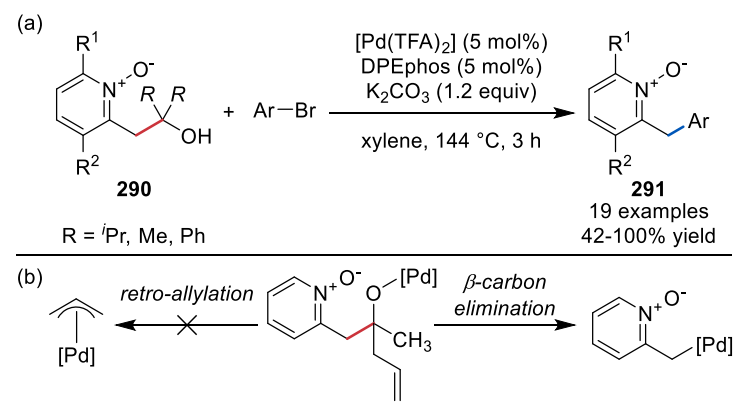

A classical approach to facilitate $\mathrm{C}-\mathrm{C}$ bond cleavage is the retro-aldol reaction. Zhang and co-workers reported a palladium-mediated retroaldol-arylation reaction that converts $\beta$-hydroxyketones 292 into mono- $\alpha$-arylated ketones 294 with release of acetone as volatile by-product (Scheme 47). ${ }^{109}$ The reaction proceeded with electron-poor and -neutral arenes and tolerated various functional groups. The proposed mechanism supported by DFT calculations begins with the oxidative addition of aryl halide 293, followed by ligand exchange with 294 and ratelimiting retro-aldol reaction from species $\mathbf{2 9 7}$. The so-formed palladium-enolate $\mathbf{2 9 8}$ subsequently undergoes reductive elimination to form the product and regenerate the catalyst. 
This document is the Accepted Manuscript version of a Published Work that appeared in final form in Chemical Reviews, copyright (C) American Chemical Society after peer review and technical editing by the publisher. To access the final edited and published work see https://doi.org/10.1021/acs.chemrev.0c00154

Scheme 47

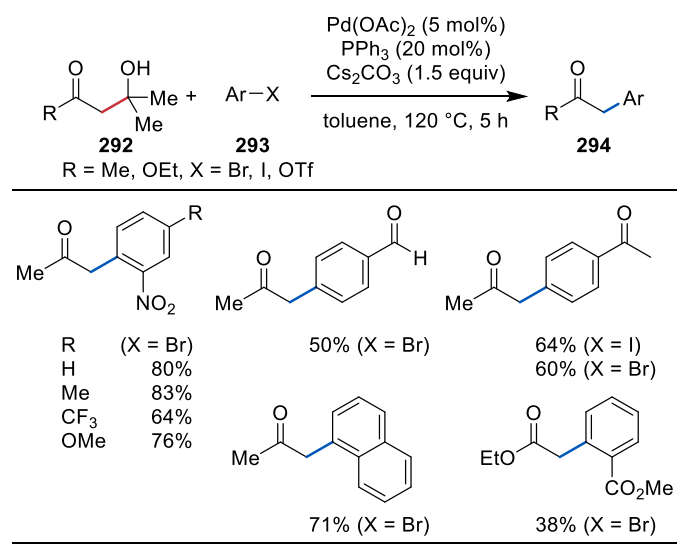

Control experiments
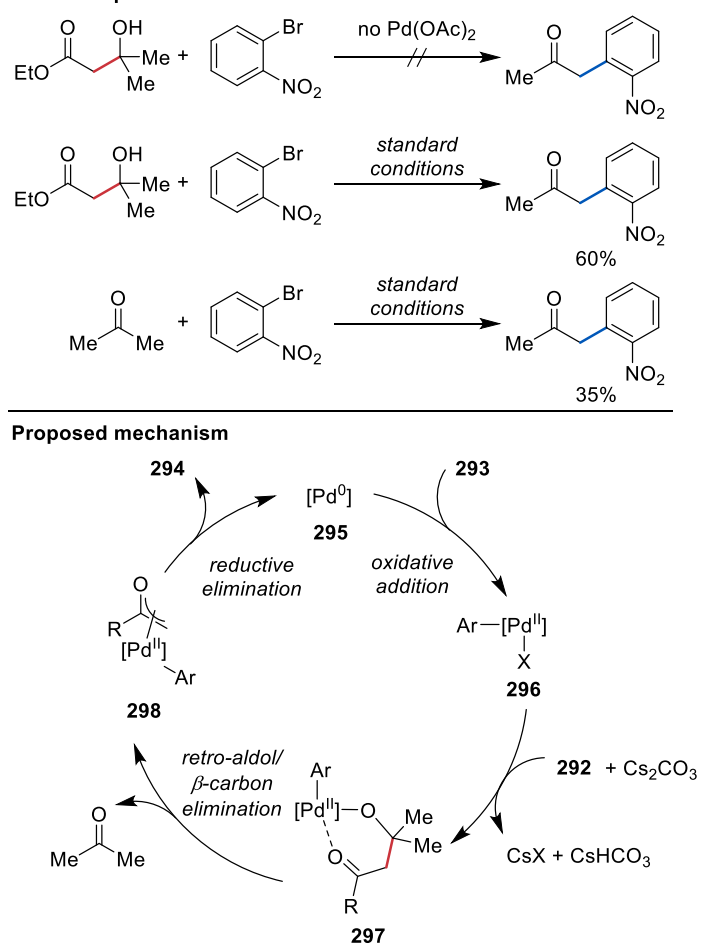

Chiba et al. disclosed a mechanistically intriguing ring-expansion of cyclic 2-azidoalcohol derivatives 299-300 which proceeds by chelationassisted $\mathrm{C}-\mathrm{C}$ bond cleavage under mild conditions (Scheme 48). ${ }^{110}$ Both cis- and trans-configured substrates underwent the transformations, although starting from the trans-configured isomer higher yields were obtained. A wide range of cyclic 2 -azidoalcohols were converted into the corresponding pyridines and fused heteroaromatic systems. While the six-membered analog remained unreactive, the corresponding cyclopentane- and cyclobutane-derivatives were converted into pyridines or pyrroles in acceptable yields. Chelation of palladium by the alkoxide and the azido group of 299-300 allows for $\beta$-carbon elimination from complex 302 which is followed by extrusion of dinitrogen. The resulting alkylideneaminopalladium(II) species 303 subsequently attacks the aldehyde group to form a cyclized intermediate 304. Consecutive dehydrative aromatization yields the aza-heterocyclic product 301. 
This document is the Accepted Manuscript version of a Published Work that appeared in final form in Chemical Reviews, copyright (C) American Chemical Society after peer review and technical editing by the publisher. To access the final edited and published work see https://doi.org/10.1021/acs.chemrev.0c00154

Scheme 48
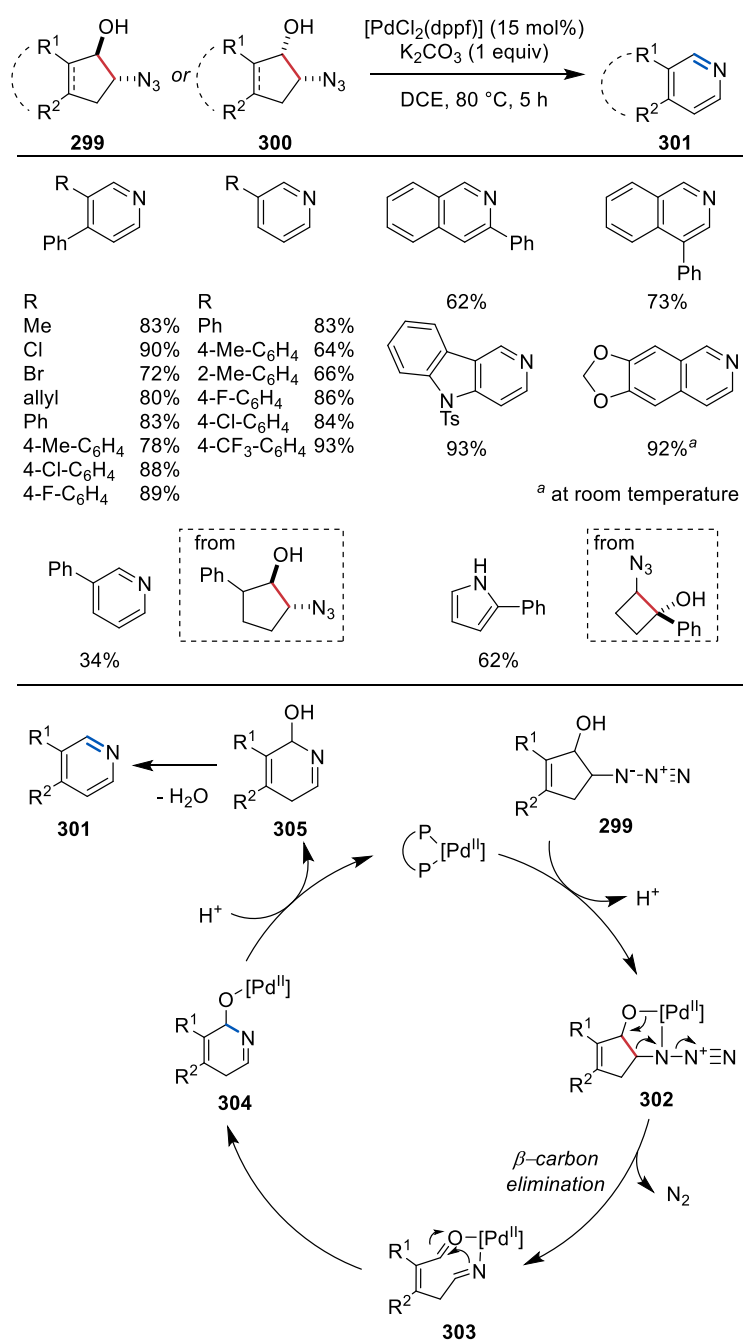

Recently, the Murakami group disclosed a cross-coupling between $\alpha$-hydroxy esters $\mathbf{3 0 6}$ and aryl bromides $\mathbf{3 0 7}$ to afford methyl benzoates $\mathbf{3 0 8}$ under release of benzophenone (Scheme 49). ${ }^{111}$ While the cleaved group in this case is an ester, the similarities to $\beta$-alkyl elimination make it worthwhile to discuss it in this section. The authors proposed a mechanism that starts with $\operatorname{Pd}(0)$ species $\mathbf{3 1 0}$ that oxidatively adds the aryl bromide to give intermediate $\mathbf{3 1 1}$. The bromide is then exchanged with $\mathbf{3 0 6}$, and $\beta$-carbon elimination from the palladium alkoxide complex 312 occurs to release benzophenone (309) as leaving group. Finally, reductive elimination furnishes the product. The scope of aryl bromides includes electron-rich and -poor arenes, with the latter delivering moderate yields. 
This document is the Accepted Manuscript version of a Published Work that appeared in final form in Chemical Reviews, copyright (C) American Chemical Society after peer review and technical editing by the publisher. To access the final edited and published work see https://doi.org/10.1021/acs.chemrev.0c00154

Scheme 49
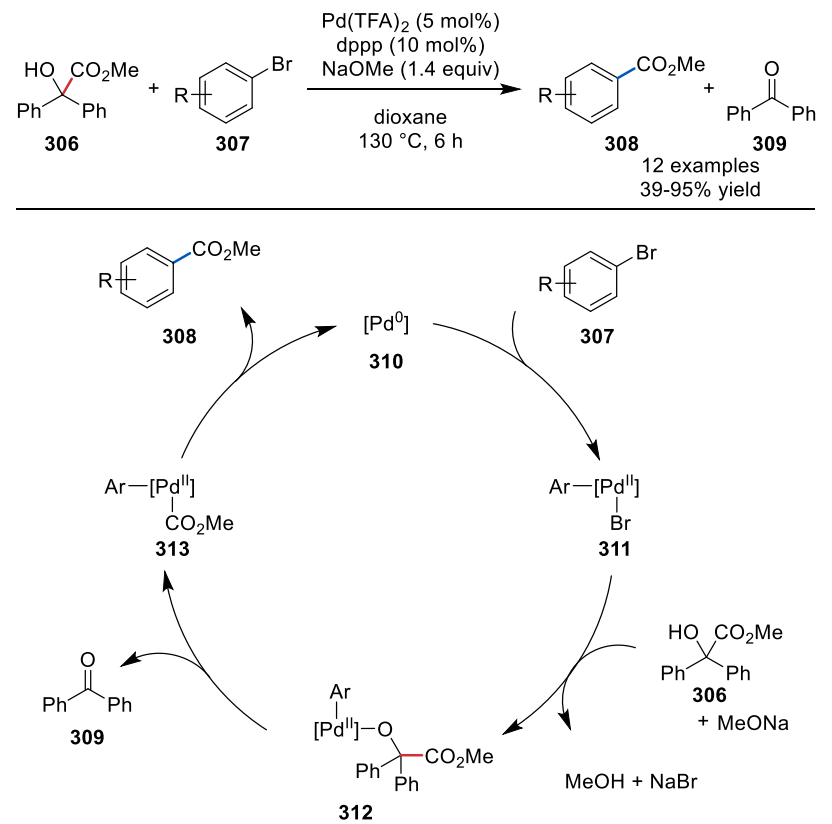

\section{2. $\beta$-Alkyl Elimination with Rhodium}

Oshima and Yorimitsu reported a retro-aldol reaction of $\beta$-hydroxycarbonyl compounds 314 followed by reaction with aldehydes 315 catalyzed by rhodium (Scheme 50). ${ }^{112}$ Bidentate coordination to the substrate 314 initiates the retro-aldol reaction which results in a rhodium enolate which can be trapped with a suitable electrophile. Curiously, the diamine ligand TMEDA was best suited for this transformation. Several aryl and linear alkyl aldehydes underwent the transformation in high yields, however, electron-rich aldehydes such as pivaldehyde were not tolerated. Notably, cinnamaldehyde was reacted regioselectively to give the corresponding 1,2-addition product.

\section{Scheme 50}

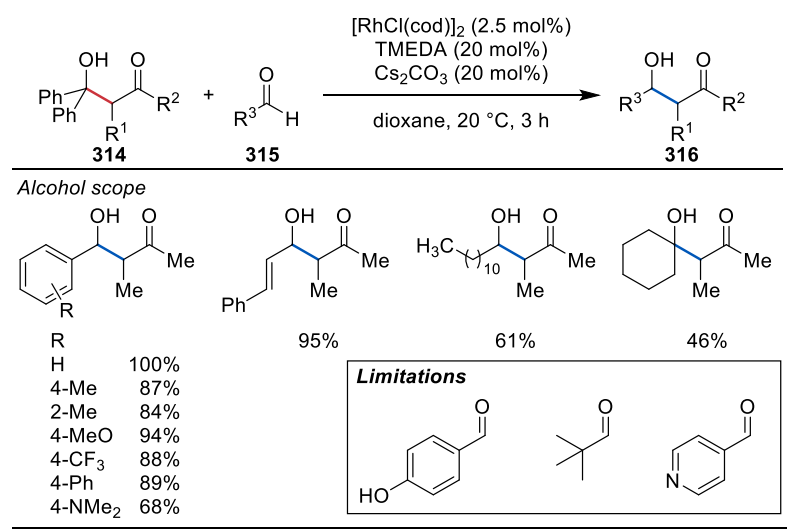

Carbonyl acceptor scope

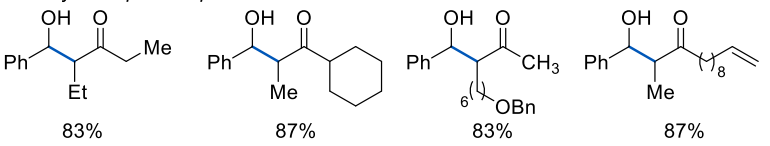

\section{3. $\beta$-Alkyl Elimination with Nickel}

Cheng et al. reported an annulation cascade reaction of $o$-iodoaryl alkyl ketones and $o$-iodoaryl aldehydes with norbornenes that is proposed to proceed via $\beta$-alkyl elimination from a $\mathrm{Ni}(\mathrm{II})$ alkoxide species. ${ }^{113}$ 
This document is the Accepted Manuscript version of a Published Work that appeared in final form in Chemical Reviews, copyright (C) American Chemical Society after peer review and technical editing by the publisher. To access the final edited and published work see https://doi.org/10.1021/acs.chemrev.0c00154

\section{5. $\beta$-CARBON ELIMINATION FROM PRIMARY ALCOHOLS}

As mentioned earlier, the cleavage of unactivated $\mathrm{C}-\mathrm{C}$ bonds in the presence of $\beta$-hydrides is disfavored, rendering selective $\mathrm{C}-\mathrm{C}$ bond cleavage of $1^{\circ}$ alcohols challenging. For that reason, examples that only formally correspond to a $\mathrm{C}-\mathrm{C}$ bond cleavage of alcohols but are converted into different intermediates are also listed for comprehensiveness.

Jang demonstrated in 2015 that primary propargyl alcohols can also formally undergo C $-\mathrm{C}$ cleavage after in situ oxidation to the aldehyde. ${ }^{114}$ In the presence of catalytic amounts of copper and under an oxygen atmosphere, substrate $\mathbf{3 1 7}$ is oxidized and subsequently trapped by an amine or alcohol to afford a hemiaminal or hemiacetal (321) (Scheme 51). $\beta$-Carbon elimination releases formamide and a copper acetylide (323). The latter was engaged with azide 318 to form triazoles 319. In the absence of azide, the Glaser coupling products were isolated instead.

\section{Scheme 51}

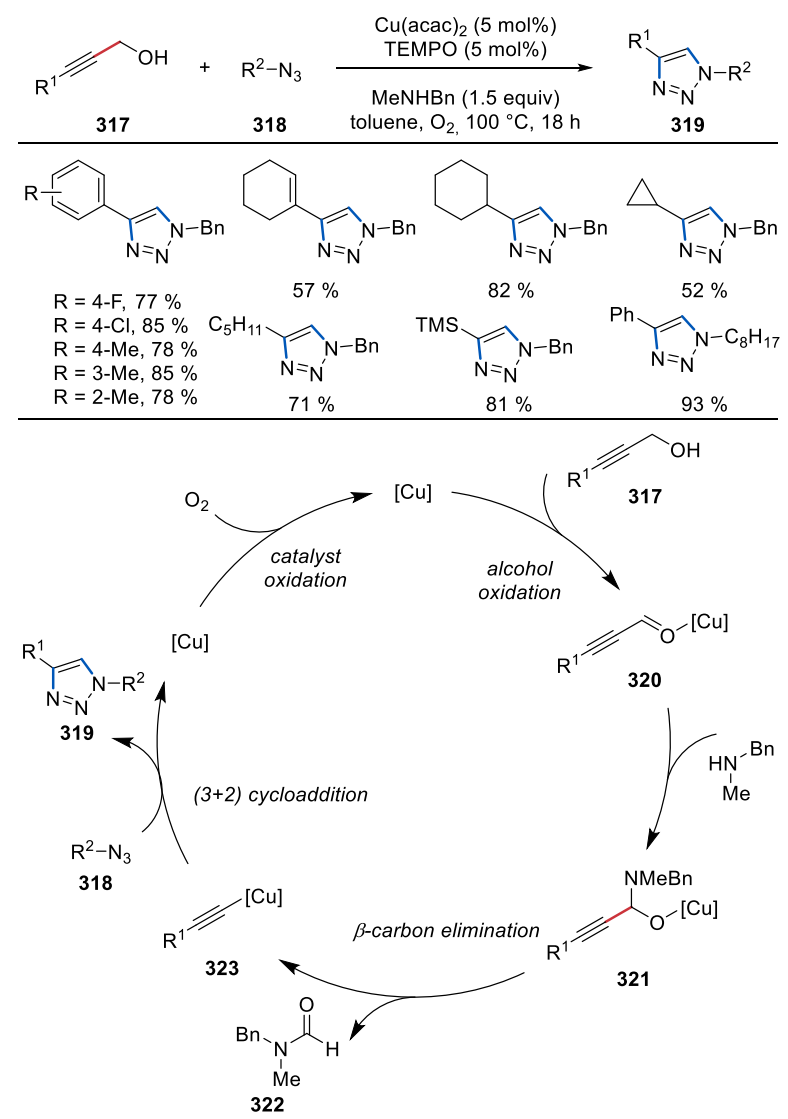

Yin et al. reported the $\alpha$-arylation of furans originating from primary furfuryl alcohols $\mathbf{3 2 4}$ with arylboronic acids $\mathbf{3 2 5}$ (Scheme 52 ). ${ }^{115}$ While electron-rich substrates gave good yields, electron-withdrawing and sterically demanding substituents lowered the reaction yield significantly. Importantly, in this reaction secondary, and especially, tertiary alcohols are not tolerated. While formally a C-C bond of a primary benzylic alcohol is cleaved, mechanistically this reaction proceeds via electrophilic palladation of the electron-rich furan ring (327) and not via $\beta$-carbon elimination. The so formed oxonium ion $\mathbf{3 2 8}$ then rearomatizes by expelling formaldehyde. The formed furyl palladium species $\mathbf{3 2 9}$ is then set up to undergo reductive elimination to afford the product and a $\mathrm{Pd}(0)$ species that is reoxidized under the aerobic conditions. 
This document is the Accepted Manuscript version of a Published Work that appeared in final form in Chemical Reviews, copyright (C) American Chemical Society after peer review and technical editing by the publisher. To access the final edited and published work see https://doi.org/10.1021/acs.chemrev.0c00154

Scheme 52

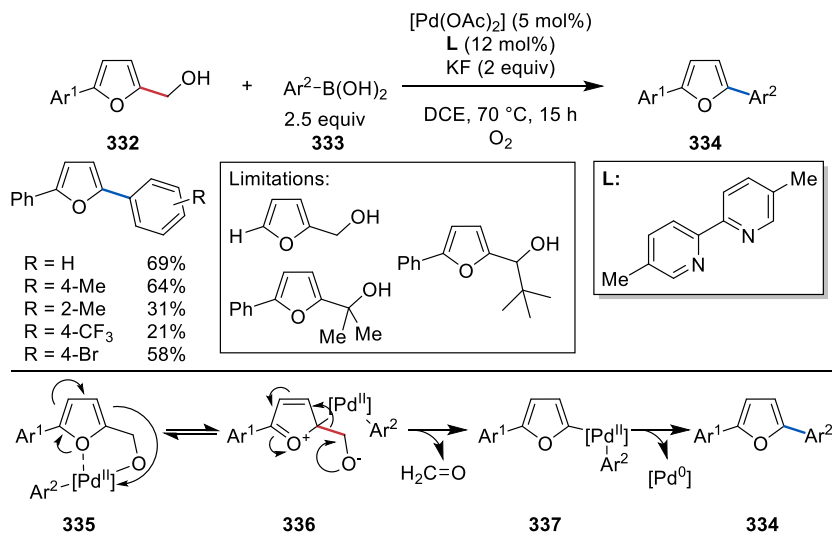

The same group expanded the scope of the reaction to monoprotected furfuryl diols 331 using slightly modified conditions (Scheme 53). ${ }^{116}$ To confirm the mechanistic hypothesis that the mechanism proceeds via an oxonium ion and not via $\beta$-carbon elimination, the authors conducted a Hammett study. The large negative $\rho$ value of -0.56 , together with the inverse reactivity trend of substitution of the alcohol supported the mechanism proposed above (Scheme 52).

Scheme 53

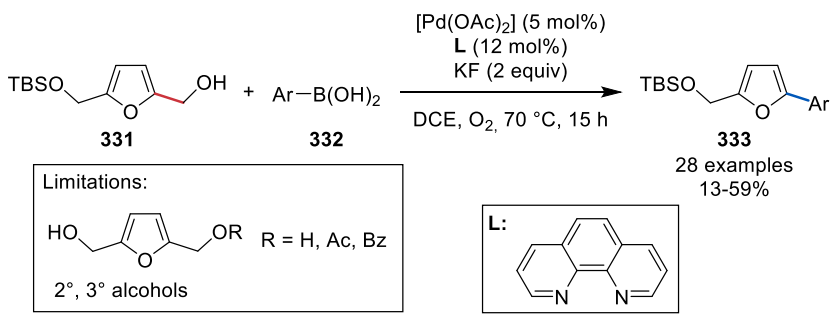

\section{CONCLUSION AND OUTLOOK}

In this review, we have summarized the developments in the activation of unstrained alcohols by $\beta$-carbon elimination. Significant advances in developing catalytic systems that cleave unactivated $\mathrm{C}-\mathrm{C}$ bonds in a variety of substrate classes have been made. Nevertheless, many challenges remain. Reports of $\mathrm{C}\left(\mathrm{sp}^{3}\right)-\mathrm{C}\left(\mathrm{sp}^{3}\right)$ scissions are still relatively rare and limited to selected scaffolds yet would offer great synthetic utility. In addition, the activation of secondary and particularly, primary alcohols, remains challenging and requires the use of directing groups.

Outstanding questions to be answered include how to arrive at benign reaction conditions that would allow for broader substrate compatibility. While the majority of reaction conditions did not call for strongly acidic or oxidizing reagents, the reaction temperature often surpassed $100{ }^{\circ} \mathrm{C}$. One possible direction could be emerging radical-driven processes that allow for $\mathrm{C}-\mathrm{C}$ bond cleavages under mild conditions. ${ }^{6,36,117-120} \mathrm{Moreover}$, using first-row transition metals might allow the exploitation of different reaction pathways compared to precious $\mathrm{Pd}$ and $\mathrm{Rh}$ catalysts that were predominantly used in the field. Three examples using $\mathrm{Mn},{ }^{100} \mathrm{Co},{ }^{99}$ and $\mathrm{Ni}^{113}$ were discussed herein.

With respect to the mechanistic understanding, further studies about the proposed intermediates and their reactivity will inform future catalyst design for more efficient $\mathrm{C}-\mathrm{C}$ bond activation. In addition, the discovery of new activation strategies will likely broaden the scope of substrate classes amenable to selective $\mathrm{C}-\mathrm{C}$ bond cleavages. An open question is whether other activation modes than $\beta$-carbon elimination can be conceived to activate $\mathrm{C}-\mathrm{C}$ bonds in unstrained alcohols.

While conceptually interesting, many reported reactions are not yet suited to replace classical transformations in terms of synthetic utility. For example, several reports detailed cross-couplings that are complementary to traditional methods using readily available reagents, like aryl halides and terminal alkynes, under more benign conditions. To this end, we envision that newly developed reactivities can be leveraged to expedite the construction of complex molecules in an efficient manner using strategically unusual disconnections, following the example of strained C$\mathrm{C}$ bond activations in total synthesis, e.g. in ring expansions. ${ }^{15,32,121}$ Aside from the construction of molecules, the possibility to deconstruct complex molecules to arrive at valuable synthetic fragments also harbors immense potential.

We hope that this review will contribute to inspire new research about synthetic and mechanistic aspects of C-C bond activations. Taking into account the availability of alcohol-containing feedstocks, they may serve as inexpensive and less toxic reagents to replace halide-containing 
This document is the Accepted Manuscript version of a Published Work that appeared in final form in Chemical Reviews, copyright (C) American Chemical Society after peer review and technical editing by the publisher. To access the final edited and published work see https://doi.org/10.1021/acs.chemrev.0c00154

molecules. Also in the context of renewable feedstocks, such as biomass (e.g. lignin, sugars), we see great potential for their use in a sustainable chemical economy to replace fossil-derived molecules.

\section{AUTHOR INFORMATION}

\section{Corresponding Author}

*E-mail: bill.morandi@org.chem.ethz.ch

\section{ORCID}

Marius Lutz: 0000-0003-3842-2295

Bill Morandi: 0000-0003-3968-1424

\section{Funding Sources}

We thank the European Research Council for financial support (ERC Grant 757608 ShuttleCat). M.D.R.L. is grateful for funding from the German Academic Scholarship Foundation.

\section{Notes}

The authors declare no competing financial interests.

\section{Biographies}

Marius D. R. Lutz was born in Heidelberg, Germany in 1993. He received his B.Sc. and M.Sc. degrees from ETH Zurich in 2015 and 2017, respectively, conducting his master's thesis with Prof. Barry M. Trost at Stanford University developing new binuclear-zinc catalyzed asymmetric reactions. He then moved to Basel to carry out two industrial placements with Roche and Actelion/Idorsia. Since October 2018 he is a PhD student under the supervision of Prof. Bill Morandi. His current research interests include transition-metal-catalyzed C-C single bond activation and reversible isofunctional reactions.

Bill Morandi was born in 1983 in Fribourg, Switzerland. He studied at the ETH Zurich (2003-2008), earning a BSc in Biology and an MSc in Chemical Biology as an Oskar-Jeger Scholar. After a PhD with Prof. Erick M. Carreira, he moved in 2012 to CalTech to work with Prof. Robert H. Grubbs as a Swiss National Science Foundation postdoctoral fellow. In 2014, he was awarded an independent Max Planck Research Group Leader position by the Max Planck Society to start independent research at the Max-Planck-Institut für Kohlenforschung. Since July 2018, he has been a professor at the Laboratorium für Organische Chemie of the ETH Zurich.

\section{ABBREVIATIONS}

$\begin{array}{ll}\text { BDE } & \text { bond dissociation energy } \\ \text { BINAP } & \text { 2,2'-bis(diphenylphosphino)-1,1'-binaphthyl } \\ \text { CCE } & \text { constant current electrolysis } \\ \text { CMD } & \text { concerted metalation-deprotonation } \\ \text { Cp } & \text { pentamethylcyclopentadienyl } \\ \text { dppb } & \text { 1,4-bis(diphenylphosphino)butane } \\ \text { dppp } & \text { 1,3-bis(diphenylphosphino)propane } \\ \text { Fc } & \text { ferrocenyl } \\ \text { KIE } & \text { Kinetic isotope effect } \\ \text { Np } & \text { naphthyl } \\ \text { PCET } & \text { proton-coupled electron transfer } \\ \text { TBDMS } & \text { tert-butyldimethylsilyl } \\ \text { TEMPO } & 2,2,6,6 \text {-tetramethylpiperidinyloxyl } \\ \text { TFA } & \text { trifluoroacetic acid } \\ \text { TIPS } & \text { triisopropylsilyl } \\ \text { TMEDA } & \text { tetramethylethylenediamine } \\ \text { tosyl } & \text { toluenesulfonyl } \\ & \\ 44 & \end{array}$


This document is the Accepted Manuscript version of a Published Work that appeared in final form in Chemical Reviews, copyright (C) American Chemical Society after peer review and technical editing by the publisher. To access the final edited and published work see https://doi.org/10.1021/acs.chemrev.0c00154

\section{REFERENCES}

(1) Miura, M.; Satoh, T. Catalytic Processes Involving $\beta$-Carbon Elimination. In Palladium in Organic Synthesis; Springer, Berlin, Heidelberg: Heidelberg, 2005; pp 1-20.https://doi.org/10.1007/b104133.

(2) Chen, F.; Wang, T.; Jiao, N. Recent Advances in Transition-Metal-Catalyzed Functionalization of Unstrained Carbon-Carbon Bonds. Chem. Rev. 2014, 114, 8613-8661. https://doi.org/10.1021/cr400628s.

(3) Matar, S.; Hatch, L. F. Crude Oil Processing and Production of Hydrocarbon Intermediates. In Chemistry of Petrochemical Processes; Gulf Professional Publishing, 2001; pp 49-110. https://doi.org/10.1016/B978-088415315-3/50004-3.

(4) Zakzeski, J.; Bruijnincx, P. C. A.; Jongerius, A. L.; Weckhuysen, B. M. The Catalytic Valorization of Lignin for the Production of Renewable Chemicals. Chem. Rev. 2010, 110, 3552-3599. https://doi.org/10.1021/cr900354u.

(5) Zhang, C.; Wang, F. Catalytic Lignin Depolymerization to Aromatic Chemicals. Acc. Chem. Res. 2020, 53, 470-484. https://doi.org/10.1021/acs.accounts.9b00573.

(6) Yayla, H. G.; Wang, H.; Tarantino, K. T.; Orbe, H. S.; Knowles, R. R. Catalytic Ring-Opening of Cyclic Alcohols Enabled by PCET Activation of Strong O-H Bonds. J. Am. Chem. Soc. 2016, 138, 10794-10797. https://doi.org/10.1021/jacs.6b06517.

(7) Tong, X.; Ma, Y.; Li, Y. Biomass into Chemicals: Conversion of Sugars to Furan Derivatives by Catalytic Processes. Appl. Catal. A Gen. 2010, $385,1-13$. https://doi.org/10.1016/j.apcata.2010.06.049.

(8) Mika, L. T.; Cséfalvay, E.; Németh, Á. Catalytic Conversion of Carbohydrates to Initial Platform Chemicals: Chemistry and Sustainability. Chem. Rev. 2018, 118, 505-613. https://doi.org/10.1021/acs.chemrev.7b00395.

(9) Sun, Z.; Fridrich, B.; De Santi, A.; Elangovan, S.; Barta, K. Bright Side of Lignin Depolymerization: Toward New Platform Chemicals. Chem. Rev. 2018, 118, 614-678. https://doi.org/10.1021/acs.chemrev.7b00588.

(10) Jambeck, J. R.; Geyer, R.; Wilcox, C.; Siegler, T. R.; Perryman, M.; Andrady, A.; Narayan, R.; Law, K. L. Plastic Waste Inputs from Land into the Ocean. Science 2015, 347, 768-771. https://doi.org/10.1126/science.1260352.

(11) Gross, R. A.; Kalra, B. Biodegradable Polymers for the Environment. Science 2002, 297, 803-807. https://doi.org/10.1126/science.297.5582.803.

(12) Geyer, R; Jambeck, J. R; Law, K. L. Production, Use, and Fate of All Plastics Ever Made. Sci.Adv. 2017, 3, e1700782. https://doi.org/10.1126/sciadv.1700782.

(13) Trost, B. The Atom Economy--a Search for Synthetic Efficiency. Science 1991, 254, 1471-1477. https://doi.org/10.1126/science.1962206.

(14) Trost, B. M. Atom Economy-A Challenge for Organic Synthesis: Homogeneous Catalysis Leads the Way. Angew. Chemie Int. Ed. 1995, 34, 259-281. https://doi.org/10.1002/anie.199502591.

(15) Sarpong, R.; Wang, B.; Perea, M. A. Transition Metal-Mediated C-C Single Bond Cleavage: Making the Cut in Total Synthesis. Angew. Chemie Int. Ed. 2020. https://doi.org/10.1002/anie.201915657.

(16) O'Reilly, M. E.; Dutta, S.; Veige, A. S.; O’Reilly, M. E.; Dutta, S.; Veige, A. S. ß-Alkyl Elimination: Fundamental Principles and Some Applications. Chem. Rev. 2016, 116, 8105-8145. https://doi.org/10.1021/acs.chemrev.6b00054.

(17) Li, H.; Shi, Z.J. Catalysis in C-C Activation. In Homogeneous Catalysis for Unreactive Bond Activation; Wiley Blackwell: Hoboken, NJ, USA, 2014; pp 575-619. https://doi.org/10.1002/9781118788981.ch7.

(18) Jun, C.-H. Transition Metal-Catalyzed Carbon-Carbon Bond Activation. Chem. Soc. Rev. 2004, 33, 610-618. https://doi.org/10.1039/B308864M.

(19) Muzart, J. Palladium-Catalysed Reactions of Alcohols. Part D: Rearrangements, Carbonylations, Carboxylations and Miscellaneous Reactions. Tetrahedron 2005, 61, 9423-9463. https://doi.org/10.1016/j.tet.2005.06.103.

(20) Ruhland, K. Transition-Metal-Mediated Cleavage and Activation of C-C Single Bonds. European J. Org. Chem. 2012, 2012, 2683-2706. https://doi.org/10.1002/ejoc.201101616.

(21) Dong, G. C-C Bond Activation; Dong, G., Ed.; Topics in Current Chemistry; Springer: Berlin, Heidelberg, 2014; Vol. 346. https://doi.org/10.1007/978-3-64255055-3.

(22) Murakami, M.; Ishida, N. Potential of Metal-Catalyzed C-C Single Bond Cleavage for Organic Synthesis. J. Am. Chem. Soc. 2016, 138, 13759-13769. https://doi.org/10.1021/jacs.6b01656.

(23) Murakami, M.; Ito, Y. Cleavage of Carbon—Carbon Single Bonds by Transition Metals. In Activation of Unreactive Bonds and Organic Synthesis; Springer: Heidelberg, 1999; Vol. 18, pp 97-129. https://doi.org/10.1007/3-540-68525-1_5.

(24) Murakami, M. Cleavage of Carbon-Carbon Single Bonds by Transition Metals; Murakami, M., Murakami, M., Eds.; Wiley-VCH Verlag GmbH \& Co. KGaA: Weinheim, Germany, 2015. https://doi.org/10.1002/9783527680092.

(25) Nairoukh, Z.; Cormier, M.; Marek, I. Merging C-H and C-C Bond Cleavage in Organic Synthesis. Nat. Rev. Chem. 2017, 1, 0035. https://doi.org/10.1038/s41570-017-0035.

(26) Song, F.; Gou, T.; Wang, B.-Q.; Shi, Z.-J. Catalytic Activations of Unstrained C-C Bond Involving Organometallic Intermediates. Chem. Soc. Rev. 2018, 47, 7078-7115. https://doi.org/10.1039/C8CS00253C.

(27) Rybtchinski, B.; Milstein, D. Metal Insertion into C-C Bonds in Solution. Angew. Chemie Int. Ed. 1999, 38, 870-883. https://doi.org/10.1002/(SICI)15213773(19990401)38:7<870::AID-ANIE870>3.0.CO;2-3.

(28) Souillart, L.; Cramer, N. Catalytic C-C Bond Activations via Oxidative Addition to Transition Metals. Chem. Rev. 2015, 115, 9410-9464. https://doi.org/10.1021/acs.chemrev.5b00138.

(29) Kondo, T. Ruthenium- and Rhodium-Catalyzed Strain-Driven Cleavage and Reconstruction of the C-C Bond. European J. Org. Chem. 2016, 2016, 1232-1242. https://doi.org/10.1002/ejoc.201501291.

(30) Yorimitsu, H. Retro-Allylation and Deallylation. In Cleavage of Carbon-Carbon Single Bonds by Transition Metals; Murakami, M., Ed.; Wiley-VCH Verlag GmbH \& Co. KGaA: Weinheim, Germany, 2015; pp 165-192. https://doi.org/10.1002/9783527680092.ch5.

(31) Seiser, T.; Cramer, N. Enantioselective Metal-Catalyzed Activation of Strained Rings. Org. Biomol. Chem. 2009, 7, 2835-2840. https://doi.org/10.1039/b904405a.

(32) Fumagalli, G.; Stanton, S.; Bower, J. F. Recent Methodologies That Exploit C-C Single-Bond Cleavage of Strained Ring Systems by Transition Metal Complexes. Chem. Rev. 2017, 117, 9404-9432. https://doi.org/10.1021/acs.chemrev.6b00599. 
This document is the Accepted Manuscript version of a Published Work that appeared in final form in Chemical Reviews, copyright (C) American Chemical Society after peer review and technical editing by the publisher. To access the final edited and published work see https://doi.org/10.1021/acs.chemrev.0c00154

(33) Murakami, M.; Matsuda, T. Metal-Catalysed Cleavage of Carbon-Carbon Bonds. Chem. Commun. 2011, 47, 1100-1105. https://doi.org/10.1039/C0CC02566F.

(34) Marek, I.; Masarwa, A.; Delaye, P. O.; Leibeling, M. Selective Carbon-Carbon Bond Cleavage for the Stereoselective Synthesis of Acyclic Systems. Angew. Chemie - Int.Ed. 2015, 54, 414-429. https://doi.org/10.1002/anie.201405067.

(35) Sivaguru, P.; Wang, Z.; Zanoni, G.; Bi, X. Cleavage of Carbon-Carbon Bonds by Radical Reactions. Chem. Soc. Rev. 2019, 48, $2615-2656$. https://doi.org/10.1039/c8cs00386f.

(36) Morcillo, S. P. Radical-Promoted C-C Bond Cleavage: A Deconstructive Approach for Selective Functionalization. Angew. Chemie Int. Ed. 2019, 58, 14044 14054. https://doi.org/10.1002/anie.201905218.

(37) Halpern, J. Determination and Significance of Transition-Metal-Alkyl Bond Dissociation Energies. Acc. Chem. Res. 1982, 15, 238-244. https://doi.org/10.1021/ar00080a002.

(38) Lyons, T. W.; Sanford, M. S. Palladium-Catalyzed Ligand-Directed C-H Functionalization Reactions. Chem. Rev. 2010, 110, 1147-1169. https://doi.org/10.1021/cr900184e.

(39) Colby, D. A.; Bergman, R. G.; Ellman, J. A. Rhodium-Catalyzed C-C Bond Formation via Heteroatom-Directed C-H Bond Activation. Chem. Rev. 2010, 110, 624-655. https://doi.org/10.1021/cr900005n.

(40) Dreis, A. M.; Douglas, C. J. Catalytic Carbon-Carbon $\sigma$ Bond Activation: An Intramolecular Carbo-Acylation Reaction with Acylquinolines. J. Am. Chem. Soc. 2009, 131, 412-413. https://doi.org/10.1021/ja8066308.

(41) Blanksby, S. J.; Ellison, G. B. Bond Dissociation Energies of Organic Molecules. Acc. Chem. Res. 2003, 36, 255-263. https://doi.org/10.1021/ar020230d.

(42) Neufeldt, S. R; Sanford, M. S. Controlling Site Selectivity in Palladium-Catalyzed C-H Bond Functionalization. Acc. Chem. Res. 2012, 45, 936-946. https://doi.org/10.1021/ar300014f.

(43) Havens, S. J.; Hergenrother, P. M. Synthesis of Arylacetylenes by the Sodium Hydride Catalyzed Cleavage of 4-Aryl-2-Methyl-3-Butyn-2-Ols. J. Org. Chem. 1985, 50, 1763-1765. https://doi.org/10.1021/jo00210a042.

(44) Swindell, C. S.; Fan, W.; Klimko, P. G. Pinacol Closure of Oxygenated Taxane Skeleta at C-1-C-2 with Stereoinduction by Oxygen Substituents at C-9 and C10. Tetrahedron Lett. 1994, 35, 4959-4962. https://doi.org/10.1016/S0040-4039(00)73292-8.

(45) Rodríguez, J. G.; Martín-Villamil, R.; Cano, F. H.; Fonseca, I. Synthesis of 1,4-Di(n-Pyridyl)Buta-1,3-Diyne and Formation of Charge-Transfer Complexes. XRay Structure of 1,4-Di(3-Pyridyl)Buta-1,3-Diyne. J. Chem. Soc. - Perkin Trans. 1 1997, No. 5, 709-714. https://doi.org/10.1039/a605468d.

(46) Chow, H. F.; Wan, C. W.; Low, K. H.; Yeung, Y. Y. A Highly Selective Synthesis of Diarylethynes and Their Oligomers by a Palladium-Catalyzed Sonogashira Coupling Reaction under Phase Transfer Conditions. J. Org. Chem. 2001, 66, 1910-1913. https://doi.org/10.1021/jo001538q.

(47) Nishimura, T.; Araki, H.; Maeda, Y.; Uemura, S. Palladium-Catalyzed Oxidative Alkynylation of Alkenes via C-C Bond Cleavage under Oxygen Atmosphere. Org. Lett. 2003, 5, 2997-2999. https://doi.org/10.1021/ol0348405.

(48) Funayama, A.; Satoh, T.; Miura, M. Regio- and Stereoselective Homocoupling of $\gamma$-Arylated Tert-Propargyl Alcohols with Liberation of a Ketone Molecule and Successive Cyclization to Produce Fluorescent Dihydrofuran Derivatives. J. Am. Chem. Soc. 2005, 127, $15354-15355$. https://doi.org/10.1021/ja055452w.

(49) Dyker, G.; Kellner, A. A Palladium Catalyzed Domino Coupling Process to Substituted Phenanthrenes. Tetrahedron Lett. 1994, 35, 7633-7636. https://doi.org/10.1016/S0040-4039(00)78361-4.

(50) Dou, X.; Liu, N.; Yao, J.; Lu, T. Rhodium-Catalyzed Homocoupling of $\gamma$-Alkylated Tert-Propargylic Alcohols. Org. Lett. 2018, 20, $272-275$. https://doi.org/10.1021/acs.orglett.7b03663.

(51) Miura, T.; Shimizu, H.; Igarashi, T.; Murakami, M. Stereoselective Synthesis of Vinyl-Substituted (Z)-Stilbenes by Rhodium-Catalysed Addition of Arylboronic Acids to Allenic Alcohols. Org. Biomol. Chem. 2010, 8, 4074-4076. https://doi.org/10.1039/c0ob00163e.

(52) Nishimura, T.; Katoh, T.; Takatsu, K.; Shintani, R; Hayashi, T. Rhodium-Catalyzed Asymmetric Rearrangement of Alkynyl Alkenyl Carbinols: Synthetic Equivalent to Asymmetric Conjugate Alkynylation of Enones. J. Am. Chem. Soc. 2007, 129, 14158-14159. https://doi.org/10.1021/ja076346s.

(53) Nikishin, G. I.; Kovalev, I. P. Novel Vinyl Ketone - Acetylene Cross-Coupling Catalyzed by RhCl(PMe3)3. Tetrahedron Lett. 1990, 31, 7063-7064. https://doi.org/10.1016/S0040-4039(00)97243-5.

(54) Lerum, R. V.; Chisholm, J. D. Rhodium-Catalyzed 1,4-Addition of Terminal Alkynes to Vinyl Ketones. Tetrahedron Lett. 2004, 45, 6591-6594. https://doi.org/10.1016/j.tetlet.2004.07.036.

(55) Shintani, R.; Takatsu, K.; Katoh, T.; Nishimura, T.; Hayashi, T. Rhodium-Catalyzed Rearrangement of Aryl Bis(Alkynyl) Carbinols to 3-Alkynyl-1-Indanones. Angew. Chemie Int.Ed.2008, 47, 1447-1449. https://doi.org/10.1002/anie.200704818.

(56) Nishimura, T.; Nagaosa, M.; Hayashi, T. Rhodium-Catalyzed Oxidative Alkynylation of Acrylate Esters with Propargylic Alcohols. Tetrahedron Lett. 2011, 52, 2185-2187. https://doi.org/10.1016/j.tetlet.2010.11.120.

(57) Dou, X.; Huang, Y.; Hayashi, T. Asymmetric Conjugate Alkynylation of Cyclic $\alpha, \beta$-Unsaturated Carbonyl Compounds with a Chiral Diene Rhodium Catalyst. Angew. Chemie - Int. Ed. 2016, 55, 1133-1137. https://doi.org/10.1002/anie.201509778.

(58) Zhi, Y.; Huang, J.; Liu, N.; Lu, T.; Dou, X. Rhodium-Catalyzed Asymmetric Conjugate Alkynylation of $\beta, \gamma$-Unsaturated $\alpha$-Ketoesters. Org. Lett. 2017, 19, 23782381. https://doi.org/10.1021/acs.orglett.7b00909.

(59) Choo, K. L.; Lautens, M. Rhodium-Catalyzed Asymmetric Conjugate Alkynylation/Aldol Cyclization Cascade for the Formation of $\alpha$-Propargyl- $\beta$ Hydroxyketones. Org. Lett. 2018, 20, 1380-1383. https://doi.org/10.1021/acs.orglett.8b00153.

(60) Yasui, K.; Chatani, N.; Tobisu, M. Rhodium-Catalyzed C-O Bond Alkynylation of Aryl Carbamates with Propargyl Alcohols. Org. Lett. 2018, 20, $2108-2111$. https://doi.org/10.1021/acs.orglett.8b00674.

(61) Li, T.; Wang, Z.; Zhang, M.; Zhang, H.J.; Wen, T. Bin. Rh/Cu-Catalyzed Multiple C-H, C-C, and C-N Bond Cleavage: Facile Synthesis of Pyrido[2,1-a]Indoles from 1-(Pyridin-2-Y1)-1H-Indoles and $\gamma$-Substituted Propargyl Alcohols. Chem. Commun. 2015, 51, 6777-6780. https://doi.org/10.1039/c5cc01412c.

(62) Li, T.; Wang, Z.; Qin, W. B.; Wen, T. Bin. Rhodium-Catalyzed/Copper-Mediated Selective C2 Alkynylation of Indoles and C1 Alkynylation of Carbazoles with $\gamma$-Substituted Tert-Propargyl Alcohols. ChemCatChem 2016, 8, 2146-2154. https://doi.org/10.1002/cctc.201600218.

(63) Yan, X.; Ye, R.; Sun, H.; Zhong, J.; Xiang, H.; Zhou, X. Synthesis of 2-Arylindoles by Rhodium-Catalyzed/Copper-Mediated Annulative Coupling of N-Aryl2-Aminopyridines and Propargyl Alcohols via Selective C-H/C-C Activation. Org. Lett. 2019, 21, 7455-7459. https://doi.org/10.1021/acs.orglett.9b02767. 
This document is the Accepted Manuscript version of a Published Work that appeared in final form in Chemical Reviews, copyright (C) American Chemical Society after peer review and technical editing by the publisher. To access the final edited and published work see https://doi.org/10.1021/acs.chemrev.0c00154

(64) Brookhart, M.; Green, M. L. H. Carbonhydrogen-Transition Metal Bonds. J. Organomet. Chem. 1983, 250, 395-408. https://doi.org/10.1016/0022328X(83)85065-7.

(65) Labinger, J. A.; Bercaw, J. E. Understanding and Exploiting C-H Bond Activation. Nature 2002, 417, 507-514. https://doi.org/10.1038/417507a.

(66) Cámpora, J.; Gutiérrez-Puebla, E.; López, J. A.; Monge, A.; Palma, P.; Río, D. Del; Carmona, E. Cleavage of Calkyl-Caryl Bond of [Pd-CH2CMe2Ph] Complexes. Angew. Chemie - Int. Ed. 2001, 40, 3641-3644. https://doi.org/10.1002/1521-3773(20011001)40:19<3641::AID-ANIE3641>3.0.CO;2-9.

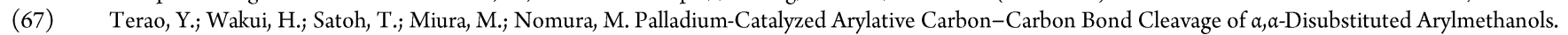
J. Am. Chem. Soc. 2001, 123, 10407-10408. https://doi.org/10.1021/ja016914i.

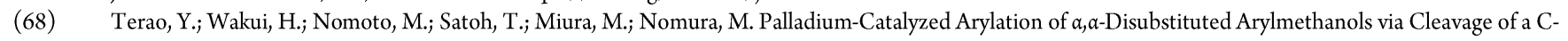
C or a C-H Bond to Give Biaryls. J. Org. Chem. 2003, 68, 5236-5243. https://doi.org/10.1021/jo0344034.

(69) Bour, J. R; Green, J. C.; Winton, V. J.; Johnson, J. B. Steric and Electronic Effects Influencing $\beta$-Aryl Elimination in the Pd-Catalyzed Carbon-Carbon Single Bond Activation of Triarylmethanols. J. Org. Chem. 2013, 78, 1665-1669. https://doi.org/10.1021/jo302592g.

(70) Zhao, P.; Hartwig, J. F. Insertions of Ketones and Nitriles into Organorhodium(i) Complexes and $\beta$-Hydrocarbyl Eliminations from Rhodium(I) Alkoxo and Iminyl Complexes. Organometallics 2008, 27, 4749-4757. https://doi.org/10.1021/om800378v.

(71) Santiago, C. B.; Milo, A.; Sigman, M. S. Developing a Modern Approach To Account for Steric Effects in Hammett-Type Correlations.J.Am. Chem. Soc. 2016, 138, 13424-13430. https://doi.org/10.1021/jacs.6b08799.

(72) Hammett, L. P. Linear Free Energy Relationships in Rate and Equilibrium Phenomena. Trans. Faraday Soc. 1938, 34, 156-165. https://doi.org/10.1039/TF9383400156.

(73) Ariëns, E. J. Drug Design. Volume III, 1st ed.; Ariëns, E. J., Ed.; Academic Press: New York, 1976.

(74) Terao, Y.; Nomoto, M.; Satoh, T.; Miura, M.; Nomura, M. Palladium-Catalyzed Dehydroarylation of Triarylmethanols and Their Coupling with Unsaturated Compounds Accompanied by C-C Bond Cleavage. J. Org. Chem. 2004, 69, 6942-6944. https://doi.org/10.1021/jo049031t.

(75) Nakano, M.; Satoh, T.; Miura, M. Palladium-Catalyzed Selective 2,3-Diarylation of $\alpha, \alpha$-Disubstituted 3-Thiophenemethanols via Cleavage of C-H and C-C Bonds. J. Org. Chem. 2006, 71, 8309-8311. https://doi.org/10.1021/jo061412e.

(76) Yokooji, A.; Satoh, T.; Miura, M.; Nomura, M. Synthesis of 5,5'-Diarylated 2,2'-Bithiophenes via Palladium-Catalyzed Arylation Reactions. Tetrahedron 2004, 60, 6757-6763. https://doi.org/10.1016/J.TET.2004.06.075.

(77) Bíró, A. B.; Kotschy, A. Selective Palladium-Catalysed Ipso Arylation of $\alpha, a$-Disubstituted Benzo[b]Thien-2-Ylmethanols with Aryl Bromides Using PCy 3 as Ligand. European J. Org. Chem. 2007, 2007, 1364-1368. https://doi.org/10.1002/ejoc.200600929.

(78) Iwasaki, M.; Iino, S.; Nishihara, Y. Palladium-Catalyzed Annulation of o-Iodobiphenyls with o-Bromobenzyl Alcohols: Synthesis of Functionalized Triphenylenes via C-C and C-H Bond Cleavages. Org. Lett. 2013, 15, 5326-5329. https://doi.org/10.1021/ol4025869.

(79) Iwasaki, M.; Araki, Y.; Iino, S.; Nishihara, Y. Synthesis of Multisubstituted Triphenylenes and Phenanthrenes by Cascade Reaction of O-Iodobiphenyls or (Z)$\beta$-Halostyrenes with o-Bromobenzyl Alcohols through Two Sequential C-C Bond Formations Catalyzed by a Palladium Complex. J. Org. Chem. 2015, 80, 9247-9263. https://doi.org/10.1021/acs.joc.5b01693.

(80) Iwasaki, M.; Araki, Y.; Nishihara, Y. Phenanthrene Synthesis by Palladium-Catalyzed Benzannulation with o-Bromobenzyl Alcohols through Multiple CarbonCarbon Bond Formations. J. Org. Chem. 2017, 82, 6242-6258. https://doi.org/10.1021/acs.joc.7b00848.

(81) Mahendar, L.; Krishna, J.; Gopi Krishna Reddy, A.; Venkat Ramulu, B.; Satyanarayana, G. A Domino Palladium-Catalyzed C-C and C-O Bonds Formation via Dual O-H Bond Activation: Synthesis of 6,6-Dialkyl-6 H -Benzo[c] Chromenes. Org. Lett. 2012, 14, 628-631. https://doi.org/10.1021/ol2032625.

(82) Mahendar, L.; Satyanarayana, G. Substitution Controlled Functionalization of Ortho -Bromobenzylic Alcohols via Palladium Catalysis: Synthesis of Chromenes and Indenols.J. Org. Chem. 2014, 79, 2059-2074. https://doi.org/10.1021/jo402763m.

(83) Della Ca, N.; Fontana, M.; Motti, E.; Catellani, M. Pd/Norbornene: A Winning Combination for Selective Aromatic Functionalization via C-H Bond Activation. Acc. Chem. Res. 2016, 49, 1389-1400. https://doi.org/10.1021/acs.accounts.6b00165.

(84) Ozawa, F.; Hidaka, T.; Yamamoto, T.; Yamamoto, A. Mechanism of Reaction of Trans- Diarylbis(Diethylphenylphosphine)Palladium(II) Complexes with Aryl Iodides to Give Biaryls. J. Organomet. Chem. 1987, 330, 253-263. https://doi.org/10.1016/0022-328X(87)80292-9.

(85) Deng, R.; Xi, J.; Li, Q.; Gu, Z. Enantioselective Carbon-Carbon Bond Cleavage for Biaryl Atropisomers Synthesis. Chem 2019, 5, $1834-1846$. https://doi.org/10.1016/j.chempr.2019.04.008.

(86) Zhao, P.; Incarvito, C. D.; Hartwig, J. F. Carbon-Oxygen Bond Formation between a Terminal Alkoxo Ligand and a Coordinated Olefin. Evidence for Olefin Insertion into a Rhodium Alkoxide.J. Am. Chem. Soc. 2006, 128, 9642-9643. https://doi.org/10.1021/ja063347w.

(87) Xue, L.; Ng, K. C.; Lin, Z. Theoretical Studies on $\beta$-Aryl Elimination from Rh(i) Complexes. J. Chem. Soc. Dalt. Trans. 2009, 0, 5841-5850. https://doi.org/10.1039/b902539a.

(88) Nishimura, T.; Katoh, T.; Hayashi, T. Rhodium-Catalyzed Aryl Transfer from Trisubstituted Aryl Methanols to $\alpha$, $\beta$-Unsaturated Carbonyl Compounds. Angew. Chemie-Int.Ed. 2007, 46, 4937-4939. https://doi.org/10.1002/anie.200700902.

(89) Uto, T.; Shimizu, M.; Ueura, K.; Tsurugi, H.; Satoh, T.; Miura, M. Rhodium-Catalyzed Oxidative Coupling of Triarylmethanols with Internal Alkynes via Successive C-H and C-C Bond Cleavages. J. Org. Chem. 2008, 73, 298-300. https://doi.org/10.1021/jo7022087.

(90) Furusawa, T.; Tanimoto, H.; Nishiyama, Y.; Morimoto, T.; Kakiuchi, K. Rhodium-Catalyzed Carbonylative Annulation of 2-Bromobenzylic Alcohols with Internal Alkynes Using Furfural via ß-Aryl Elimination. Chem. Lett. 2017, 46, 926-929. https://doi.org/10.1246/cl.170249.

(91) Kadnikov, D. V.; Larock, R. C. Palladium-Catalyzed Carbonylative Annulation of Internal Alkynes: Synthesis of 3,4-Disubstituted Coumarins. J. Org. Chem. 2003, 68, 9423-9432. https://doi.org/10.1021/jo0350763.

(92) Li, H.; Li, Y.; Zhang, X. S.; Chen, K.; Wang, X.; Shi, Z.J. Pyridinyl Directed Alkenylation with Olefins via Rh(III)-Catalyzed C-C Bond Cleavage of Secondary Arylmethanols. J. Am. Chem. Soc. 2011, 133, 15244-15247. https://doi.org/10.1021/ja205228y.

(93) Chen, K.; Li, H.; Li, Y.; Zhang, X. S.; Lei, Z. Q.; Shi, Z. J. Direct Oxidative Arylation via Rhodium-Catalyzed C-C Bond Cleavage of Secondary Alcohols with Arylsilanes. Chem. Sci. 2012, 3, 1645-1649. https://doi.org/10.1039/c2sc00923d.

(94) Zhang, X.-S.; Li, Y.; Li, H.; Chen, K.; Lei, Z.-Q.; Shi, Z.-J. Rh-Catalyzed C-C Cleavage of Benzyl/Allylic Alcohols to Produce Benzyl/Allylic Amines or Other Alcohols by Nucleophilic Addition of Intermediate Rhodacycles to Aldehydes and Imines. Chem. - A Eur. J. 2012, 18, 16214-16225. https://doi.org/10.1002/chem.201201867. 
This document is the Accepted Manuscript version of a Published Work that appeared in final form in Chemical Reviews, copyright (C) American Chemical Society after peer review and technical editing by the publisher. To access the final edited and published work see https://doi.org/10.1021/acs.chemrev.0c00154

(95) Chen, K.; Li, H.; Lei, Z. Q.; Li, Y.; Ye, W. H.; Zhang, L. S.; Sun, J.; Shi, Z. J. Reductive Cleavage of the C(Sp2)-C(Sp3) Bond of Secondary Benzyl Alcohols: Rhodium Catalysis Directed by N-Containing Groups. Angew. Chemie - Int. Ed. 2012, 51, 9851-9855. https://doi.org/10.1002/anie.201204338.

(96) Qiu, Y.; Scheremetjew, A.; Ackermann, L. Electro-Oxidative C-C Alkenylation by Rhodium(III) Catalysis. J. Am. Chem. Soc. 2019, 141, 2731-2738. https://doi.org/10.1021/jacs.8b13692.

(97) Yu, T. Y.; Zheng, Z. J.; Sun, W.; Qiao, Z. H. Direct C2-Heteroarylation of Indoles by Rhodium-Catalyzed C-C Bond Cleavage of Secondary Alcohols. Asian J. Org. Chem. 2019, 8, 466-469. https://doi.org/10.1002/ajoc.201900069.

(98) Gandeepan, P.; Müller, T.; Zell, D.; Cera, G.; Warratz, S.; Ackermann, L. 3d Transition Metals for C-H Activation. Chem. Rev. 2019, 119, 2192-2452. https://doi.org/10.1021/acs.chemrev.8b00507.

(99) Ozkal, E.; Cacherat, B.; Morandi, B. Cobalt(III)-Catalyzed Functionalization of Unstrained Carbon-Carbon Bonds through $\beta$-Carbon Cleavage of Alcohols. ACS Catal. 2015, 5, 6458-6462. https://doi.org/10.1021/acscatal.5b01753.

(100) Wang, H.; Choi, I.; Rogge, T.; Kaplaneris, N.; Ackermann, L. Versatile and Robust C-C Activation by Chelation-Assisted Manganese Catalysis. Nat. Catal. 2018, 1, 993-1001. https://doi.org/10.1038/s41929-018-0187-1.

(101) Hosokawa, T.; Maitlis, P. M. A Model System for Acid and Base Reactions, Carbonylation, and $\beta$-Hydride Elimination in Organopalladium Chemistry. J. Am. Chem. Soc. 1972, 94, 3238-3240. https://doi.org/10.1021/ja00764a060.

(102) Halcrow, M. A.; Urbanos, F.; Chaudret, B. Aromatization of the B-Ring of 5,7-Dienyl Steroids by the Electrophilic Ruthenium Fragment "[Cp*Ru]+." Organometallics 1993, 12, 955-957. https://doi.org/10.1021/om00027a054.

(103) Wakui, H.; Kawasaki, S.; Satoh, T.; Miura, M.; Nomura, M. Palladium-Catalyzed Reaction of 2-Hydroxy-2-Methylpropiophenone with Aryl Bromides: A Unique Multiple Arylation via Successive C-C and C-H Bond Cleavages. J. Am. Chem. Soc. 2004, 126, 8658-8659. https://doi.org/10.1021/ja0477874.

(104) Brunner, H.; Stöhr, F. Metal-Catalyzed Enantioselective a-Ketol Rearrangements. European J. Org. Chem. 2000, $2000,2777-2786$. https://doi.org/10.1002/1099-0690(200008)2000:15<2777::aid-ejoc2777>3.0.co;2-0.

(105) Brunner, H.; Kagan, H. B.; Kreutzer, G. Asymmetric Catalysis. Part 137: Nickel Catalysed Enantioselective $\alpha$-Ketol Rearrangement of 1-Benzoylcycloalkanols. Tetrahedron Asymmetry 2001, 12, 497-499. https://doi.org/10.1016/S0957-4166(01)00045-3.

(106) Culkin, D. A.; Hartwig, J. F. Palladium-Catalyzed a-Arylation of Carbonyl Compounds and Nitriles. Acc. Chem. Res. 2003, 36, 234-245. https://doi.org/10.1021/ar0201106.

(107) Niwa, T.; Yorimitsu, H.; Oshima, K. Palladium-Catalyzed 2-Pyridylmethyl Transfer from 2-(2-Pyridyl)-Ethanol Derivatives to Organic Halides by ChelationAssisted Cleavage of Unstrained Csp3-Csp3 Bonds. Angew. Chemie - Int. Ed. 2007, 46, 2643-2645. https://doi.org/10.1002/anie.200604472.

(108) Suehiro, T.; Niwa, T.; Yorimitsu, H.; Oshima, K. Palladium-Catalyzed (N-Oido-2-Pyridinyl)Methyl Transfer from 2-(2-Hydroxyalkyl)Pyridine N-Oxide to Aryl Halides by $\beta$-Carbon Elimination. Chem. - An Asian J. 2009, 4, 1217-1220. https://doi.org/10.1002/asia.200900151.

(109) Zhang, S.-L.; Yu, Z.-L. C-C Activation by Retro-Aldol Reaction of Two $\beta$-Hydroxy Carbonyl Compounds: Synergy with Pd-Catalyzed Cross-Coupling To Access Mono- $\alpha$-Arylated Ketones and Esters. J. Org. Chem. 2016, 81, 57-65. https://doi.org/10.1021/acs.joc.5b02098.

(110) Chiba, S.; Xu, Y.J.; Wang, Y. F. A Pd(II)-Catalyzed Ring-Expansion Reaction of Cyclic 2-Azidoalcohol Derivatives: Synthesis of Azaheterocycles. J. Am. Chem. Soc. 2009, 131, 12886-12887. https://doi.org/10.1021/ja9049564.

(111) Ishida, N.; Masuda, Y.; Liao, W.; Murakami, M. Photo-Assisted Fixation of CO2 onto Aryl Bromides Producing Aromatic Esters. Chem. Lett. 2019, 48, 13161318. https://doi.org/10.1246/cl.190563.

(112) Murakami, K.; Ohmiya, H.; Yorimitsu, H.; Oshima, K. Generation of Rhodium Enolates via Retro-Aldol Reaction and Its Application to Regioselective Aldol Reaction. Tetrahedron Lett. 2008, 49, 2388-2390. https://doi.org/10.1016/J.TETLET.2008.02.062.

(113) Shukla, P.; Cheng, C. H. Facile $\beta$-Alkyl and $\beta$-Hydride Elimination in the Nickel-Catalyzed Annulation of o-Iodophenyl Ketones and Aldehydes with Bicyclic Alkenes. Org. Lett. 2006, 8, 2867-2869. https://doi.org/10.1021/ol061051p.

(114) Kang, Y. W.; Cho, Y. J.; Ko, K. Y.; Jang, H. Y. Copper-Catalyzed Carbon-Carbon Bond Cleavage of Primary Propargyl Alcohols: $\beta$-Carbon Elimination of Hemiaminal Intermediates. Catal. Sci. Technol. 2015, 5, 3931-3934. https://doi.org/10.1039/c5cy00783f.

(115) Huang, G.; Lu, L.; Jiang, H.; Yin, B. Aerobic Oxidative $\alpha$-Arylation of Furans with Boronic Acids via Pd(II)-Catalyzed C-C Bond Cleavage of Primary Furfuryl Alcohols: Sustainable Access to Arylfurans. Chem. Commun. 2017, 53, 12217-12220. https://doi.org/10.1039/c7cc07111f.

(116) Huang, G.; Yin, B. Palladium-Catalyzed Cross-Coupling of Furfuryl Alcohols with Arylboronic Acids via Aromatization-Driven Carbon-Carbon Bond Cleavage to Synthesize 5-Arylfurfuryl Alcohols and 2,5-Diaryl Furans. Adv. Synth. Catal. 2019, 361, 5576-5586. https://doi.org/10.1002/adsc.201900799.

(117) Deng, R.; Zhan, S.; Li, C.; Gu, Z. Hypervalent-Iodine-Mediated Carbon-Carbon Bond Cleavage and Dearomatization of $9 \mathrm{H}$-Fluoren-9-Ols. Angew. Chemie Int.Ed. 2020, 59, 3093-3098. https://doi.org/10.1002/anie.201913373.

(118) Zhao, K.; Yamashita, K.; Carpenter,J. E.; Sherwood, T. C.; Ewing, W. R.; Cheng, P. T. W.; Knowles, R. R. Catalytic Ring Expansions of Cyclic Alcohols Enabled by Proton-Coupled Electron Transfer. J.Am. Chem. Soc. 2019, 141, 8752-8757.https://doi.org/10.1021/jacs.9b03973.

(119) Lübbesmeyer, M.; Mackay, E. G.; Raycroft, M. A. R.; Elfert, J.; Pratt, D. A.; Studer, A. Base-Promoted C-C Bond Activation Enables Radical Allylation with Homoallylic Alcohols. J. Am. Chem. Soc. 2020, 142, 2609-2616. https://doi.org/10.1021/jacs.9b12343.

(120) Huang, L.; Ji, T.; Rueping, M. Remote Nickel-Catalyzed Cross-Coupling Arylation via Proton-Coupled Electron Transfer-Enabled C-C Bond Cleavage. J. Am. Chem. Soc. 2020, 142, 3532-3539. https://doi.org/10.1021/jacs.9b12490.

(121) Deng, L.; Dong, G. Carbon-Carbon Bond Activation of Ketones. Trends Chem. 2020, 2, 183-198. https://doi.org/10.1016/j.trechm.2019.12.002. 
This document is the Accepted Manuscript version of a Published Work that appeared in final form in Chemical Reviews, copyright (C) American Chemical Society after peer review and technical editing by the publisher. To access the final edited and published work see https://doi.org/10.1021/acs.chemrev.0c00154

Authors are required to submit a graphic entry for the Table of Contents (TOC) that, in conjunction with the manuscript title, should give the reader a representative idea of one of the following: A key structure, reaction, equation, concept, or theorem, etc., that is discussed in the manuscript. Consult the journal's Instructions for Authors for TOC graphic specifications.

Insert Table of Contents artwork here

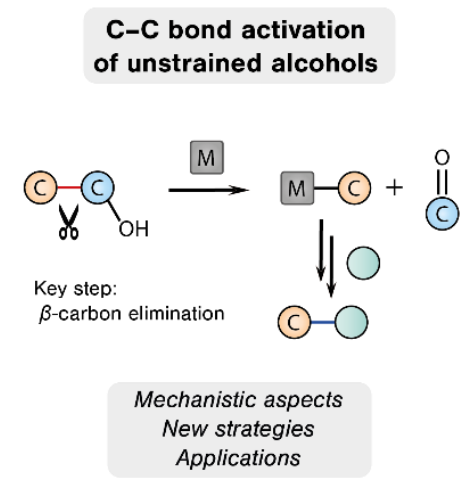

